\title{
8 Positionieren mit globaler Reichweite: Vergemeinschaftung und Distinktion entlang medien- und rezeptionsbezogener Aspekte
}

In diesem Kapitel wird der Fokus über die konkrete Serie als Positionierungsobjekt hinaus erweitert, indem untersucht wird, wie epistemische und evaluative Positionierungen auf Serien als gestaltete und rezipierte Medienprodukte bezogen sind. Es werden jene von den Teilnehmenden als relevant markierten Wissenselemente und Bewertungsmaßstäbe analysiert, die technisch-mediale (Abschnitt 2.1.2), narrative (Abschnitt 2.1.1) und soziokulturelle (Abschnitt 2.1.3) Aspekte von Serien und Serialität betreffen. Das methodische Vorgehen zur Analyse wird in Abschnitt 5.2 beschrieben.

Die Abschnitt 8.1 und 8.2 sind entlang der folgenden analyseleitenden Fragen strukturiert:

1) Welche Aspekte setzen die Jugendlichen relevant? In Abschnitt 8.1 werden in Anlehnung an die in Abschnitt 2.1 herausgearbeiteten theoretischen Grundlagen Aspekte beschrieben, die eher als medienproduktbezogen und in Abschnitt 8.2 diejenigen Aspekte, die eher als rezeptionsbezogen eingeordnet werden können. 2) Woran orientieren sich die Jugendlichen beim Positionieren in Bezug auf diese Aspekte? Die in Kapitel 7 beschriebenen Positionierungspraktiken werden als Basis zugrunde gelegt, allerdings modifiziert; denn wenn die Teilnehmenden nicht über konkrete Serien diskutieren, spielen andere Formen von Wissens- und Bewertungskommunikation eine Rolle. So ist beispielsweise nicht mehr die Kenntnis des Namens einer Hauptfigur (vgl. etwa Beispiel 9) von Belang, sondern mögliche Funktionen serieller Figuren für die Rezeption (Abschnitt 8.1.4). Genauso steht nicht mehr im Zentrum, ob ihnen die Handlung einer spezifischen Episode gefällt (wie etwa in Beispiel 27), sondern ob sie es grundsätzlich an Serien schätzen, wenn mehrere Handlungsstränge komplex ineinander verwoben sind (Abschnitt 8.1.3). Ziel der Analyse ist es, durch Konversations- und Positionierungsanalyse mikro- und makroanalytisch zu rekonstruieren, an welchen zugrunde liegenden Wissensbeständen und Bewertungsmaßstäben sich die Teilnehmenden in Bezug auf solche abstrakteren Aspekte orientieren und wie sie interaktiv damit umgehen. 3) Wie fungieren diese Elemente als Auslöser oder Motor zur Vergemeinschaftung bzw. Distinktion? Die in Abschnitt 6.2 rekonstruierten Gesprächsziele der Partizipation, Vergemeinschaftung und Distinktion, werden als grundlegend angenommen. Es wird beschrieben, wie die Teilnehmenden über Positionierungen in Bezug auf übergeordnete, serielle Aspekte Prozesse der Gemeinschaft und Abgrenzung etablieren und verändern. 
Die Kategorien, entlang derer die Unterkapitel strukturiert wurden, wurden induktiv aus der Analyse der Daten generiert. Dem theoretischen Bezugsrahmen in Abschnitt 2.1 kommen zwei Funktionen zu. Zum einen bietet er Begriffe und Beschreibungskategorien für die analytisch identifizierten Phänomene an und zum anderen liefert er Ressourcen für die Interpretation und Einordnung der Interaktionen bezüglich der übergeordneten, gesellschaftlichen Diskurse, auf die die Teilnehmenden Bezug nehmen (vgl. dazu auch Abschnitt 4.2). Ausgehend von den Analysen wird die These aufgestellt, dass sich die Teilnehmenden beim Sprechen über Serien und Serialität als Medienprodukte an prototypischen Vorstellungen (Abschnitt 8.1) und beim Sprechen über Rezeption an normativen Vorstellungen (Abschnitt 8.2) orientieren. Abschließend werden beide Analyseperspektiven über die gesprächsübergreifend verwendete Phrase „das ist doch bei jeder Serie so“ gebündelt zusammengeführt, die dazu verwendet werden kann, Distinktion auf verschiedene Art und Weise zu managen (Abschnitt 8.3).

\subsection{Orientieren an prototypischen Vorstellungen in medienproduktbezogenen Interaktionen}

In diesem Abschnitt werden Fälle betrachtet, in denen medienproduktbezogene Aspekte relevant gesetzt werden. Damit sind Positionierungsobjekte gemeint, die über eine konkrete Serie hinausgehen; einzelne Serien werden in diesem Zuge oft als (typische) Belege für Aussagen angeführt. Diese Aspekte - Serien als Abgrenzung zum Film, Seriengenres, (Narrative) Komplexität, Serienfiguren und Serien als gestaltete Produkte - ergeben sich aus einer detaillierten Sequenzanalyse und Kodierung der Daten aus der Teilnehmendenperspektive (vgl. Abschnitt 5.2). Die Ergebnisse werden wie in Abschnitt 7.2 nicht anhand einzelner Fallbeispiele, sondern zusammenfassend mit punktuellen Belegen aus den Daten dargestellt, die über die Angabe der entsprechenden Zeilenangaben im Anhang ausführlicher nachgelesen werden können. Übergeordnetes Erkenntnisinteresse ist, wie diese Diskurselemente Prozesse der Vergemeinschaftung und Distinktion bedingen. Da gezeigt wird, dass sich die Schüler*innen beim Diskutieren über medienproduktbezogene Aspekte an prototypischen Vorstellungen orientieren, sind die Unterkapitel entlang der folgenden, die Teilnehmendenperspektive einnehmenden und so die Analyse leitenden Fragen strukturiert:

- Serien als Abgrenzung zum Film: Was unterscheidet eine prototypische Serie von anderen audiovisuellen Formaten? (Abschnitt 8.1.1)

- Seriengenres: Welche prototypischen Seriengenres gibt es und was ist charakteristisch für sie? (Abschnitt 8.1.2) 
- Narrative Komplexität: Wie komplex erzählt eine prototypische Serie? (Abschnitt 8.1.3)

- Serienfiguren: Was kennzeichnet prototypische Serienfiguren? (Abschnitt 8.1.4)

- Serien als gestaltete Produkte: Wodurch sind Serien als gestaltete Produkte in prototypischer Weise gekennzeichnet? (Abschnitt 8.1.5)

\subsubsection{Serien als Abgrenzung zum Film}

Serialität kann grundlegend als narratives Formprinzip beschrieben werden, allerdings gibt es im Forschungsdiskurs keine klar und eindeutig definierten Kriterien, was eine Serie kennzeichnet (vgl. Abschnitt 2.1). Dieser Definitionsspielraum findet sich auch in den Daten wieder. Wenn die Jugendlichen in den Gesprächen den Punkt erreichen, in dem der Gesprächsgegenstand an sich im Sinne der Instruktion (Abschnitt 6.1.1) zur Disposition steht, kann es zu ausführlichen Aushandlungen der Frage kommen, was eine Serie kennzeichnet. Allerdings ,ringen` sie in diesem Zuge oft um eine Definition, ohne zu einem eindeutigen Ergebnis zu kommen. So adressiert beispielsweise Stephanie nach einer lebhaften Diskussion über serielle Merkmale von Formaten wie MEIN LOKAL - DEIN LOKAL und Rosins RESTAURANT sowie CSI (Anhang I: EMS51, Z. 410-668) die Gruppe mit der Meta-Kommentierung: „wollen wir jetzt definieren was jetzt ne serie [(IST;)]“ (Z. 669). Auch wenn Judith überlappend mit ihr „,[nö;]“ (Z. 670) äußert und damit markiert, dass es offenbar keinen Definitionsbedarf gibt, behauptet sie nur kurz darauf, dass CRIMINAL MindS für sie keine Serie sei (Z. 678). Lara, die die Serie zuvor genannt hatte, widerspricht ihr und beansprucht über das Hinzuziehen externer Wissensquellen (vgl. dazu Abschnitt 7.1.2) Expertise - wenn auch über eine weniger epistemische Gewissheit transportierende epistemische Haltung -, indem sie formuliert: , ja doch is für mich AUCH keine; aber es is glaub ich WIRklich eine,=wenn du das NACHgooglen würdest, (.) würd das da stehen dass das eine IST; [...] empfinde ICH auch nich so aber das,“ (Z. 679-684). Auffällig ist hier, dass Lara sich bzw. ihr subjektives Empfinden kontrastiv zu einer als objektiver markierten Wissensquelle positioniert, der sie mehr Gewissheit und Glaubwürdigkeit als sich selbst und damit die Deutungshoheit zur Definition einer Serie zuschreibt. Damit bearbeitet sie in komplexer Art und Weise sowohl das Ziel der Vergemeinschaftung - indem sie Judith signalisiert, ihr eigentlich zuzustimmen - als auch das der Distinktion, indem sie ihren epistemischen Status hochstuft und Judith belehrt (vgl. auch Abschnitt 7.1.4).

Meistens orientieren sich die Jugendlichen ex negativo daran, dass Serien keine Filme sind. Denn auch wenn gelegentlich Film(titel) interaktiv unproblematisch als Positionierungsobjekt (Anhang VII: RGM07, Z. 024, 082-097, Anhang IV: MNG11 
Z. 1093-1133) behandelt werden, nutzen die Teilnehmenden in den meisten anderen Fällen die Ressource des Kontrastierens, um Serien von Filmen abzugrenzen. So wiederholt Tim mehrfach, dass er sich „lieber n guten FILM rein“zöge (vgl. Anhang II: EMS53, Z. 170-176, auch: Z. 065-070) als Serien mit einer fortlaufenden „STOryline“ (Z. 074, 172, 415). Bisweilen finden sich fremdinitiierte Reparatursequenzen, die eine besondere Relevanz des Terminus Film im Kontrast zur Serie nahelegen. So leitet Bilel mit der Rahmung „ARrow ist ein; (.) äh, FILM?“ (Anhang IV: MNG11, Z. 050-052) seine Zusammenfassung des Plots der Serie ein, als Emilia ihn mit der Äußerung „das IST kein film;“ (Z. 055) unterbricht. Bilel entschuldigt sich, korrigiert den Begriff und fährt mit seiner Rekonstruktion fort (Z. 056-085). Hier zeigt sich, dass der korrekten Begrifflichkeit offenbar Relevanz für das Gespräch zukommt, da sonst die - interaktiv reibungslos verlaufende - Reparatursequenz überflüssig wäre.

Konstitutiv für den Unterschied zwischen Serie und Film scheint die Länge $\mathrm{zu}$ sein. So berichtet beispielsweise Leon von der Serie FARGO ${ }^{1}$ (vgl. auch die Analysen zu Beispiel 13) und beginnt damit, deren Abgeschlossenheit zu betonen (RHG10, Z. 809, 812). Er formuliert als Vergleich, die Serie sei „mehr so wie_n FILM, n längerer FILM halt, “ (Z. 814-815), woraufhin Jan mit einem schnellen Anschluss und der Äußerung „=BISschen länger“ (Z. 817) eine Reparatur initiiert, die Leon aufgreift (Z. 818). Es folgt eine kurze Aushandlungssequenz über die Anzahl der Episoden und die damit einhergehende Gesamtlänge des Werks. Auch wenn diese Aushandlung nicht besonders zeitintensiv ist und Leon wenig später fortfährt, für die Qualität der Serie zu argumentieren, zeigt sie doch exemplarisch, dass die (relative) Länge beim Vergleich zwischen Serien und Filmen als ausschlaggebend behandelt wird.

Ein weiteres Argument für die Relevantsetzung der Abgrenzung serieller von filmischen Formaten kann in Sequenzen beobachtet werden, in denen es zu einer kurzen Diskussion darüber kommt, ob es seitens der Forscherin erlaubt sei, über Filme zu sprechen (vgl. dazu auch Abschnitt 6.1.1). Exemplarisch zeigt sich das in einer Sequenz, in der die Gruppe den Film KingSMan positiv bewertet (vgl. OST11, Z. 392-401), bevor Ole die Frage nach der ,Erlaubnis‘ aufwirft, die zunächst ausgehandelt wird (vgl. Z. 402-418; das entsprechende Transkript findet sich in Beispiel 2). Auf Verenas ironisch gerahmte Frage „wieso sollten wir dann über FILme reden;“(Z. 418), antwortet Sevcan mit dem Vergleich über die Länge: „SErien sind so wie lange filme; “ (Z. 420). Explizit wird ihre Äußerung von den anderen zwar nicht ratifiziert - Sonja fordert lediglich Robert auf, die nächste Serie als

1 Es gibt auch einen gleichnamigen Film, er bezieht sich allerdings explizit auf die Serie. 
Positionierungsobjekt zu nennen (Z. 421) -, allerdings widerspricht Sevcan auch niemand.

Die Abgrenzung anderer audiovisueller Formate von Serien kann in solchen Sequenzen der Vergemeinschaftung als Gruppe und dem Kooperationsprinzip (Abschnitt 6.1.2) dienen, wenn sie sich nach einem Aushandlungsprozess darüber einig sind, dass Serien (und nicht Filme) Thema der Interaktion sind. Zudem stellt die Dichotomie Serien vs. Filme einen common ground zur Verfügung, der in der Regel nicht weiter elaboriert werden muss. Er bietet Chancen der Selbstpositionierung als jemand, die oder der etwas besser weiß (vgl. Abschnitt 4.3 sowie die in Abschnitt 7.1 beschrieben Praktiken) und kann damit für punktuelle Distinktion bei entstehenden Zweifeln ob der Legitimität des Gesprächsgegenstands funktionalisiert werden, indem Teilnehmende beispielsweise auf der korrekten Fachterminologie insistieren (,das IST kein film;“) oder auf Wissensquellen mit höherer Glaubwürdigkeit verweisen (,wenn du das NACHgoogeln würdest“"). Dennoch lässt sich keineswegs ableiten, die Jugendlichen würden der trivialen Feststellung, Serien seien wie lange Filme, widerspruchslos folgen. Die Aushandlungssequenz zwischen Jan und Leon in Beispiel 13 und einige weitere Sequenzen in den Daten legen stattdessen nahe, dass es sich bei dem Kriterium der Länge um die prototypische Vorstellung handelt, Serien seien, wie Hickethier (2012: 356) proklamiert „,große‘ Erzählungen“.

\subsubsection{Seriengenres}

Auch innerhalb des vorgegebenen thematischen Rahmens nehmen die Teilnehmenden Unterteilungen vor. Dafür nutzen sie die Ressource des Kategorisierens, indem sie sich unter anderem auf konventionalisierte Genres beziehen, denen sie eine oder mehrere Serien zuordnen. Genres sind Hickethier (2007: 63) zufolge „Verständigungsbegriffe“, die vorrangig der „Kommunikation über Filme, sowohl auf der Rezipienten- als auch auf der Produzentenseite sowie zwischen beiden Seiten“ dienen. Die von den Jugendlichen aufgeführten Serientypen dienen ebenfalls zur Verständnissicherung, sie sind allerdings nicht immer konventionalisierten Genres zuzuordnen. Die Zusammenstellung der folgenden Kategorien im nächsten Absatz folgt im Sinne ethnomethodologischer Prinzipien strikt der Teilnehmendenperspektive und bildet daher die Varianz ethnokategorialer Zuordnungen ab, die die Jugendlichen selbst vornehmen. Dabei handelt es sich lediglich um einen Ausschnitt, denn alphabetisch aufgelistet sind hier ausschließlich die Kategorisierungen von Serien, die dem aufbereiteten Teil des Kernkorpus (vgl. Abschnitt 5.1.2) entnommen wurden. Aus weitere Datenauswertungen würden sich vermutlich weitere Kategorien ergeben. 
Amerikanische Serien (MNG13, Z. 507), Autoserien (EMS53, Z. 706; OST11, Z. 703, 723), Deutsche Serien (OST11, Z. 304; RHG10, Z. 861, 865), Fantasy-Serien (MNG13, Z. 290; 297-298, 523, 526; EMS53, Z. 183, 237), lustige bzw. Comedy-Serien (MNG11, Z. 663, 668; OST11, Z. 723), Gruselige Serien (MNG11, Z. 662), Kinderserien/Serien für Kinder (EMS53, Z. 631, 643; MNG11, 1025-1133, 1264; OST11, Z. 156, 197, 217, 236 630, 1116), Kriminalserien (MNG11, Z. 988), Kultivierte Serien (RHG10, Z. 591), Kurzserien von Pro7 (EMS53, Z. 444), Mädchenserien (RHG10, Z. 477), MainstreamSerien (EMS51, Z. 944), Mittelalterliche Serien/Serien, die im Mittelalter spielen (MNG13, Z. 234-238, 312, 619; EMS53, Z. 183, 237), Mystische Serien (MNG11, Z. 630632, 665, 667, 783), Serien mit einer fortlaufenden Story (EMS53, Z. 075), Serien über Superhelden / Marvel-Serien (OST11, Z. 852; RHG10, Z. 801), Serien zum Mitdenken /über die man sich Gedanken macht (MNG11, Z. 670, 688; MNG13, Z. 310-344), Serien, die auf RTL laufen (OST11, Z. 703), Serien, die auf Serien basieren (EMS51, Z. 996-997), Serien, die ihre eigene Logik brechen (MNG11, Z. 763), Serien, die von Netflix produziert wurden (EMS53, Z. 675), Soaps / Soap Operas (RHG10, Z. 503, 505, 559, 596, 640), Türkische Serien (MNG13, Z. 111, 268, 268, 546, 558, 580),

Eine ausführliche analytische Darstellung des interaktiven und sequenziellen Kontextes aller Kategorien würde an dieser Stelle zu weit führen. Es lassen sich jedoch folgende übergeordnete Beobachtungen auf der Grundlage von SequenzAnalysen der hier zusammengestellten Fälle formulieren: Manche Kategorien scheinen sich an konventionalisierte Genre-Bezeichnungen für fiktionale Werke im Kulturbetrieb anzulehnen (Krimiserien; Fantasy, vgl. dazu Analysen in Abschnitt 9.1.1). Andere stellen komplexere Attribuierungen dar (Serien, die ihre eigene Logik brechen, vgl. dazu die Analysen in Abschnitt 8.2.1), die - meistens - im Anschluss interaktiv elaboriert werden. Manche Kategorien verweisen auf den Produktionsort (deutsche, türkische, amerikanische Serien, vgl. dazu auch Beispiel 22) oder auf den Distributionskanal (Kurzserien auf Pro7; Serien, die auf RTL laufen) und werden interaktiv unproblematisch folgebehandelt, d.h. es entwickelt sich keine Notwendigkeit zur Elaborierung. Einzelne Kategorien scheinen durch die Art und Weise, wie sie in das Gespräch eingebracht und behandelt werden, mit Wertungen versehen (Mädchenserien; Mainstream-Serien und kultivierte Serien, vgl. zu letzteren beiden die Analysen in Abschnitt 8.2.2). Viele dieser Kategorisierungen sind nur für eine oder zwei der Gesprächsgruppen relevant (so z.B. die Superheldenserien, über die nur OST11 und RHG10 diskutieren), andere Kategorisierungen kommen einmalig vor und werden im Anschluss interaktiv auch nicht weiter relevant gesetzt (z.B. gruselige Serien).

Die Teilnehmenden nutzen bisweilen Kontrastieren als eine zusätzliche Ressource, um Kategorien voneinander abzugrenzen, wie z.B. gruselige von fröhlichen Serien (Anhang IV: MNG11, Z. 662-663). Oder sie ordnen einer Kategorie eine konkrete Serie zu, z.B. CLUB DER ROTEN BÄNDER als deutsche Serie (OST11, Z. 304, 
vgl. Beispiel 44) oder How I MET Your MOTHER als Soap (RHG, Z. 503 u.a., vgl. dazu auch die Analysen in Abschnitt 7.3.3). Die so zugeordneten konkreten Serien fungieren damit als (proto-)typische Belege für eine Kategorie und unterstützen die Argumentation für die Präferenzen der Jugendlichen. Im Sinne der Funktion von Genres als „Verständigungsbegriffe“ verlassen sich die Teilnehmenden auf die wechselseitig unterstellte Annahme, alle Gruppenmitglieder wüssten um die Bedeutung einer Kategorie. So kategorisiert und kontrastiert zum Beispiel Ole Serien wie The WALKIng DEAD mit GAME of Thrones als typische Repräsentationen von „zwei ARten von serien“ (OST11, Z. 890, vgl. Beispiel 11), die sich sowohl auf der narrativen als auch auf der Produktionsebene voneinander unterscheiden und erhält daraufhin sowohl epistemische als auch evaluative Zustimmung der anderen Gruppenmitglieder (vgl. Z. 890-911).

Bezugnahmen auf Kategorien dienen vor allem der Vergemeinschaftung der Gruppe als Ganzes (vgl. auch Abschnitt 7.3.1). Exemplarisch wird das an der Kategorie Kinderserien deutlich, die sowohl OST11 als auch MNG11 über einen längeren Zeitraum hinweg thematisieren. Beide Gruppen sind sich interaktiv einig, dass die Kinderserien, die sie selbst als Kinder rezipiert haben, qualitativ ,besser' seien als die Kinderserien, die gegenwärtig ausgestrahlt werden (Anhang IX: OST11, Z. 128142, 197-219; Anhang IV: MNG11, Z. 1023-1028, 1264). Das betrifft insbesondere den Animationsstil und die „MESSage“ (MNG11, Z. 1029-1030) der Serien. Wie anhand der Beispiele 28, 29 und 30 mikroanalytisch rekonstruiert wurde, fungieren solche gemeinsamen Erinnerungsaktivitäten primär dafür, sich ähnlicher Bewertungen und letztlich ähnlicher Identitätsfacetten (hier: vergleichbare Kindheitserfahrungen) zu vergewissern. Eine Distinktion erfolgt in beiden Gruppen gemeinschaftlich von den aktuellen Kinderserien und sorgt somit für einen Moment der Vergemeinschaftung als ganze Gruppe. In den meisten Fällen zeigt sich, dass die Teilnehmenden auf geteiltes Wissen zur Attribuierung der Kategorien zurückgreifen können. Eine exemplarische Analyse eines Falls, in dem einer Kategorie unterschiedliche Attribute zugeordnet werden, die wechselseitiges Verstehen erschweren, wird in Abschnitt 9.1.1 in Bezug auf GAME OF THRONES diskutiert. Diese Analyse zeigt, dass über die unterschiedliche Verwendung und evaluative Aufladung serienbezogener Kategorien Distinktionsmechanismen etabliert und aufrechterhalten werden können.

\subsection{3 (Narrative) Komplexität}

Narrative Komplexität unterscheidet sich je nach episodenorientiertem bzw. fortsetzungsorientiertem Erzählen. Beide Formen stellen Pole eines Kontinuums dar, auf dem sich graduell verschiedene Serientypen verorten lassen (vgl. Ausführungen 
in Abschnitt 2.1.1). Narrativ komplexe Formate stellen Handlungsentwicklungen in den Vordergrund, d.h. das Beziehungs- und Figurendrama entwickelt sich im Unterschied $\mathrm{zu}$ weniger komplex erzählenden Serien wie Soaps aus dem Plot heraus (vgl. Mittell 2012: 105) und sie brechen eher mit - genrebezogenen und daher konventionalisierten - Erwartungen. Mit Komplexität ist aber auch die gesellschaftliche Wertung von so genanntem Quality TV (vgl.dazu Abschnitt 2.1.1 und v.a. Abschnitt 2.1.3) verbunden. Inwiefern sich derartige Wertungen in den Gesprächen widerspiegeln, wird in Abschnitt 8.2.2 diskutiert. In diesem Abschnitt wird herausgearbeitet, dass die Jugendlichen episodenorientiertes und fortsetzungsorientiertes Erzählen als prototypische Ausprägungen serieller Formate behandeln auch wenn sie keine ,Fachterminologie“ verwenden - und zur Vergemeinschaftung und Distinktion funktionalisieren.

Wenn sich die Teilnehmenden auf episodenorientiertes Erzählen beziehen, betonen sie insbesondere den Aspekt der Abgeschlossenheit. Als typische Serien dafür führen sie Two AND A HALF Men, The Big BANg Theory (Anhang V: MNG13, Z. 015, 017) oder DR. House (Anhang II: EMS53, Z. 076) an. Beispielsweise formuliert Tim in Bezug auf letztere Serie ein Rezeptionsszenario:

wo man sich dann abends HINsetzt? man guckt, =fangt die FOLge an? (.) und die: ist ABgeschlossen einfach zum schluss; [...] =du legst dich ins BETT, guckst noch ne folge SErie, die ist einfach man fängt AN und; (.) ENdet einfach; (-) die geschichte ist einfach zu ENde; (.) für die FOLge;(EMS53, Z. 077-080, Z. 090-095)

Er betont mehrfach seinen Gefallen daran, dass innerhalb einer Episode eine Geschichte beendet wird. Die iterativen Formulierungen sowie die wiederholte Verwendung von „einfach“ (vgl. Spreckels 2009) deuten darauf hin, dass er gegen eine konträre Position innerhalb der Gruppe argumentiert. Tatsächlich ist seine Elaborierung interaktiv eingebettet in eine Sequenz, in der er daran arbeitet, sich von den anderen Gruppenmitgliedern, die gerne GAME OF THRONES schauen, abzugrenzen und einen kontrastiven Geschmack zu etablieren. Er erhält auch punktuell Zustimmung von einzelnen Gruppenmitgliedern, beispielsweise von Hendrik (EMS53, Z. 086-087). Andere Teilnehmer verstärken diese Distinktion, indem sie ihn (ungläubig) nach seinem offenbar nicht vorhandenen Drang zur Fortsetzung befragen (EMS53, Z. 096, 165; vgl. dazu auch die Analyse zu Beispiel 48). Zudem koppelt Tim das Kriterium der Abgeschlossenheit eng an sein eigenes, hier als rituell markiertes, Rezeptionsverhalten (vgl. dazu auch Abschnitt 8.2.4.3), was er als zusätzliche argumentative Unterstützung für seine Präferenz nutzt. Auf den damit einhergehenden, weniger ausgeprägten narrativen Zusammenhang von Serien wie Two AND A HALF MEN nehmen Paul und Tufan kooperativ in ähnlicher Art und Weise Bezug: „TUF: das ist halt ne serie wenn du die die dritte folge nich geGUCKT 
hast kannst_e die trotzdem weiter gucken; [...] PAU: und man braucht keinen zusammenhang zwischen den einzelnen FOLgen; “ (Anhang V: MNG13, Z. 054-063); vergleichbar argumentiert auch Judith für GZSZ (Anhang I: EMS51, Z. 706-722). Tufan und Paul ergänzen im Folgenden ihre Äußerungen wechselseitig fast nahtlos, so dass sie über diese geteilten Präferenzen punktuell Gemeinschaft herstellen.

Ein weiteres erzählerisches Kriterium ist das der Wiederholung (das Schema im Eco'schen Sinne, vgl. Abschnitt 2.1). Amüsiert rekonstruieren Norbert, Hendrik und Moritz gemeinsam, wie in ALARM FÜR Kobra 11 jede Episode eine Reihenfolge bestimmter Handlungselemente aufweist:

am anfang ist immer irgendwas pasSIERT, dann verFOLgungsjagd auf der AUtobahn, das schaffen se nicht weil das AUto kaputt geht? die entkommen? dann (-) n bisschen HANdlung, (-) dann am ENde, (-) ÜBergriff,=WIEder auf der autobahn, und dann HAben se_n meistens; und explosion; (Anhang II: EMS53, Z. 683-692).

Die listenförmige Strukturierung durch die Intonationsphrasen spiegelt die Gleichförmigkeit der Serie wider und sorgt in dieser Sequenz für vergnüglichen Konsens und Vergemeinschaftung der gesamten Gruppe. Insgesamt wird auf dieses Merkmal häufig in Scherzinteraktionen Bezug genommen. So verweist auch Igdir auf die „typische Erzählweise von türkischen Serien“ (Anhang V: MNG13, Z. 544-589) und ruft damit allgemeine Heiterkeit der anderen Interagierenden hervor (Z. 583-587, 604-605, 609). Die Monotonie zyklischen Erzählens episodenorientierter Formate kann auch nonverbal angezeigt werden. So vollzieht beispielsweise Katharina eine Drehbewegung mit den Händen, während sie die Serie How I MET YOUR MOTHER genau dafür kritisiert (RHG10, Z. 577). ${ }^{2}$ Anders als in den Sequenzen zu ALARM FÜR KOBRA 11 oder der Diskussion um türkische Serien fungiert diese Geste hier als Aufrechterhaltung der Distinktion zwischen Katharina (sowie Friederike und Sophie) einerseits und Leon (und Jan) andererseits, wie sie in Abschnitt 7.3.3 analysiert wird.

Diejenigen Gruppenmitglieder, die episodenorientiertes Erzählen positiv bewerten, führen überwiegend Zufriedenheit über die Abgeschlossenheit der Erzählstränge und Unterhaltung als Kriterien für ihr Urteil an (Anhang II: EMS53, Z. 164; 089 oder Anhang V: MNG13, Z. 052, 061). Josefine kommuniziert beispielsweise ihre Präferenz für die Serie SUPERGIRL als Vehikel zur Unterhaltung nach einem anstrengenden und langen Schultag, kategorisiert sie kontrastiv jedoch als ,nicht spannend" und „nicht so dass ich sie DURCHsuchten würde; “ (Anhang IV: MNG11, Z. 120-131; zum Begriff des Durchsuchtens vgl. Abschnitt 8.2.4.2). Auch wenn Jose-

2 Der Ausschnitt ist zeitlich zwischen der in Abschnitt 7.3.3 analysierten Sequenz 33 und der in Abschnitt 8.2.2 analysierten Sequenz 37 verortet. 
fine hier Spannung als Antinomie zu Unterhaltung etabliert, bedeutet das nicht, dass alle Studienteilnehmenden dieses Unterscheidungskriterium teilen. So betont Judith immer wieder, dass sie die Serie GZSZ vorrangig zu Unterhaltungszwecken rezipiert, sie aber „trotzdem [...] irgendwie spannend“ (Anhang I: EMS51, Z. 492) bliebe. Daran wird deutlich, dass Spannung und Langeweile individuelle Kategorien sind, die sich je nach Serientyp und Erwartungen bzw. Ansprüchen für die Rezeption unterscheiden können. Zudem können sie zu sehr ausführlichen Auseinandersetzungen bezüglich der Einordnung einer Serie als langweilig bzw. spannend führen (vgl. Anhang I: EMS51, Z. 122-134; 485-501; 829-847), wodurch wiederum die Distinktion innerhalb der Gruppe, die sich entlang der Präferenzen für narrativ komplexe und weniger komplexe Serien etabliert hat, aufrechterhalten bleiben kann.

Tatsächlich behandeln die Jugendlichen fortsetzungsorientiert erzählende Serien häufig komplementär zu episodenorientierten Serien, indem sie sie beispielsweise als Serien mit einer ,fortlaufende[n] STOry“ (Anhang II: EMS53, Z. 074075) charakterisieren. Während Tim aus der Gruppe EMS53 sich auf diese Art und Weise von narrativ komplexeren Serien distanziert, signalisiert Ali (Gruppe MNG13) dazu eine hohe Affinität. Er argumentiert mehrfach, er möge Serien, die eine ,geSCHICHte" erzählen, an der er sich "festhalten kann" (Anhang V: MNG13, Z. 068, 075, 083-084, 228, 248). Es wird deutlich, dass er insbesondere im konfrontativen Dialog mit David um Worte und Formulierungen ringt, um zu präzisieren, was er mit dem Terminus „Geschichte“ meint. Zwischen Ali und David finden so überwiegend Distinktionsaktivitäten im Hinblick auf die Bewertung von Komplexität statt. Der Verweis auf narrativ komplexere Serien bleibt dabei insgesamt eher implizit und kann vor allem unter Einbezug des gesamten Interaktionsverlaufs gedeutet werden, denn Ali distanziert sich von Serien wie The BIg BANG Theory (MNG13, Z. 035, 038), markiert eindeutig seine Präferenz für Serien, die zum Nachdenken anregen (vgl. Beispiel 17) und signalisiert ein hohes Involvement in serielle Narrationen (Z. 382, 385; vgl. dazu auch Abschnitt 8.1.4 und 8.2.4.1).

Das Nachdenken über oder auch Lernen durch komplexe Serien wird auch in anderen Interaktionskontexten als relevant behandelt. Sowohl Magnus und Leni (Anhang IV: MNG11, Z. 672-688) als auch Niko und Burim (Anhang I: EMS51, Z. 273-293) signalisieren eine Präferenz für Plots, die sie auch nach der Rezeption noch beschäftigen:

MAG: ich mag auch so SErien wo du so; (.) äh richtig viel MITdenken musst; [...] wo_s n (.) RICHtig komplizierten plot gibt?=dann immer SEHR sehr viele twists und äh, (.) SAChen die man halt nich herVORsehen konnte, [...] LEN: kennt ihr detektiv COnan? [...] da musst du AUCH voll viel nachdenken; MAG: ich hab Alle sechshundert DURCHgezockt; ((lachen)) LEN: HEFtig; (MNG11, Z. 669-674; 686-691). 
In ihrer geteilten positiven Bewertung vergemeinschaften sich die beiden Gruppenmitglieder als Subgruppe, sie erfahren keinen Widerspruch von anderen Personen. Bei abweichenden Bewertungen greifen die Teilnehmenden bisweilen auf Formulierungen zurück, mit denen sie anderen eine längere Beschäftigung mit der Serie nahelegen, um „reinzukommen“ (z.B. Anhang I: EMS51, Z. 358; Anhang II: EMS53, Z. 296; Anhang IV: MNG11; Z. 458; Anhang VI: RHG10, Z. 427, 460, 911). Damit empfehlen sie einen Rezeptionsmodus (vgl. Abschnitt 7.1.4), der der Komplexität der jeweiligen Serien gerecht wird.

Als grundlegend prototypisch für serielles Erzählen gelten Cliffhanger, die nach dem Ende einer Episode oder Staffel die Rezipient*innen im Unklaren über den Fortgang lassen (vgl. ausführlicher Abschnitt 2.1.1). Wenn Cliffhanger thematisiert werden, führt das häufig zur Bildung von Allianzen und Distinktion gleichermaßen: Während manche Gruppenmitglieder sich darüber vergemeinschaften, dass sie Cliffhanger spannend finden und dadurch angeregt werden, schnell weiter zu schauen, kritisieren andere diese Erzählelemente und rezipieren bewusst keine Serien, die hauptsächlich damit arbeiten (Anhang V: MNG13, Z. 773-776; Anhang II: EMS53, Z. 114, 379, vgl. auch Beispiel 48). Manche Jugendliche nennen auch als Kennzeichen für Komplexität, wenn eine Serie nicht den Erwartungen des Fortgangs der Story (MNG13, Z. 686-704) oder den linearen Präsentationsgewohnheiten (Anhang IX: OST11, Z. 820-851) entspricht. Beides markieren sie als besonders, bewerten es allerdings auch je unterschiedlich - während Ole die unkonventionelle Erzählweise von BLACK MIRROR anpreist, kann Sevcan damit nichts anfangen (vgl. OST, Z. 825-826; 831-843) -, so dass sich daraus ebenfalls wieder Auslöser zur Vergemeinschaftung oder Distinktion ergeben.

Insgesamt lässt sich feststellen, dass Vergemeinschaftung nie in Bezug auf die gesamte Gruppe - wie es beispielsweise bei der Thematisierung von Kinderserien der Fall ist (vgl. Abschnitt 8.1.2) -, sondern nur innerhalb von aus zwei bis drei Personen bestehenden Subgruppen etabliert wird. Generell scheint der in diesem Abschnitt analysierte Aspekt für die Kommunikation einen hohen Stellenwert zu haben, da es in (fast) allen Daten Dynamiken zwischen zwei oder mehreren Gruppenmitgliedern gibt, die Komplexität unterschiedlich bewerten: Ali vs. David sowie Paul und Tufan in MNG13 (Abschnitt 9.1.1), Burim vs. Judith und Niko in EMS51 (Abschnitt 8.2.2), Leon vs. Katharina in RHG10 (Abschnitt 7.3.3), Tim vs. Sascha in EMS53 (Abschnitt 9.1.1). Daher fungiert Komplexität gleichzeitig sowohl als Instrument zur Vergemeinschaftung mit Gleichgesinnten als auch als Distinktionsmittel. Allerdings darf eine Serie auch nicht $z u$ komplex sein (Anhang I: EMS51, Z. 282, OST11, Z. 823); vgl. auch insgesamt die Orientierung an Angemessenheit in Abschnitt 8.2.4), da sie ansonsten den Reiz zur Rezeption bei vielen Jugendlichen verliert. 


\subsubsection{Serienfiguren}

Figuren werden allgemein wichtige Funktionen für die Serienrezeption zugeschrieben. Sie bringen nicht nur die Handlung voran und können für komplexe Entwicklungen verantwortlich sein, sondern bieten Rezipient*innen auch Identifikationsmöglichkeiten und zeigen alternative Lebensentwürfe auf. Es wird unterschieden zwischen ,runden' und ,flachen' Charakteren. Flache Figuren sind eher stereotyp dargestellt, während runde Figuren mehrere und komplexere Eigenschaften und Verhaltensweisen aufweisen sowie eine Entwicklung durchlaufen. Zudem ist eine gewisse Konstanz des Figureninventars ein Kennzeichen serieller Formate (vgl. Ausführungen in Abschnitt 2.1.1).

Die Teilnehmenden setzen Serienfiguren interaktiv meistens erst dann relevant, wenn die Serie mehreren Beteiligten bekannt ist. Mit der Praktik Managen divergenter Wissens(be)stände (vgl. Abschnitt 7.1.1) werden im Zuge wissensausgleichender Interaktionen Figuren häufig in ihrer Bedeutung für die Handlung thematisiert. Charaktere werden dann nicht mit ihrem Eigennamen eingeführt, sondern über ihre Funktion für den Plot, wie zum Beispiel „dieser RECHTSanwalt der betrunken auto gefahren ist; “(Anhang I: EMS51, Z. 875) oder „ein; (.) äh JUNge? der seinen BRUder finden möchte, “(Anhang V: MNG13, Z. 138-140). Wenn Figuren namentlich genannt werden, erfolgt oft entweder eine fremdinitiierte Elaborierung zur Einordnung der Personen in die Figuren (vgl. z.B. Beispiel 36) oder die Jugendlichen ergänzen diese Information explizit selbst: ,ja äh bei FAmiliy guy, IST peter griffin? (.) also das ist die HAUPTperson wenn ihr die nicht kennt, =äh mit, (.) mit nem GAbelstapler in nen WAL reingefahren; “(Anhang IX: OST11, Z. 337-339). Seltener erfolgt keine Elaborierung: „=bei house of CARD zum beispiel, war das SO schlimm mit peter RUSsow und so weiter, “(Anhang II: EMS53, Z. 294-295), was auf die überwiegende Bekanntheit der Serie schließen lässt. In den vorliegenden Daten findet also selten eine Auseinandersetzung mit konkreten Figuren statt, sondern auf einer abstrakteren Ebene, insbesondere anhand der Kriterien Konstanz, Figurentypen und Identifikationsangebote.

Figurenkonstanz wird in der Fachliteratur häufig als ein Merkmal unter vielen dargestellt, etwas, das zwar konstitutiv für Serialität (vgl. u.a. die Definition von Kelleter 2012: 18), aber nicht ausschlaggebend ist (vgl. Weber und Junklewitz 2008: 16). Die Jugendlichen verleihen diesem Kriterium deutlich mehr Gewicht. So kritisieren beispielsweise sowohl Stephanie (Anhang I: EMS51, Z. 502-509) als auch Leni (Anhang IV: MNG11, Z. 241-244), dass manche Figuren von wechselnden Darsteller^innen gespielt werden. Während Leni von allen anderen Gruppenmitgliedern für diese Aussage Zustimmung erhält, erntet Stephanie Widerspruch von Judith. Auf GZSZ beziehend erläutert sie, dass das nur bei einer Figur - Ayla - dort der Fall war und sie damit „ganz gut klar“ kam (Anhang I: EMS51, Z. 521). Damit 
relativiert sie Stephanies Aussage, die mit der Verwendung des Adverbs „immer“ (Z. 502), Allgemeingültigkeit beansprucht und von einer mit den anderen geteilten Bewertung ausgeht. Es folgt eine Aushandlungssequenz, während derer sich Lara mit Stephanie vergemeinschaftet (Z. 518) und Judith bei ihrer Position bleibt. Sie begründet den Wechsel als nicht schlimm, denn „das macht es ja noch SPANnender;“ (Z. 530-531). Figurenkonstanz wird also zwar als Kriterium für Serialität im common ground der Gruppen angenommen, kann dann aber je nach subjektiver Bewertung sowohl zu Vergemeinschaftungsaktivitäten als auch Distinktion führen.

Figurenkonstanz betrifft nicht nur die Darsteller^innen, sondern auch die Frage, ob Protagonist`innen überleben. So bewertet Robert es als besonders schlimm, wenn die Hauptcharaktere sterben (Anhang IX: OST11, Z. 912-913). Aus Verenas daraufhin folgender Äußerung ,ja aber die kommen EH zurück“ (Z. 915) lässt sich schließen, dass die Interagierenden als geteiltes Wissen zugrunde legen, dass Hauptfiguren üblicherweise ihre Rezipient*innen konstant durch eine Serie begleiten. Dem widerspricht Ole mit Verweis auf GAME of Thrones (Z. 921-922). Tatsächlich werden die Serien GAME of Thrones und The Walking DeAD meistens als abweichend von dieser Prämisse behandelt (für GAME of THRONES vgl. auch die Ausführungen in Abschnitt 9.1). Deutlich wird das beispielsweise anhand Pauls iterativ formulierter und mit hoher epistemischer Gewissheit ausgestattete Behauptung, bei THE WALKING DEAD sei ,ja die einzige diskusSION immer, WER is gestorben; wer is gestorben, wer is gestorben; “(Anhang V: MNG13, Z. 668-671), wofür er Zustimmung von David erhält und sich damit mit ihm vergemeinschaftet (Z. 672-673). Explizit thematisiert Hendrik die Abweichung in GAME of Thrones von den diesbezüglichen Erwartungen: ,du denkst ja oke läuft jetzt so wie in JEder normalen serie ne, =die hauptcharaktEre, (.) STERben einfach nicht und; (.) (leben) DURCH und, im endeffekt werden die alle so hinterhältig UMgebracht; “ (Anhang II: EMS53, Z. 289-292). Diese Abweichungen bilden den Ausgangspunkt für Vergemeinschaftungsaktivitäten über geteilte Bewertungen. Zugleich ist aber auch Distinktion möglich, wenn die Jugendlichen zum Beispiel GAME OF THRONEs den alleinigen Anspruch auf die Sterbewahrscheinlichkeit von Hauptfiguren absprechen (Anhang I: EMS53, Z. 293-295; Anhang V: MNG13, Z. 680).

Ebenfalls als abweichend von gängigen Stereotypen skizziert Burim die Figuren in seiner Lieblingsserie Oz - HöLLE HINTER GITTERN (Anhang I: EMS51, Z. 866-868). Es folgt eine längere Aushandlungssequenz, als Stephanie sich erfolglos an einer Typisierung von Figuren in dieser Serie versucht (Z. 914-942). Da sie selbst die Serie nicht kennt, muss sie sich an Burims bisherigen Äußerungen orientieren (Z. 075-125, 867-909). So interferiert sie aus seinen Schilderungen, dass es mit hoher Wahrscheinlichkeit Figuren gibt, die dem Genre entsprechende spezifische Rollen und Funktionen einnehmen. Aufschlussreich ist in diesem Zusammenhang ihre Reparatur von einer potentiellen Frage mit Verberststellung: ,ist 
da ein," (Z. 915) zu einer deklarativen Formulierung in Thesenform, die deutlich mehr epistemische Autorität beansprucht: „da ist EIner der rAUswill.“ (Z. 916). Mit dem Begriff „rauswill“ bezieht sie sich auf das Setting der Serie, das im Gefängnis spielt. Auch die anderen von ihr aufgeführten Figurentypen: ,der versucht sich ANzupassen;“ (Z. 921) oder „einer der die ganze zeit NETT ist?“(Z. 926), „einer der voll der reBELL is, “(Z. 929), „also so n; (-) so n Oberhaupt, n chEf von ALlem?“ (Z. 932933) zeigen ihre medien- bzw. genrebezogenen Erfahrungen, die sie als Grundlage für ihre Auflistung hinzuzieht. Sie verweist mehrfach auf die angenommene Stabilität dieser Wissenselemente (Z. 852, 858-864; mit interaktiver Zustimmung und Unterstützung von Judith; Z. 941). Somit nutzt sie ihr bekannte Figurenkonstellationen (hier handelt es sich wieder um Schemata im Eco'schen Sinne), die sie versucht auf unbekannte Serien anzuwenden. Allerdings hat sie damit keinen Erfolg, da Burim ihre Behauptungen jedes Mal negiert. Das ist insofern nicht verwunderlich, als diese Sequenz in Burims Argumentation eingebettet ist, in der er seine Lieblingsserie - und darüber implizit sich selbst - kontinuierlich als einzigartig und individuell darstellt. So betont er beispielsweise wiederholt, für ihn sei die „chaRAKterentwicklung“ der Figuren essentiell wichtig für die Rezeption (Z. 770775, 847-850, 867-909). Daher ist es nur konsequent, wenn er die Figurentypen in ,seiner' Serie als abweichend vom common ground markiert und Stephanies Vergemeinschaftungsangebot zurückweist. Seine Distinktionsbemühungen werden von den anderen Teilnehmenden gestützt, insbesondere durch Lara, indem sie ihm zuschreibt, im Unterschied zum Rest der Gruppe keine „MAINstream serien“ (Z. 944) zu konsumieren. Diese Kategorisierung wird ausführlicher in Abschnitt 8.2.2 diskutiert.

Auch in anderen Daten werden Figuren als typisch oder abweichend eingeordnet, beispielsweise die Figur des Clay in 13 REAsons Why, dessen Verhalten daraufhin überprüft wird, ob es dem eines „kliSCHEE, (.) außenseiter“s (RHG10, Z 274-275 ) entspricht (vgl. dazu die Analyse von Beispiel 36). Auch das Verhalten der Figur ARRow wird kritisch in Bezug darauf diskutiert, ob es innerhalb der Serienwelt als plausibel gilt (vgl. Analyse in Beispiel 24 in Abschnitt 7.1.4; zu Plausibilität als Bewertungsmaßstab in Serien allgemein vgl. auch Abschnitt 8.2.1). Auch wenn sich die Beteiligten einig sind, dass es solche prototypischen Figuren gibt, die zur Orientierung und Verständigung dienen, werden sie interaktiv vor allem zur Distinktion über entweder eine divergierende Bewertung (vgl. Anhang VI: RHG10, Z. 518-527) funktionalisiert oder zur Selbstpositionierung als abweichend vom Mainstream (s.o.) genutzt.

Außerdem spielen Figuren als Identifikationsangebote eine Rolle. Deutlich wird das beispielsweise an Alis These: „serien sind dafür um sich halt drin REIN zu so; so hinEIN zu versetzen und man, man denkt man ist drin oder so was; “ (Anhang V: MNG13, Z. 382-383). Er erhält von Igdir (Z. 386-388) und David starke Zustim- 
mung. Insbesondere Davids Aussage „ja ja norMAL, “ (Z. 389) weist darauf hin, dass dieses Wissenselement als geteilt vorausgesetzt werden kann. Allerdings wird der Aspekt der Identifikation nicht häufig in den Gruppengesprächen thematisiert. Das mag möglicherweise an dem Öffentlichkeitscharakter der Interaktion liegen (vgl. Abschnitt 6.1.2). Als Leni den anderen Teilnehmenden zu ihrer Rezeption die Frage stellt: „stellt ihr euch so vor wie !IHR! das so seid so, (.) ich BIN das so,“ (Anhang IV: MNG11, Z. 300-301), erhält sie gemischte Reaktionen: Martha stimmt ihr enthusiastisch zu und führt mit XENA ein Beispiel für eine solche Serie an sie wäre auch gerne eine „warrior princess“ (Z. 303-306). Nelli jedoch verneint Lenis Frage, lacht und artikuliert mit „tsch“ (Z. 302) ein Geräusch, das in diesem Kontext unter Einbezug ihres Blickverhaltens als Unverständnis gedeutet werden kann. Leni fährt jedoch damit fort, ihre Positionierung zu elaborieren und erhält im Anschluss eine zustimmende Zweitbewertung von Josefine, wodurch es zu einer Vergemeinschaftungssequenz zwischen beiden kommt (Z. 307-348; vgl. für eine detaillierte Analyse und einen längeren Transkriptausschnitt Beispiel 15, S. 130).

Die Kommunikation des eigenen Identifikationsverhaltens mit Serienfiguren ist - zumindest in den vorliegenden Daten - offenbar heikel, da sie zur facebedrohenden Fremdpositionierung genutzt werden kann. So nimmt David einige Minuten später Bezug auf Alis Äußerung des „Hineinversetzens“ in folgender Art und Weise: „, (.) GUCK mal, (.) du sagst geRAde? man äh:; verSETZT sich so in andere identiẗ̈ten und so. =also dass du: (.) so (.) denkst du kannst dich (.) mit denen identifiZIERen; (-) und (wenn dann) IRgend so einer mit SCHWERT und äh, (.) keine BILdung < <lachend>(äh sagst du geNAU; alter (der) BIN ich voll;> ((lacht))“ (Anhang V: MNG13, Z. 627-634). Eingebettet ist diese Äußerung in eine argumentative Sequenz, in der David sein Unverständnis einer Präferenz historischer Settings in Serien zum Ausdruck bringt (vgl. auch Beispiel 17, S. 136 in Abschnitt 7.1.2 und Abschnitt 9.1.1). So positioniert er Ali kurz darauf als „dumm“ (Z. 640), weil er diese Serien mag. Die Argumentationskette dahinter besteht darin, dass Ali, der sich mit damals lebenden Personen identifiziert, genauso ungebildet sein müsse wie die solches symbolisierenden Figuren. Auch wenn die Äußerung scherzhaft gerahmt ist, reiht sie sich doch in diverse teasing-Aktivitäten Davids gegen Ali ein und enthält face-bedrohendes Potential (vgl. Beispiel 7). Ali pariert Davids Fremdpositionierung jedoch und lässt sie quasi ,ins Leere laufen': „ja kann doch SEIN, wenn ich da IN, «dim> dieser zeit geLEBT hätte, warum NICH;> [...] ja äh die (.) die waren bestimmt nich DUMM für die damalige zeit" (Z. 635-638; 641).

Es wird deutlich, dass die evaluative Positionierung einer Serie immer auch die Möglichkeit bietet, gleichermaßen als Positionierung der Person, die diese Serie mag, gelesen zu werden, wie es auch schon in Abschnitt 7.3.3 herausgearbeitet wird. Figuren werden also durchaus als potentielle Identifikationsangebote wahrgenommen, aber selten als solche kommuniziert. Dieser Aspekt kann gemein- 
schaftsstiftend sein (Anhang V: MNG13, Z. 382-393; Anhang IV: MNG11, Z. 297-348), zugleich birgt er aber das Risiko face-bedrohender Distinktion (MNG11, Z. 302; MNG13, Z. 640).

\subsubsection{Serien als gestaltete Produkte}

Die Teilnehmenden thematisieren nicht nur die Serie als Medienprodukt, sondern auch Aspekte der Präsentation und Produktion (vgl. Abschnitt 2.1.2) sowie damit verknüpfte Wertungen (Abschnitt 2.1.3). Gestaltet bezieht sich in diesem Zusammenhang auf die Analyse von Sequenzen, in denen Teilnehmende die ,Gemachtheit' von Serien thematisieren und diskutieren.

Darunter fallen beispielsweise Aspekte der Postproduktion. So platziert Friederike sequenziell passend kontextualisiert eine als scherzhaft gerahmte BeschwerdeErzählung, in der sie kritisiert, dass durch das Herausschneiden von Gewalt-Szenen in einem Film aus Rücksichtnahme auf jüngere Zuschauer`innen die Handlung so verändert wurde, dass sie nicht mehr nachvollziehbar sei (Anhang VI: RHG10, Z. 126-149). Diese Nebensequenz wird jedoch nicht weiter aufgegriffen, so dass Friederike hier kommunikativ nicht erfolgreich ein neues Positionierungsobjekt etablieren konnte (vgl. Abschnitt 7.2.3), sondern die Jugendlichen ratifizieren ihre Ausführungen nur kurz und fahren dann mit der Diskussion der Serie 13 REASONS WHY fort (die Transkriptausschnitte und Analysen zur Diskussion dieser Serie finden sich in den Beispielen 36 und 43). Nicht nur Schnitte, sondern auch die visuelle und auditive Gestaltung fallen unter diesen Aspekt, der jedoch innerhalb der Daten eher selten thematisiert wird. Leon führt die Bild- und Klangästhetik als Qualitätsmerkmal für die Serie FARGO an: „das ist spannend geMACHT; (-) die muSIK, die BILder, (.) die sind ähnlich wie die bilder wie die COhen brothers; =wenn ihr den origiNALfilm gesehen habt, (.) das sind auch so weite bilder im SCHNEE und so was, “ (RHG10, Z 846-851; vgl. auch die Analysen der hier verwendeten Praktik des Managens divergenter Wissensbestände in Abschnitt 7.1.1.

Auf der Formulierungsebene werden Hinweise auf die Gestaltung von Serien an Aussagen wie, dass etwas „extra“ oder „bewusst“ gemacht wurde, deutlich. Beispielsweise ko-konstruieren Paul, Igdir und David gemeinsam die Aussage, dass Serien manchmal mit den Erwartungen der Rezipient^innen brechen: „PAU: ja das, das [is aber EXtra gemacht;] IGD: [das is IMmer genau das gegenteil] [was passiert;] DAV: [ja aber das is,] ja das is, das is ja nich ohne GRUND extra so;" (Anhang V: MNG13, Z. 695-700). Auch im Kontext der Diskussion darum, ob CSI eine „richtige Serie“ (vgl. auch Ausführungen in Abschnitt 8.1.1) sei, argumentiert Lara dafür, indem sie darauf verweist, dass einzelne Handlungselemente aus früheren Episoden später wieder aufgegriffen werden: „das ist SCHON so; wenn du dir das 
bewusst ANgucken würdest, dass irgendwas passiert am anfang zum beispiel der STAFfel, und die LETZte folge, (.) greift das dann wieder AUF. “(Anhang I: EMS51, Z. 688-692), wobei sie sich mit der Praktik des Empfehlens eines Rezeptionsmodus (Z. 689; vgl. Abschnitt 7.1.4) epistemisch als $K^{+}$positioniert. Diese Funktion erfüllt auch die Kritik an den Produktionspraktiken von RTL, die Ole und Johann in Bezug auf SCHWIEGERTOCHTER GESUCHT üben (OST 11, Z. 734-813; für eine ausführliche Analyse vgl. Beispiel 18, S. 139) und über die sie sich gemeinsam als Experten vergemeinschaften.

Bei der Frage nach der Gestaltung von Serien spielen Qualität und Wertungen eine Rolle. Diese Bewertungen sind eng mit der Frage nach narrativer Komplexität (vgl. Abschnitt 8.1.3) und dem Trivialitätsdiskurs (Abschnitt 8.2.2) verbunden. Dazu zählen Gesprächsbeiträge, die dezidiert auf die Produktionsebene Bezug nehmen: So setzen beispielsweise die Teilnehmenden die eingespielten Lacher eines Studiopublikums mit dem Attribut „BILlig“ gleich (RHG10, Z. 555-572, vgl. auch die Analyse in Beispiel 37). Die gleiche Zuschreibung verwenden die Teilnehmer gegenüber Kurzserien auf Pro 7 (vgl. Anhang II: EMS53, Z. 443-463). Dass diese Serien ,billig' produziert wurden, führt in dieser Sequenz allerdings - anders als in Beispiel 37, in der dieser Aspekt zur Aufrechterhaltung von Dissens fungiert - zur Vergemeinschaftung über die wechselseitige Vergewisserung der Geringschätzung und damit einhergehenden Belustigung über diesen Serientyp. Verknüpft mit der Frage nach ,billigen' Produktionen ist der Aspekt der Kommerzialisierung. Explizit kritisiert Burim diesen Prozess: „also ich finde was äh serien oft TÖtet, ist der kommerzielle geDANke dahinter; =natürlich jede serie wird erstmal (.) geMACHT? (.) um GELD zu verdienen. (Anhang I: EMS1, Z. 533-536). Dabei wird deutlich, dass er nicht den Aspekt des Geld-Verdienens an sich negativ bewertet, sondern insbesondere die „Unkreativität“ der Produzent`innen am Beispiel der Serie SuPERNATURAL (Z. 533-560) kritisiert - etwas, was auch beispielsweise Ole als negativ anführt (vgl. Anhang IX: OST11, Z. 876-891).

Auch die an der Produktion beteiligten Schauspieler ${ }^{\star}$ innen scheinen für die Interagierenden relevant zu sein - nicht nur, wenn sie eine Serie verlassen (vgl. Abschnitt 8.1.4 oder Beispiel 23). So wird die Besetzung der Serie MORD MIT AusSICHT mit Theaterschauspieler*innen argumentativ als Beleg für eine hohe Qualität angeführt (RHG10, Z. 878-886; vgl. Beispiel 20, S. 148), während ,nicht türkisch aussehende“ Schauspieler in türkischen Serien als „HEFtig“ betitelt werden (Anhang V: MNG13, Z. 816-848). Unabhängig von der Bewertung, die Igdir mit dieser Zuschreibung vornimmt und die sich weder eindeutig positiv noch eindeutig negativ einordnen lässt, wird an der Äußerung dennoch erkennbar, dass Darsteller`innen im Zuge von Brüchen mit Erwartungen interaktiv als hervorstechend markiert und diskutiert werden. Einerseits kann somit Vergemeinschaftung innerhalb der Gruppe oder einer Subgruppe hergestellt werden, andererseits wird über so hinzu- 
gezogenes serienexternes Wissen (vgl. Abschnitt 7.1.2) auch Selbstpositionierung als Experte oder Expertin und damit auch eine Abgrenzung von den anderen betrieben.

\subsubsection{Zusammenfassung: Prototypische Vorstellungen}

Die Teilnehmenden nutzen als im common ground verortete, medienproduktbezogene Wissenselemente als Ausgangspunkt für Vergemeinschaftungs- und Distinktionsaktivitäten. Vergemeinschaftung findet entweder in der Gesamtgruppe oder innerhalb von Subgruppen über die gegenseitige Vergewisserung bezüglich der Elemente, die sie kennen und ähnlich bewerten statt, d.h. über das, was interaktiv als prototypisch angesehen wird. Dazu zählt beispielsweise, dass Serien als vorgegebener Gesprächsgegenstand beibehalten werden sollten und dass sie sich von Filmen durch die Länge abgrenzen (Abschnitt 8.1.1). Dabei zeigen die Teilnehmenden an, dass sie sich bewusst sind, dass durch Postproduktion bestimmte Wirkungen erzeugt werden (Abschnitt 8.1.5). Serien teilen sie teilweise in Kategorien ein, die entweder konventionalisierten Genres entsprechen oder individuelle Zuschreibungen umfassen. Diese Kategorien dienen in erster Linie der Verständnissicherung und der wechselseitigen Vergewisserung geteilter Bedeutungen (Abschnitt 8.1.2). Bezüglich der Erzählstruktur sind sich die Teilnehmenden weitgehend einig, dass es auf der einen Seite eher prototypisch episodenorientierte - die sich auszeichnen durch die Merkmale Abgeschlossenheit, Wiederholung und Nutzen für Unterhaltungszwecke - und auf der anderen Seite eher prototypisch fortsetzungsorientierte Serien gibt, die eine fortlaufende Geschichte erzählen, die zum Nachdenken oder gar Lernen anregen, weil sie mit den Erwartungen brechen (Abschnitt 8.1.3). Für die Handlung spielen Figuren zwar eine wichtige Rolle, allerdings werden sie selten namentlich eingeführt. Zudem ordnen die Teilnehmenden Figuren bestimmten Typen zu und erkennen, dass Figuren Identifikationsangebote für Rezipient`innen bereithalten (Abschnitt 8.1.4).

Über diese narratologischen Aspekte erfolgt Distinktion vor allem über eine unterschiedlich vorgenommene evaluative Positionierung in Bezug auf diese Elemente. Insbesondere mit dem Aspekt der Komplexität werden unterschiedliche (Qualitäts-)Erwartungen und -Ansprüche an die Serienproduktion gestellt. Distinktion wird also einerseits überwiegend über eine abweichende Bewertung eines Elements, das als prototypisch behandelt wird, hergestellt. Andererseits kann Distinktion auch über die abweichende Einordnung einer Serie oder eines Serientyps als prototypisch etabliert werden. Besonders deutlich wird das in den Analysen zu How I MET YOUR MOTHER (Abschnitt 7.3.3), in der sich die Jugendlichen zwar einig über die Kategorisierung der Serie als Soap sind, eine Subgruppe 
sie allerdings als prototypische Soap einordnet und eine andere Subgruppe dafür argumentiert, sie als abweichend vom Prototypischen zu verstehen. Dann wird der eigene Geschmack als individuell und vom Prototypischen abweichend - im Sinne von doing being extraordinary - dargestellt. Dafür können die Teilnehmenden ihr Wissen über diese Elemente zeigen und mittels der in Abschnitt 7.1 beschriebenen Praktiken sich zugleich als Expertin oder Experte positionieren, die es besser und anders wissen.

\subsection{Orientieren an normativen Vorstellungen in rezeptionsbezogenen Interaktionen}

In diesem Abschnitt werden Fälle betrachtet, in denen rezeptionsbezogene Aspekte relevant gesetzt werden. Damit werden Positionierungsobjekte erfasst, die Erwartungen sowohl an das Medienprodukt aus Rezipient*innenperspektive als auch an das Rezeptionsverhalten kommunizieren. Die Analyse zeigt, dass sich die Teilnehmenden an normativen Vorstellungen orientieren, die Serien als Medienprodukte in Form von Bewertungen der Handlungslogik (Abschnitt 8.2.1) und der (Rezeption von) Serientypen (Abschnitt 8.2.2) sowie den adäquaten rezipient*innenseitigen Umgang mit dem narrativen Status Quo bzw. der Weitergabe von Medienwissen (Abschnitt 8.2.3) umfassen. Weiterhin betreffen die normativen Erwartungen auch das individuelle Rezeptionsverhalten, das im Hinblick auf seine Angemessenheit (Abschnitt 8.2.4) diskursiv verhandelt wird.

Der Konversationsanalyse folgend wird diese Orientierung einerseits anhand von auf der interaktiven Oberfläche erkennbaren Phänomenen wie nuancierte Bewertungen, Fremdpositionierungen und Rechtfertigungen und Formulierungsaufwand für Aussagen mikroanalytisch rekonstruiert und andererseits wird mit den Interagierenden kulturell und medial geteiltes Wissen als Ressource zur Interpretation genutzt (vgl. Abschnitt 4.2 und 2.1). Die Unterkapitel sind folgendermaßen aufgebaut: Zunächst wird eine kurze thematische Einführung gegeben, dann folgen zwei bis drei exemplarische Transkriptausschnitte, die im Hinblick auf die Frage nach normativen Orientierungen der Teilnehmenden analysiert werden.

\subsection{1 „serien die ihre eigene LOgik brechen“ - Narratologische Plausibilität als Bewertungsmaßstab}

Ein zentrales Kriterium, anhand dessen die Jugendlichen ihre Präferenzen für bestimmte Serien begründen, ist das der narratologischen Plausibilität. Das bedeutet, dass die Teilnehmenden den Anspruch kommunizieren, dass Serien der Logik 
der erzählten Welt folgen sollten und Serien (auch) danach bewerten, ob bzw. wie sie diese Erwartung erfüllen. Es werden im Folgenden ein Transkriptausschnitt analysiert, in dem dieses Kriterium sehr explizit benannt und elaboriert wird (Beispiel 35, S. 230), sowie eine Sequenz, in der das Agieren einer Figur kritisch im Hinblick auf Plausibilität diskutiert wird (Beispiele 36 oder 24).

\section{(35) UNlogische dinge sind ja oKE;}

JOH: UNlogische dinge sind ja okE; so lange sie aufeinander baSIEren wenigstens; aber bei FLASH, kannst du nich auf der EInen seite vor pistolenkugeln, und allem möglichen WEGlaufen?

(.) ZEITsprünge machen, und die maTErie verändern, und an ANdererseits, [die ]

ROB: [matErie] verändern lernt er erst ganz SPÄT;

VER: [ja das find ich aber OHne scheiß; ]

$\mathrm{JOH}$ : [ja das GEHT doch [((unverständlich))]

ROB. $\quad[(($ unverständlich $))]$

OLE: man BAUT ja dann ne alternative realität auf; und dAs muss man halt Logisch machen;

$\mathrm{JOH}$ : RICHtig; =das muss WENigstens aufeinander begründet [sein;]

VER:

[nein ] ich finde EINfach, man überTREIBT voll; bei richtig vielen serien überTREIBT man einfach voll am ende; =so am anfang ist das immer noch so [ganz] oKAY,

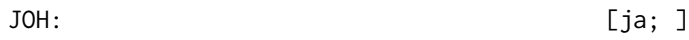


Diese Sequenz ist in eine Diskussion um Superheldenserien wie THE FLASH und BATMAN eingebettet, denen die Interagierenden zuvor einen unlogischen Handlungsverlauf attestiert hatten (vgl. Anhang IX: OST11, Z. 852). Der nun folgende Transkriptauszug beginnt mit Johanns Relativierung, dass „UNlogische dinge [...] ja oKE“ (Z. 853) seien, sofern sie bestimmte Voraussetzungen erfüllen würden (Z. 854-861). Er erhält im Anschluss starke Zustimmung der anderen Interagierenden (Z. 863-889). Johann stützt seine Argumentation auf eine exemplarische Serie (THE FLASH), in der bestimmte Handlungselemente nach alltagsweltlichem Verständnis nicht plausibel erscheinen (Pistolenkugeln ausweichen, Zeitsprünge machen und Materie verändern können; vgl. Z. 856-859). Der zweite Teil des Kontrasts, den Johann hier projiziert (Z. 860), wird aufgrund von Überlappungen nicht weiter ausgeführt, da Robert ihn inhaltlich korrigiert und damit auch eine $K^{+}$-Position beansprucht. Roberts Äußerung wird jedoch interaktiv nicht weiter relevant, stattdessen elaboriert Ole Johanns These, indem er den Anspruch an Serien so formuliert, dass die „alternative realiTÄT“, die aufgebaut wird, „halt LOgisch“ gemacht werden sollte (Z. 866-867). Die Partikel „halt“ deutet auch hier wieder auf als geteilt angenommenes Wissen hin. Tatsächlich signalisiert Verena in Form von als ironisch gerahmter Redewiedergabe mit diversen extreme case-Formulierungen ein hohes Maß an Zustimmung (Z. 863, 870-880). Es wird deutlich, dass sich die Teilnehmenden mittels der gemeinsamen Belustigung über unlogische Handlungselemente und Produktionsentscheidungen vergemeinschaften. Zudem offenbaren die Jugendlichen aber auch implizites Wissen über die Prinzipien fiktionaler Werke, die einen „plausiblen Weltentwurf“ (Abraham 2012: 21) konstruieren sollten.

Die so thematisierte Handlungs(un)logik als Bewertungsmaßstab funktioniert als Vergemeinschaftungsinstrument, wenn sich alle Beteiligten evaluativ einig sind (Beispiel 35). Gleichermaßen kann sie in den vorliegenden Daten aber auch als ein potentieller Auslöser für Distinktionsaktivitäten fungieren, wenn einzelne Teilnehmende eine Serie oder Figurenhandeln als „unlogisch“ bezeichnen, ohne dass diese Einschätzung von allen gleichermaßen geteilt wird. Beispielsweise werden sowohl Bilel bei der Diskussion der Serie ARROw - wie sie in Abschnitt 7.1.4 analysiert wurde - als auch Gisem über BoLLYwood-Produktionen (vgl. Abschnitt 7.1.3) in den Zugzwang gebracht, zu begründen, warum die Figuren in den Serien, die sie gerne schauen und gut kennen, sehr wohl plausibel und logisch handeln. Anhand eines weiteren Fallbeispiels wird dieser bisweilen sehr fein kalibrierte Aushandlungsprozess analytisch rekonstruiert: 


\section{(36) es macht !SINN!}

JAN: [ich] FAND,

(.) ich fand die war gut geMACHT, aber ich fand der hauptcharakter für mich zu (geTRAgen);

LEO: clay,

JAN: clay;

LEO: doch, (.) [ich FAND] den clay war symPAthisch,

KAT: $\quad[$ do: $\mathrm{ch} ;]$

LEO: war interessant ZUzu[gucken,]

JAN: [ich ] fand der ist,

war $\mathrm{n}$ bisschen überTRIEben das ganze;

LEO: <<leise und schnell>(das war doch nich überTRIEben;)

JAN: (ja $[$ das, $]$ )

FRI : $\quad$ [wie, ]

in welchem beZUG stand der zu der;

(.) zu der TOten?

LEO: [ähm]

JAN: [ja ] er er ER stand auf sie, und sie stand auf IHN; =aber die waren nicht,

(.) zuSAMmen [(oder so;)

KAT: $\quad$ [ja das war $\mathrm{n}$ bisschen] [komplizIERT ] so;

LEO: [müdes interESse]

$[($ an ihm $)]$

JAN: [geNAU; ]

[und es ] WAR aber,

FRI : $\quad[(($ nickt $))]$

JAN: [o (.) aber ich FAND, ]

LEO: $[(($ lacht $)) \quad]$

JAN: ich fand er HAT, er hat halt so RICHT; =er halt So auf; so auf (.) RAchezug irgendwie so $\mathrm{n}$ bisschen gemacht, und DAS fand ich [(nich so;)]

LEO: $\quad[j a, \quad]$ $\mathrm{DOCH}$ ich fand, =ich fand ich=also fand ich auch gut motiVIERT weil das [(is so (unverständlich))]

KAT: [aber ich ] FAND der war sich FAND der war; der war $\mathrm{n}$ bisschen so äh (.) speZIELL der charakter, =das war hat voll gUt so gepasst für den HAUPT[charakter;]

LEO: ja aber das war vielleicht das proBLEM; 


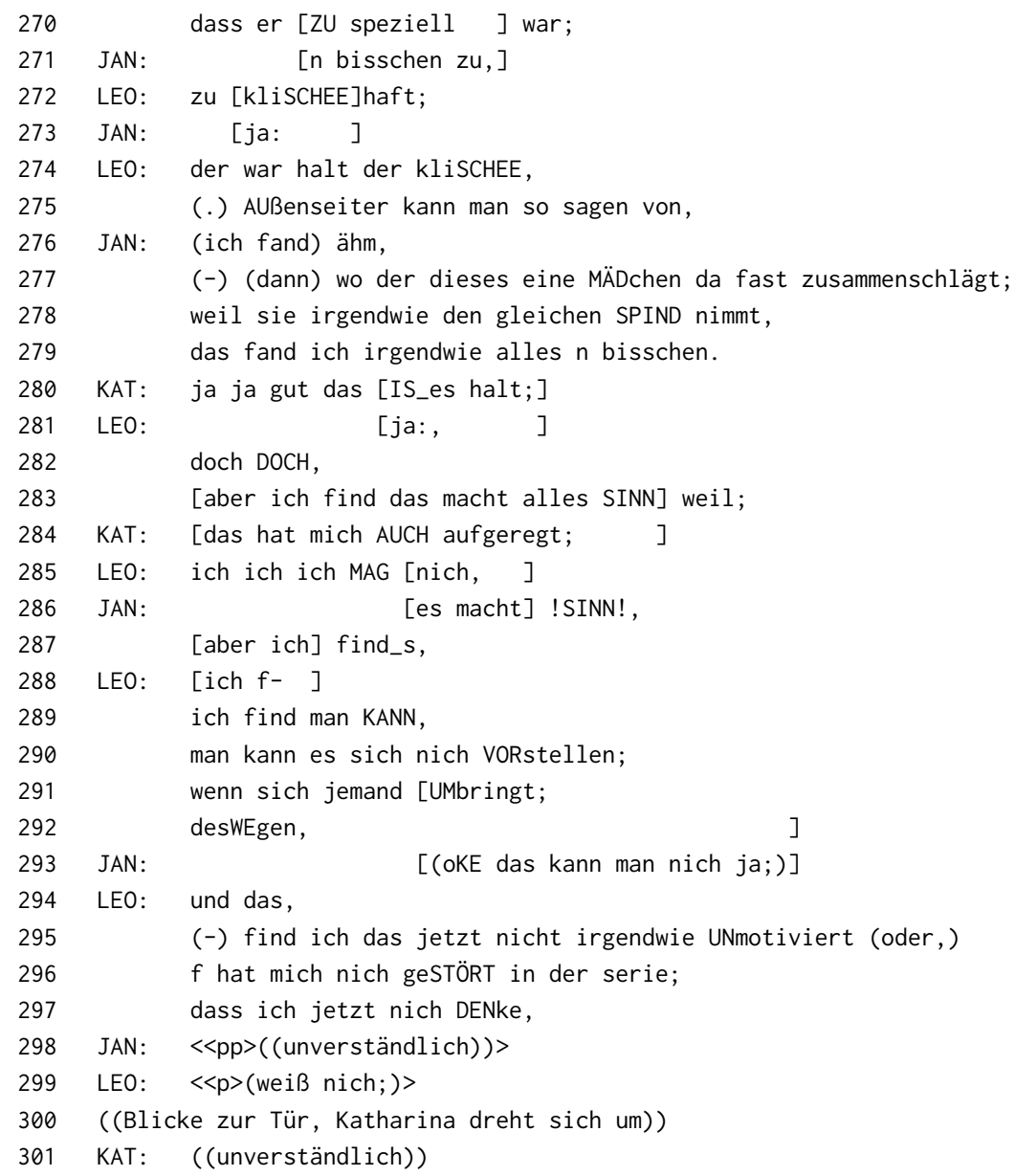

Dieser Ausschnitt entstammt der über einen längeren Zeitraum andauernden Diskussion um die Serie 13 REAsons WHY. Weitere Transkriptausschnitte dazu werden zum einen in Abschnitt 7.2.4 (Beispiel 26) unter der Frage nach epistemischen Positionierungen von Sophie als auch in Abschnitt 8.2.4.1 (Beispiel 43) unter dem Aspekt emotionaler Involviertheit diskutiert. Im Folgenden liegt der analytische Fokus darauf, wie die Jugendlichen das Verhalten der Figur Clay, die Jan in die Interaktion einbringt (Z. 230), im Hinblick auf Plausibilität darstellen und einschätzen. Ausgehend von Jans Zuschreibung, Clay sei ,übertrieben“ dargestellt worden (Z. 232-239), verengt sich dann der Fokus auf die Frage, ob die Figur in nachvollziehbarer Art und Weise filmisch inszeniert wurde. Nach einer kurzen Zwi- 
schensequenz, in der zu Zwecken der Gesprächspartizipation die verschiedenen Wissensbestände der Beteiligten gemanagt werden (Z. 240-252, vgl. auch Abschnitt 7.1.1), schließt sich eine diskursive Aushandlung zwischen Jan, Katharina und Leon an, in der sie die Motive der Hauptfigur einer kritischen Interpretation unterziehen (Z. 253-297).

Zunächst ist bemerkenswert, dass anders als in den meisten anderen Fällen, in denen Figuren diskutiert werden, die Hauptfigur hier mit ihrem Namen benannt wird (Z. 231-233; vgl. Abschnitt 8.1.4). Damit wird die Grundlage dafür geschaffen, sich diskursiv tiefer mit der Handlung zu befassen, anstatt abstrakter und distanzierter über die Serie zu sprechen. Jan kritisiert, dass für ihn die Figur „zu geTRAgen“ (Z. 230) sei und dass sie „n bisschen überTRIEben“ (Z. 237) dargestellt wird. Dem widerspricht Leon mit der Bewertung, dass er Clay „symPAthisch“ (Z. 233) fände, und es interessant fand, ihm „ZUzugucken“(Z. 235). Damit sind zwei gegensätzliche Positionierungen in Bezug auf die Figur etabliert, die sich zunächst noch auf subjektive Bewertungen stützen, die im Folgenden elaboriert werden. Dafür greifen die Jugendlichen auf figurenbezogenes, prototypisches Wissen zurück: „kliSCHEE, (.) AUßenseiter“ (Z. 272-273), der „so auf (.) RAchezug irgendwie so n bisschen gemacht“ hat (Z. 258), wofür sie einzelne Szenen aus der Serie als Beleg rekonstruieren (Z. 276-279). Auch, wenn sich die Beteiligten darin einig sind, dass der Charakter „speziell“ (Z. 266, 270) sei, beginnt Leon schließlich mit einer außerserienweltlichen Begründung für die möglicherweise aus Rezeptionsperspektive nicht nachvollziehbaren Beweggründe des Protagonisten, der den Suizid der weiblichen Hauptfigur verarbeiten muss: „man kann es sich nich VORstellen; wenn sich jemand UMbringt“ (Z. 291). Damit zieht Leon eine Parallele zur Alltagswelt, in der die Beteiligten - augenscheinlich - keine vergleichbaren Erfahrungen haben bzw. sie es als unwahrscheinlich markieren, diese Erfahrung machen zu müssen. Diese Unmöglichkeit zur Perspektivübernahme, die in anderen Zweifelsfällen den Jugendlichen ein hilfreiches Instrument an die Hand gibt, um Handlungsstränge und Figurenkonzeptionen auf ihre Glaubwürdigkeit hin zu überprüfen, verhindert daher in letzter Konsequenz ein finales Urteil zur Plausibilität. Deutlich wird diese Interpretation auch daran, dass die anderen Jugendlichen Leon diesbezüglich zustimmen (Z. 293) und es keine weiteren Widersprüche oder Aushandlungen gibt.

Insgesamt gesehen stellt diese Art der Themenbehandlung jedoch einen Einzelfall im Korpus dar. Ansonsten liegt der Fokus eher auf vergnüglicher Vergemeinschaftung, wie in Beispiel 35). Auch Magnus bewertet in Form einer extreme case-Formulierung Serien, die ,ihre eigene LOgik brechen“ (Z. 763) sehr negativ. Als Beispiel führt er die Serie UnDER THE Dome an, in der Figuren sich offenbar ohne Schwierigkeiten über in der Serienwelt herrschende Regeln hinwegsetzen können. Plausibilität kann sich nicht nur auf das „Brechen ungeschriebener Regeln“, sondern auch auf „Plot Twists“ beziehen. So wird beispielsweise die sukzessive 
interaktiv heruntergestufte Bewertung der Serie SHERLOCK - dieser Prozess wird ausführlich in Abschnitt 7.3.2 analysiert - erst dadurch ausgelöst, dass sich die Interagierenden darin einig sind, dass die letzte Staffel „so verWIRrend“ (OST11, Z. 1047) war und „die [...] so viele PLOT twists reingebaut [haben]“ (Z. 1063). Auch wenn Deppermann (1997) darauf hinweist, dass Verwirrung in Medientexten sowohl „Rezeptionsproblem“ als auch „--attraktion“ sein kann, behandeln die Teilnehmenden in den vorliegenden Daten Verwirrung eher als ein „Rezeptionsproblem“. In Abschnitt 7.1.2 wurde bereits diskutiert, dass Glaubwürdigkeit in doppelter Hinsicht - als Maßstab für die Teilnehmenden selbst sowie für den Interaktionsgegenstand - eine zentrale Rolle zukommt. Dabei greifen die Jugendlichen zur Argumentation auf Erfahrungs- und Weltwissen zurück - oder legitimieren, warum das eben nicht möglich ist, wie in Beispiel 36. So trägt die Diskussion um (Un)Logik eher zur Distinktion als zur Vergemeinschaftung bei, wenn sie sich in der Bewertung hinsichtlich der Erfüllung des Plausibilitätsanspruchs nicht einig sind.

\subsection{2 „MAINstream-“vs. „kultiVIERte“ Serien - Implizite Verweise auf gesellschaftliche Wertungen von Populärkultur}

Anknüpfend an den Umgang der Teilnehmenden mit Serien unterschiedlicher Komplexität(sgrade) (vgl. Abschnitt 8.1.3) wird im Folgenden anhand zweier Fallbeispiele herausgearbeitet, wie sie die gesellschaftlich damit verbundenen Wertungen relevant setzen. Damit verweisen die Jugendlichen implizit auf normative Vorstellungen, dass Quality TV eine ,sinnvollere' und höher angesehene Freizeitbeschäftigung darstelle als die Rezeption populärkultureller Serien, die ,nur‘ der Unterhaltung dienen (vgl. theoretische Ausführungen in Abschnitt 2.1.3).

Besonders auffällig ist die Orientierung an normativen Vorstellung in zwei Sequenzen unterschiedlicher Gruppen, in denen die Teilnehmenden auf explizite Kategorisierungen von Serientypen (vgl. Abschnitt 8.1.2) in argumentativen Kontexten zurückgreifen. Diese expliziten Verweise beziehen sich auf die schon im Titel des Abschnitts anklingenden Ethnokategorien kultivierte Serien (RHG10, Z. 591, Beispiel 37) sowie Mainstream-Serien (EMS51, Z. 944, Beispiel 38). Es wird zunächst beschrieben, wie diese Ethnokategorien jeweils interaktiv kontextualisiert sind, bevor analytisch nachgezeichnet wird, wie sich die Jugendlichen an den damit einhergehenden normativen Implikationen orientieren.

Die Sequenz, in die die Kategorisierung von ,kultivierten' Serien eingebettet ist, wurde im Hinblick auf die Gesprächsorganisation und Positionierungsdynamiken bereits in Abschnitt 7.3.3 (Beispiele 32 und 33) analysiert. Mit Katharina, Friederike, Sophie und Oliver sowie Jan und Leon haben sich zwei Subgruppen gebildet, die die Serie How I MET YOUR MOTHER zwar einvernehmlich der Kategorie 
Soaps zuordnen, sie dabei aber als Kritiker`innen bzw. Unterstützerinnen sehr unterschiedlich bewerten (vgl. Analysen in Abschnitt 7.3.3.). Der hier gewählte Ausschnitt beginnt, nachdem die beiden Gruppen je unterschiedliche Ebenen zur Bewertung relevant gesetzt haben. Auf der einen Seite kritisieren Katharina, Friederike, Sophie und Oliver den als ,billig' markierten Produktionskontext (vgl. dazu auch Abschnitt 8.1.5), auf der anderen Seite heben Leon und Jan die Erlebnisqualität der Serie hervor (vgl. auch Abschnitt 8.2.4.1). Leons Formulierungen ab Z. 583 bereiten nun darauf vor, das Gespräch wieder von den unterschiedlichen Bewertungsebenen zurück zu der Rahmung seiner zu Beginn der Sequenz getätigten Aussage zurückzuführen: Serien, die er nebenbei schaut, rezipiert er lieber auf Deutsch.

(37) man kann ja auch (.) kultiVIERte serien gucken,

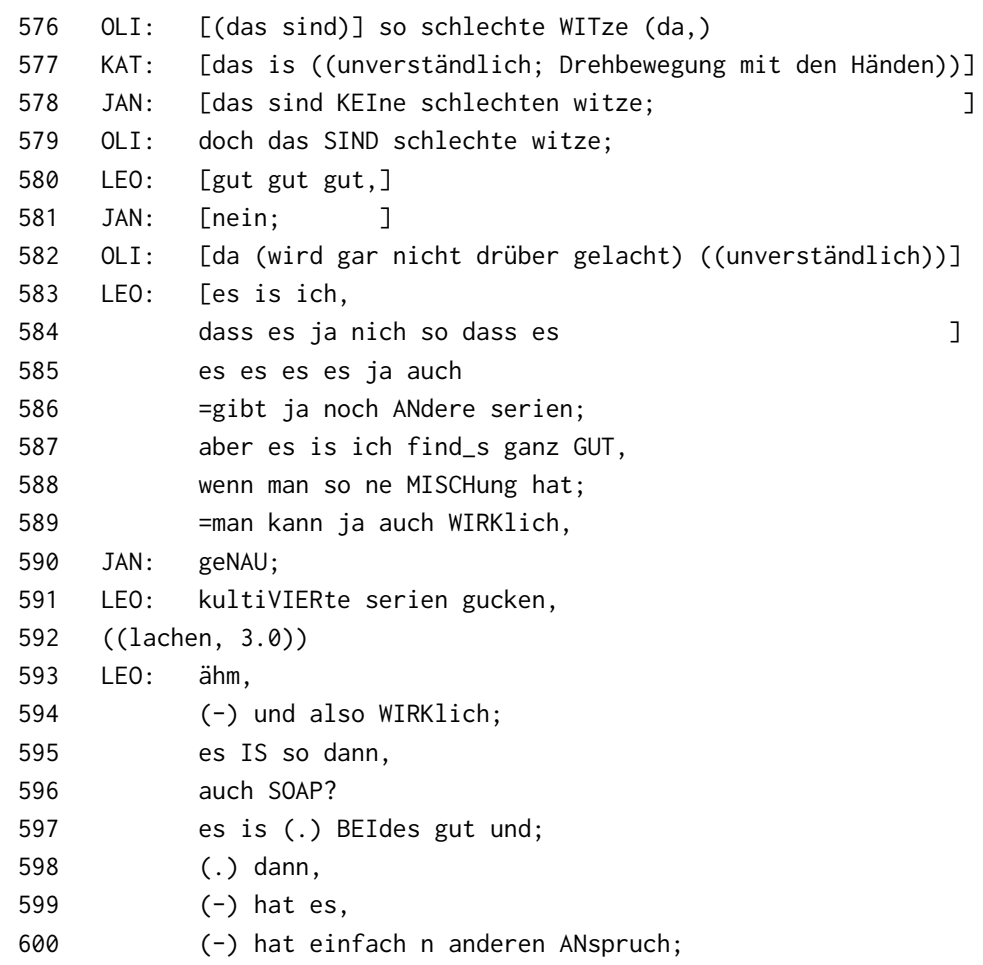

RHG10, 12:45-13:15

Oliver kritisiert die schlechte Qualität der Witze in How I MET YOUR MOTHER (Z. 576, 579), während Katharina nonverbal mit einer Drehbewegung ihrer Hände anzeigt, 
dass die Serie sehr starken Wiederholungscharakter hat (Z. 577; vgl. auch Abschnitt 8.1.3). Daraufhin kommt Leon den Kritikerinnen argumentativ entgegen, indem er den Umstand, dass es „noch ANdere serien;“ (Z. 586) gibt, als eine Art Zugeständnis rahmt. Ähnlich wie sich zuvor die Kategorie „SOwas“ interaktiv zu „soaps“ (vgl. Analyse in Abschnitt 7.3.3) entwickelt hat, lässt sich in dieser Sequenz auch feststellen, dass die von Leon als „ANdere serien“ bezeichneten Produktionen wenig später als „kultivierte Serien“ (Z. 591) spezifiziert werden; eine Kategorie, die er wiederum erkennbar als Gegensatz zu How I MET YOUR MOTHER etabliert (Z. 587-600).

Diese Entwicklung wird im Folgenden mikroanalytisch rekonstruiert, indem Leons Formulierungen und sukzessive Hinführung zu der Kategorisierung im Zusammenspiel mit den anderen Interagierenden betrachtet werden. Er argumentiert zunächst für eine „MISCHung“ (Z. 588) verschiedener Serienformate. Damit wehrt er sich gegen einen - nicht dezidiert ausgesprochenen, aber implizit deutlichen Anspruch, es sei aus normativer Perspektive höher angesehen, überhaupt keine Soaps zu schauen. Mit einer generischen „man“-Konstruktion und dem Fokusakzent auf der ersten Silbe von „WIRKlich“ hebt er die Allgemeingültigkeit seiner Aussage hervor. Die Intonationskontur am Ende dieser Äußerung verläuft nach oben, woraufhin Jan sehr präzise seine Zustimmung ohne Überlappung platziert (Z. 590). Erst danach führt Leon die andere Komponente der Mischung an, die er als „kultivierte Serien“ (Z. 591) bezeichnet. Auch während dieser Äußerung verläuft seine Intonationskontur nach oben und es folgt Gelächter aller Teilnehmenden, einschließlich Leon selbst für drei Sekunden. Zusammengenommen weist Leons Äußerungsgestaltung (Pause, gemeinsames Lachen, Betonung von „kultiVIERT“) darauf hin, dass diese Kategorie Attribute enthält, von denen er sich einerseits scherzhaft - distanziert, er andererseits aber auch um mit den anderen geteiltes Wissen und die geteilte Bedeutung der Eigenschaften dieser Kategorie weiß: Kultivierte Serien bilden eine dichotome Kategorie zu den zuvor thematisierten Soaps, die sich vor allem über ihren unterschiedlichen Anspruch (Z. 600-604) voneinander unterscheiden. Diese Trennung versucht Leon als Ressource zur Legitimation und damit zur interaktiven Bestätigung der Angemessenheit seiner Position zu verwenden. Allerdings hat er damit nur bedingt Erfolg, denn die Kritikerinnen gehen nicht darauf ein, sondern verschieben erneut die Bewertungsebenen (hin zu Leons Rezeptionsverhalten als Positionierungsobjekt; vgl. Analyse zu Beispiel 33), woraufhin Leon seine Strategie ändert und seinerseits die Serien-Präferenzen der Kritiker*innen kritisiert (vgl. Beispiel 34).

Leo managt in dieser Sequenz also die komplexe Anforderung, sich einerseits mit den anderen Gruppenmitgliedern zu vergemeinschaften, indem er das Keying (Goffman 1974) der Interaktion in eine scherzhafte Richtung bewegt und für Zustimmung und Verständnis für seine Präferenzen wirbt. Andererseits verteidigt er aber 
auch seine eigene, von den meisten anderen Gruppenmitgliedern als abweichend behandelte Position und hält somit Distinktion zu den Kritiker^innen aufrecht. Im Mittelpunkt stehen hier also keine epistemischen Differenzen - alle Gruppenmitglieder stimmen darin überein, dass die Serie als ,billig' positioniert werden kann (Z. 564) -, sondern die Frage, inwiefern das Abweichen von als normativ behandelten Vorstellungen „guter Serienrezeption“, d.h. die Rezeption von Serien, die nicht unter Trivialitäts- und Manipulationsverdacht (vgl. dazu Ausführungen in Abschnitt 2.1.3) stehen, legitim ist.

Im Folgenden wird mit Beispiel 38 ein Fall analysiert, in dem eine Gruppe eine vergleichbare Kategorisierung vornimmt. Für das Verständnis der Sequenz ist als vorheriger Kontext bedeutsam, dass Burim konstant seine Lieblingsserie (Oz - HöLLE HINTER GitTERN) in Abgrenzung zu den Präferenzen der anderen Gruppenmitglieder positioniert. Das wird seit Beginn des Gesprächs deutlich, als er den Rest der Gruppe als eindeutig $K^{-}$bezüglich der Serie fremdpositioniert: „die werdet ihr zu !TAU!sendprozent nicht kennen, “(Anhang I: EMS51, Z. 068). Im weiteren Verlauf der Interaktion erläutert er mehrmals Handlungselemente und die Plotstruktur dieser Serie und sichert sich damit jeweils über eine längere Zeit hinweg das Rederecht. Außerdem betont er, ihm sei bei der Rezeption von Serien der Aspekt der Charakterentwicklung sehr wichtig und begründet diese Präferenz mit der Serie. Daraufhin entfaltet sich eine Diskussion um prototypische Figuren (vgl. Ausführungen in Abschnitt 8.1.4), an die der folgende Ausschnitt anschließt:

(38) aber vielleicht weil wir immer so nur diese MAINstream serien gucken.

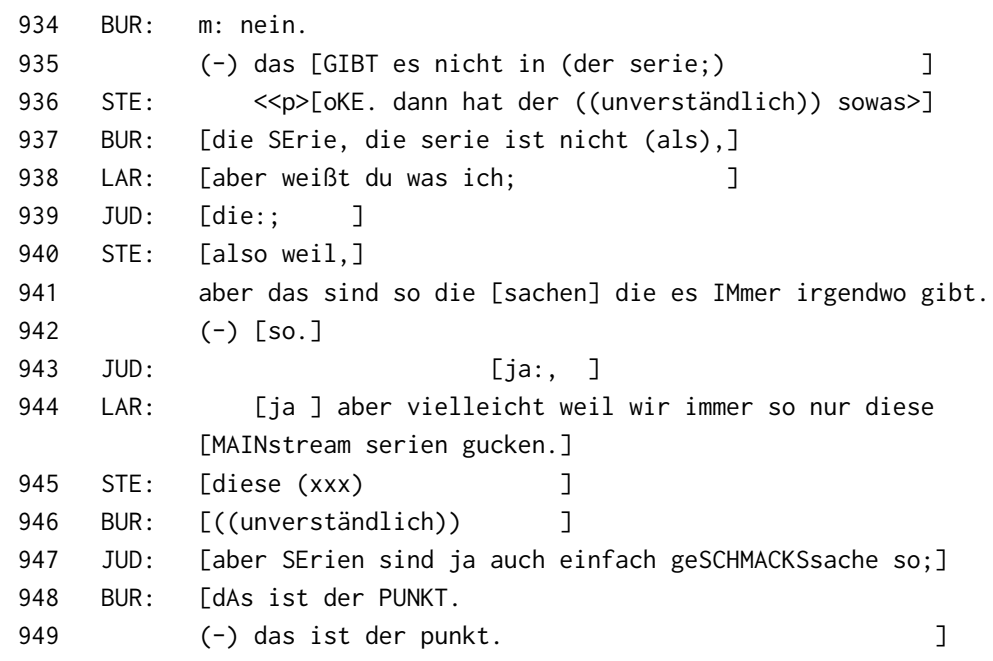


Stephanie hatte Burim zuvor wiederholt nach bestimmten Figurentypen in $\mathrm{Oz}-$ HÖLLE HINTER GITTERN gefragt. Nun reagiert sie zunächst leise auf Burims erneute Zurückweisung ihres Typisierungsversuchs von Figuren (Z. 936), den sie aus einer $K^{-}$-Position heraus formuliert. Da es sich um eine überlappende Äußerung handelt, ist sie inhaltlich schwer zu verstehen. Sie schüttelt dabei leicht den Kopf und die Vermutung liegt nahe, dass sie ihre Verwunderung über Burims Negierung ausdrückt. Gestützt wird diese Interpretation durch ihre anschließende mit ,also weil“ (Z. 940) eingeleiteten generalisierende und auf prototypische Vorstellungen (Abschnitt 8.1) verweisende These „aber das sind so die sachen die es IMmer irgendwo gibt.“ (Z. 941). Zugleich setzt Burim mit einer Elaborierung an (Z. 938), die jedoch unvollständig bleibt und kommunikativ erfolglos ist. Judith, die Stephanie auch zuvor schon Unterstützung ihrer Aussagen signalisiert hatte - indem sie die von Stephanie aufgezählten Figurentypen reformuliert und ergänzt hat (Z. 862-863) -, stimmt ihr in dieser Sequenz erneut zu (Z. 943).

Bemerkenswert ist nun Laras Äußerung, mit der sie eine mögliche Erklärung für Stephanies Verwunderung formuliert: „ja aber vielleicht weil wir immer so nur diese MAINstream serien gucken. “ (Z. 944). Vergleichbar mit Leon in Beispiel 37 nimmt sie eine Kategorisierung vor, von der sie sich im gleichen Zuge abgrenzt, denn sie malt mit den Fingern der rechten Hand Anführungszeichen in die Luft, während sie „MAINstream“ artikuliert. Die Bedeutung ihrer Aussage ließe sich folgendermaßen paraphrasieren: Sie selbst und (fast) alle anderen Mitglieder dieser Gruppe außer Burim rezipieren „Mainstream-Serien“. Da ihnen aus diesem Grund die Rezeptionserfahrung mit Serien, die nicht für ein Massenpublikum konzipiert wurden, fehlt, können sie eine nicht typische Figurenkonstellation nicht nachvollziehen. Durch das inkludierende „wir“ unterstützt sie die Distinktion zwischen Burim und dem Rest der Gruppe. Somit festigt sie ebenfalls Burims Positionierung seiner Serie als außergewöhnlich, da sie diese von populären Produkten abgrenzt. Mit den Attributen, die die von ihr gewählte Kategorisierung evoziert, verweist sie implizit auch auf die damit zusammenhängende normativ niedrigere Bewertung bezüglich der Unterkomplexität populärkultureller serieller Formate. So führt auch Lara eine komplexe Positionierung zwischen Vergemeinschaftung und Distinktion durch. Einerseits vergemeinschaftet sie sich mit den anderen Gruppenmitgliedern und verstärkt so die Distinktion, die Burim zuvor erfolgreich etabliert hatte. Andererseits vergemeinschaftet sie sich aber auch mit Burim, indem sie ihn mit einer positiven Zuschreibung fremdpositioniert und ihm damit weiterhin die epistemische Autorität und Expertise für komplexere Serienformen zuweist. Zugleich signalisiert sie Verständnis für seine Position - im Unterschied zu Stephanie und Judith - und kommuniziert ihm damit, auch eine gewisse Affinität zu seiner Position $\mathrm{zu}$ haben. 
Die Mehrfachpositionierung, die sowohl Lara als auch Leon mutmaßlich aufgrund des Kooperationsprinzips (vgl. Abschnitt 6.1.2) vornehmen, ist im Hinblick auf Praktiken des face-work potentiell heikel. Denn Rezipient*innen, die unter dem Verdacht stehen, triviale Serien zu schauen, stehen oft unter dem Zugzwang, Gründe dafür angeben, wie beispielsweise das Bedürfnis nach Unterhaltung und Entspannung nach Schultagen, die mangelnde Zeit usw. (vgl. dazu jeweils Analysen in Abschnitt 8.1.3 und 8.2.4.3). So wird auch verständlich, warum Laras Erklärungversuch interaktiv nicht aufgegriffen oder weiter relevant gesetzt wird. Stattdessen beendet Judith die Sequenz mit der generalisierenden Aussage „aber SErien sind ja auch einfach geSCHMACKSsache so; “ (Z. 947). Damit entschärft sie die Situation, indem sie den Fokus von normativ aufgeladenen Wertungen hin zu subjektiven Begründungen für Präferenzen verschiebt (vgl. dazu auch die Analysen in Abschnitt 7.1.3). Burim ko-konstruiert diesen Schlichtungsversuch, indem er ihr bekräftigend zustimmt (Z. 948-949). Auch Leon wagt sich auf schwieriges Interaktions-Terrain im Hinblick auf face-work, indem er sich selbst - aufgrund seiner Rahmung natürlich nur teilweise - abspricht, ,kultivierte' Serien zu bevorzugen. Anders als Judith ist er jedoch nicht erfolgreich damit, das Gespräch wieder auf die Ebene der subjektiven Bewertung zu verschieben (vgl. Analysen zu Beispiel 34). Auch wenn die beiden hier analysierten Fälle sehr explizit auf Vorstellungen populärkultureller Trivialitätsvorwürfe Bezug nehmen, zeigt sich in dem gesamten Korpus, dass sich die Jugendlichen auch implizit daran orientieren und dazu positionieren. Sie indizieren ein Spannungsfeld, über das sie das Wissen anzeigen, dass es Medienformate gibt, die (eher) gesellschaftlich angesehen sind, d.h. solchen Serien, die nicht primär zur Unterhaltungszwecken produziert und rezipiert werden, sondern die komplexer sind, bei denen mehr nachgedacht werden muss, sich Zusammenhänge nicht auf den ersten Blick erschließen usw. Letztlich bildet diese Dichotomie den Überbau für die in Abschnitt 8.2.4 analysierten Spannungsfelder, die das angemessene Rezeptionsverhalten betreffen.

\subsection{3 „aber nicht SPOllern oke?“ - normativer Umgang mit divergenten und optionalisierten Wissens(be)ständen}

Während in Abschnitt 7.1.1 herausgearbeitet wurde, dass mit der komplexen Anforderung, verschiedene Wissensstände und -bestände in angemessener Art und Weise zu adressieren, epistemische Autorität beansprucht werden kann, liegt in diesem Abschnitt der Analysefokus auf den interaktiven Konsequenzen, wenn einer Person zu viel Wissen in Bezug auf eine Serie vermittelt wird, d.h. wenn jemand gespoilert wird. Gothe und Leichner (2012: 177) definieren Spoiler als die „Bezeichnung [, die sich] im Internet insbesondere im Kontext der Bereitstellung 
von Informationen zu fiktional-narrativen Unterhaltungsangeboten als Kennzeichnung von Informationen etabliert [hat], die über einen - wie auch immer jeweils bestimmten - hegemonialen status quo einer Narration hinausgehen“. Der Begriff ist mittlerweile über online-Diskurse hinaus im alltäglichen Sprachgebrauch verankert und wird auch im Duden sowohl als Substantiv ${ }^{3}$ als auch als Verb aufgeführt. ${ }^{4}$

Die Teilnehmenden orientieren sich explizit oder implizit an der Gruppennorm, dass die Gespräche ,spoilerfrei‘ verlaufen sollen (z.B. Anhang I: EMS51, Z. 044-045; Anhang VI: RHG10, Z. 109, 111, 114, 834). Im Folgenden werden vier Fälle analysiert, in denen Spoilern in unterschiedlicher Weise relevant wird. In Beispiel 39 erfolgt absichtsvolles Spoilern seitens eines Gruppenmitglieds, während in Beispiel 40 absichtslos gespoilert wird. In Beispiel 41 wird rekonstruiert, wie die Interagierenden allgemein den Stellenwert von Spoilern für die Serienrezeption verhandeln. Abschließend wird die Bedeutung von agenslosem Spoilern diskutiert.

(39) das war doch KLAR dass das passiert;

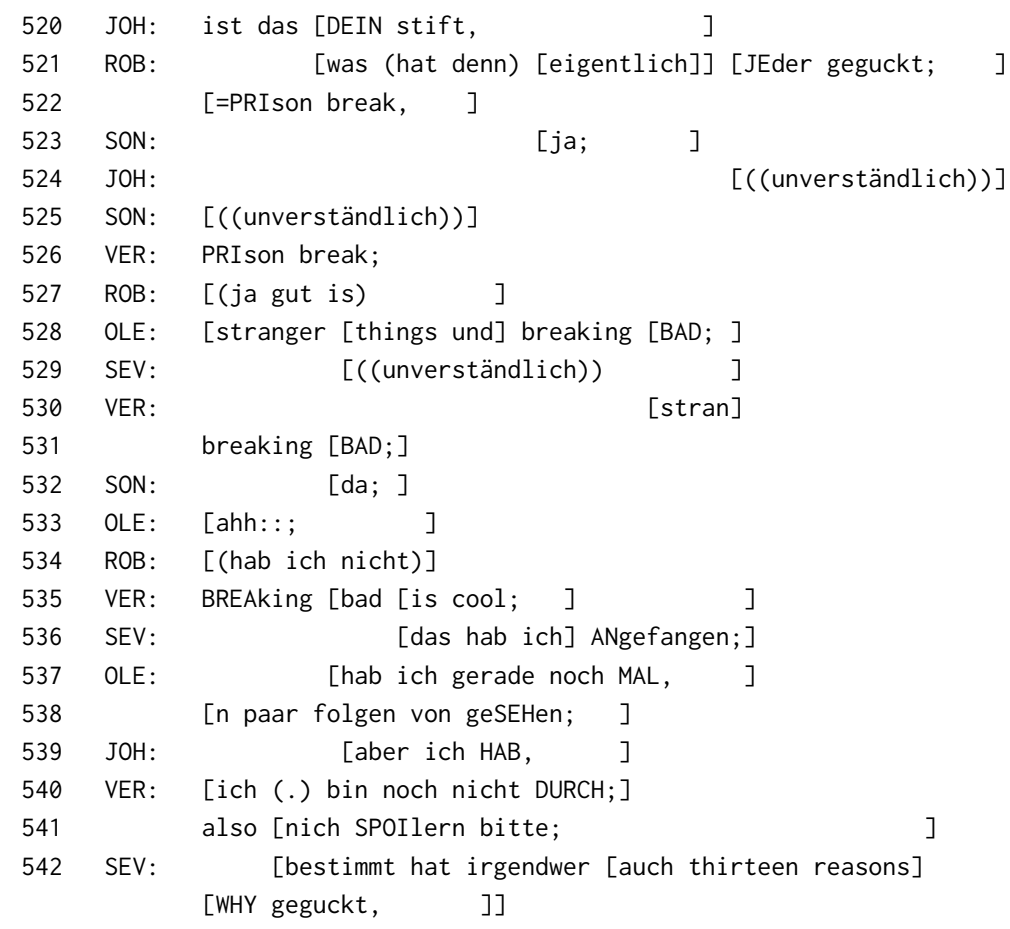

$3 \mathrm{https} / / /$ www.duden.de/rechtschreibung/Spoiler [zuletzt abgerufen: 01.06.2021].

4 https://www.duden.de/rechtschreibung/spoilern [zuletzt abgerufen: 01.06.2021]. 
543

$\mathrm{JOH}:$ SENdung?

544 OLE: [WALter white stirbt;]

545 VER: hä,

546 ROB: wer hat das [NICH geguckt; ]

$547 \mathrm{JOH}: \quad$ [oh:: mein GO:TT; ]

548 [du bist so ein ARSCH. ]

549 VER: [<<lachend $>$ oh go(h)ott $>]$

550 SEV: [was, ]

551 OLE: [das ] weiß JEder;

$552 \mathrm{JOH}$ : SOLL ich ihn schlagen,

553 VER: !ICH! [aber nich; ]

554 SEV: [wer stirbt, ]

555 OLE: [((unverständlich) $)]$

556 ROB: WAS denn.

557 VER: is mir eGAL;

$558 \mathrm{JOH}:$ [ist der nich (unheilbar KRANK, )]

559 SEV: [WAS hast du gesagt, ]

560 =WAS hat [der gesagt, ]

561 OLE: [ja naTÜRlich;]

562

563

564

565

566

567

568

569

570

571

572

573

574

575

576

577

578

579

580

581

582

583

584

[bei breaking] BAD,

ROB: [WAS denn; ]

OLE: ja,

SEV: is doch KLAR,

=der hat doch KREBS;

VER: ja: :

JOH: [höy is doch KLAR, ((lacht))

SEV: ja ICH $[\mathrm{hab}$,

JOH: $\quad[j a]$ denkst du [mal $\mathrm{NACH}$,

$\mathrm{JOH}$ :

[(halt; )]

VER: ((lacht))

OLE: [als ] ob das $n$ happy END hat.

ROB: ((lacht))

VER: <<lachend>kann ich nich HOFFen?>

OLE: oke an sich is es SCHON;

(-) ja; [((unverständlich)) welche

das war [doch KLAR] [dass das passiert;

]

[ich WUSSte das aber [nicht; ]]

[bei wa,]

[aber ich wollte dass das IN der serie passiert;]

SEV: $\quad[i$ ch hab ] mir das schon [geDACHT; ]

[(WALter; )] 
VER: oke,

[hör einfach auf zu REden;]

Nachdem die Gruppe zunächst auf der Suche nach einem neuen Positionierungsobjekt war, das dem Kriterium größtmöglicher Partizipation entspricht (Z. 520-531), dreht sich das Gespräch im Folgenden um die von Verena etablierte Serie BREAKING BAD, zu der alle Beteiligten ihren epistemischen Status kommunizieren (Z. 532540). Trotz Verenas Bitte, sie nicht zu spoilern (Z. 541), verrät Ole ihr das Ende der Serie (Z. 544). Johann bemerkt die Implikationen von Oles Äußerung noch vor Verena und es folgt eine scherzhaft gerahmte Beleidigungs-Interaktion zwischen Johann, Verena und Ole (Z. 547-549). Sowohl Ole als auch Sevcan relativieren daraufhin die Spoiler-Handlung damit, dass das Ende narratologisch vorhersehbar sei (Z. 558-582). Bevor Ole weitere Handlungselemente verraten kann (Z. 583-586), etabliert die Gruppe mit THE WALKING DEAD ein neues Positionierungsobjekt. In den vorliegenden Daten ist dieser Fall in der Form tatsächlich einmalig. ${ }^{5}$ Absichtsvolles Spoilern, wie Ole es hier gegenüber Verena praktiziert, findet sich sonst nicht. Im Folgenden wird zunächst der Akt des Spoilerns analysiert, dann die Folgebehandlungen sowohl des Spoilernden und der Gespoilerten als auch die Reaktionen der anderen Gruppenmitglieder.

Oles Formulierung „hab ich gerade noch MAL, $n$ paar folgen von geSEHen“ (Z. 537-538), die implizit darauf verweist, dass er die Serie gut kennt, nutzt Verena, um wiederum explizit ihren epistemischen Status zu kommunizieren (Z. 540) und daraus die Bitte um das Vermeiden von Spoilern (Z. 541) abzuleiten. Im Folgenden laufen mehrere Gesprächsstränge parallel und augenscheinlich registrieren nicht alle Beteiligten vollständig alle Gesprächsbeiträge (Z. 542, 546, 550, 554, 556). Daher scheint Oles Spoiler - er thematisiert den Tod des Protagonisten am Ende der Serie - auf den ersten Blick in parallelen Äußerungen unterzugehen. Er adressiert die Äußerung offenbar an Verena gerichtet, da er sie währenddessen die ganze Zeit ansieht. Sie erwidert den Blick jedoch nicht, sondern formuliert zunächst ein Verständnisproblem: „hä,“ (Z. 545). Erst als Johann bemerkt, dass Oles Äußerung als bewusster Spoiler konzipiert ist - erkennbar an seiner Interjektion und der darauffolgenden Beleidigung (Z. 547-548) -, wird Verena ebenfalls darauf aufmerksam. Sie reagiert mit dem von Lachpartikeln begleiteten Ausruf „oh go(h)ott“ (Z. 549) und hält eine Hand vor ihr Gesicht. Sowohl ihre Reaktion

5 Lediglich teilweise vergleichbar ist eine weitere Sequenz zwischen Ole und Sevcan, die in Abschnitt 9.1.4 analysiert wird. 
als auch Johanns Beleidigung und scherzhaft gerahmtes Angebot an Verena, ihn - als Person, die direkt neben ihm sitzt - zu „schlagen,“(Z. 553) ko-konstruieren Oles Normverletzung als erfolgreich: Verena wurden zu viele und unerwünschte Informationen vermittelt.

Diese Normverletzung wird in der darauf folgenden Aushandlungssequenz aufgrund einer Reihe von Rechtfertigungen sichtbar, die sowohl von Ole als auch von Sevcan vorgetragen werden. Letzteres ist insofern bemerkenswert, als Sevcan zuvor angegeben hatte, die Serie bisher noch nicht beendet zu haben (Z. 536), so dass sie theoretisch ebenfalls durch Oles Aussage gespoilert wurde. Sie vergemeinschaftet sich darin jedoch nicht mit Verena, sondern mit Ole, indem sie seiner Äußerung gerade keinen Spoiler-Charakter zuschreibt (Z. 576). ${ }^{6}$ So versuchen dann beide zu erklären, dass der Tod der Hauptfigur aufgrund seiner Krankheit vorherzusehen war (Z. 551, 561-562, 569-570). Mit ihrer wiederholten Betonung, dass dieses Handlungselement als selbstverständlich angenommen werden kann (,das weiß JEder;“, Z. 551 und „das war doch KLAR dass das passiert“, Z. 562 bzw. „is doch $K L A R$,“, Z. 569), positionieren sie sowohl sich selbst als auch Verena epistemisch in komplexer Art und Weise: Erstens beanspruchen sie für sich selbst einen hohen epistemischen Status, da sie signalisieren, über ein fundiertes Medienwissen (vgl. Abschnitt 7.1.2) zu verfügen, das es ihnen erlaubt, allein auf der Grundlage der Serienexposition deren narrative Entwicklungen zu antizipieren; sie orientieren sich also eher an prototypischen Vorstellungen (Abschnitt 8.1) serieller Erzählungen. Zweitens verankern sie dieses Wissen als generell im common ground vorhanden. Drittens sprechen sie Verena die Kenntnis von genau diesem common ground ab. Sie werten also das ,epistemische Defizit', den Handlungsfortgang angemessen antizipieren zu können, höher als Verenas von sich aus kommunizierten $K^{-}$-Status. Darüber legitimieren sie ihre Argumentation, dass Oles Äußerung nicht als Spoiler zu klassifizieren ist. Diese Positionierung greift auch Johann auf, indem er die Fremdpositionierung Verenas - weiterhin scherzhaft gerahmt - noch zuspitzt und verstärkt: „höy is doch KLAR, ((lacht)) ja denkst du mal NACH,“ (Z. 573, 575).

Verena dagegen verteidigt ihre Position der Gespoilerten und hält die Zuschreibung von Oles Äußerung als Spoiler aufrecht. Sie argumentiert auf verschiedenen Ebenen gegen Oles und Sevcans Position. Zunächst distanziert sie sich selbst sehr stark von der generalisierten Zuschreibung, dass „JEder“ (Z. 551) das wüsste (,!ICH! aber nicht“, Z. 553 und „ich WUSste das aber nicht;“, Z. 564). Als schließlich der Verweis auf ihren eigenen $\mathrm{K}^{-}$-Status aufgrund des entstandenen epistemischen Positionierungsgefüges nicht mehr ausreicht, verweist sie auf die Implikationen

6 Wenig später behandelt Ole Sevcans Anspruch, von ihm zu GAME OF THRONES gespoilert worden zu sein, jedoch als nicht legitim (vgl. Abschnitt 9.1.4). 
der Normverletzung durch Spoilern, die nicht das rationale Nachdenken über eine Serie, sondern deren subjektive Rezeption betreffen: „aber ich wollte dass das IN der serie passiert; “ (Z. 572). Damit weist sie auf das Kernproblem des Spoiler-Akts hin, das vorrangig moralischer Natur ist. Denn indem (relevante) Wissenselemente über den Fortgang einer Serie außerhalb der Serienrezeption erworben werden, wird der ästhetische - und diese Serie betreffend letztlich auch emotionale, vgl. auch Abschnitt 8.2.4.1 - Genuss gestört. ${ }^{7}$ Dieser Genuss besteht darin, wie an Verenas Äußerungen deutlich wird, weiterhin Spannung und Überraschung über den Fortgang - hier: das „HOFfen“ (Z. 582) auf ein Happy End - einer Serie zuzulassen, so dass nicht der Drang, weiter schauen zu müssen (vgl. dafür Abschnitt 8.2.4.2) verloren geht. Ihre durchgehend von Lachen geprägten Äußerungen (Z. 549, 579, 582) deuten jedoch darauf hin, dass sie ebenfalls daran mitarbeitet, die Sequenz als Scherzinteraktion zu rahmen. Möglicherweise betreibt sie damit auch face-work, da Johann, der sich zuvor mit ihr vergemeinschaftet hat, nun ,die Seite gewechselt* hat (von Z. 547-548 über Z. $558 \mathrm{zu}$ Z. 573-575). Letztlich behält sie kommunikativ aber das letzte Wort, indem sie Ole erfolgreich untersagt, weitere potentielle Spoiler zu BREAKING BAD zu äußern (Z. 586).

Dieser einzige Fall von absichtsvollem Spoilern zeigt letztlich, dass eine solche Gruppennorm-Verletzung auch - neben ihrer Funktion als Frotzel-Aktivität und Beziehungsmanagement - mit epistemischer Positionierung und Selbstdarstellung zusammenhängt, d.h. dass Ole sich bewusst über die Regel des Nicht-Spoilerns hinweggesetzt hat, um epistemische Autorität zu beanspruchen. Er hat die divergenten Wissensstände in der Gruppe damit zwar nicht angemessen gemanagt, positioniert sich aber trotzdem als Experte - nur eben nicht bezogen auf die konkrete Serie, sondern auf die narrative Gestaltung von Serien auf abstrakterer Ebene. Dennoch wird an den unterschiedlichen Reaktionen von Sevcan und Verena auch deutlich, dass Spoiler interaktiv erst als solche bestätigt bzw. ratifiziert werden müssen. Im Kontrast dazu wird im Folgenden ein Fall absichtslosen Spoilerns analysiert, der ebenfalls in den vorliegenden Daten einmalig ist:

(40) das !DARFST! du nicht sagen,

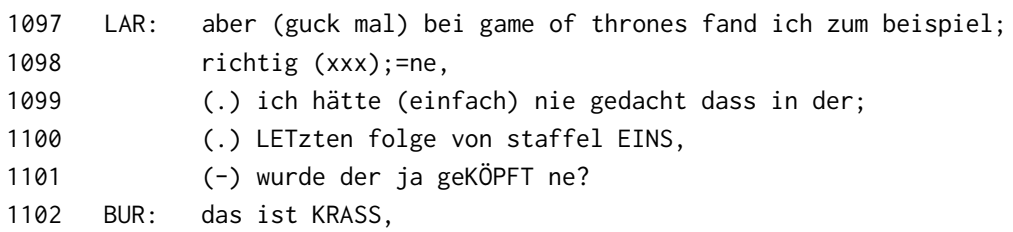

7 Im eigentlichen Wortsinn, da der Begriff in seinem englischen Wortursprung verderben oder ruinieren bedeutet. 


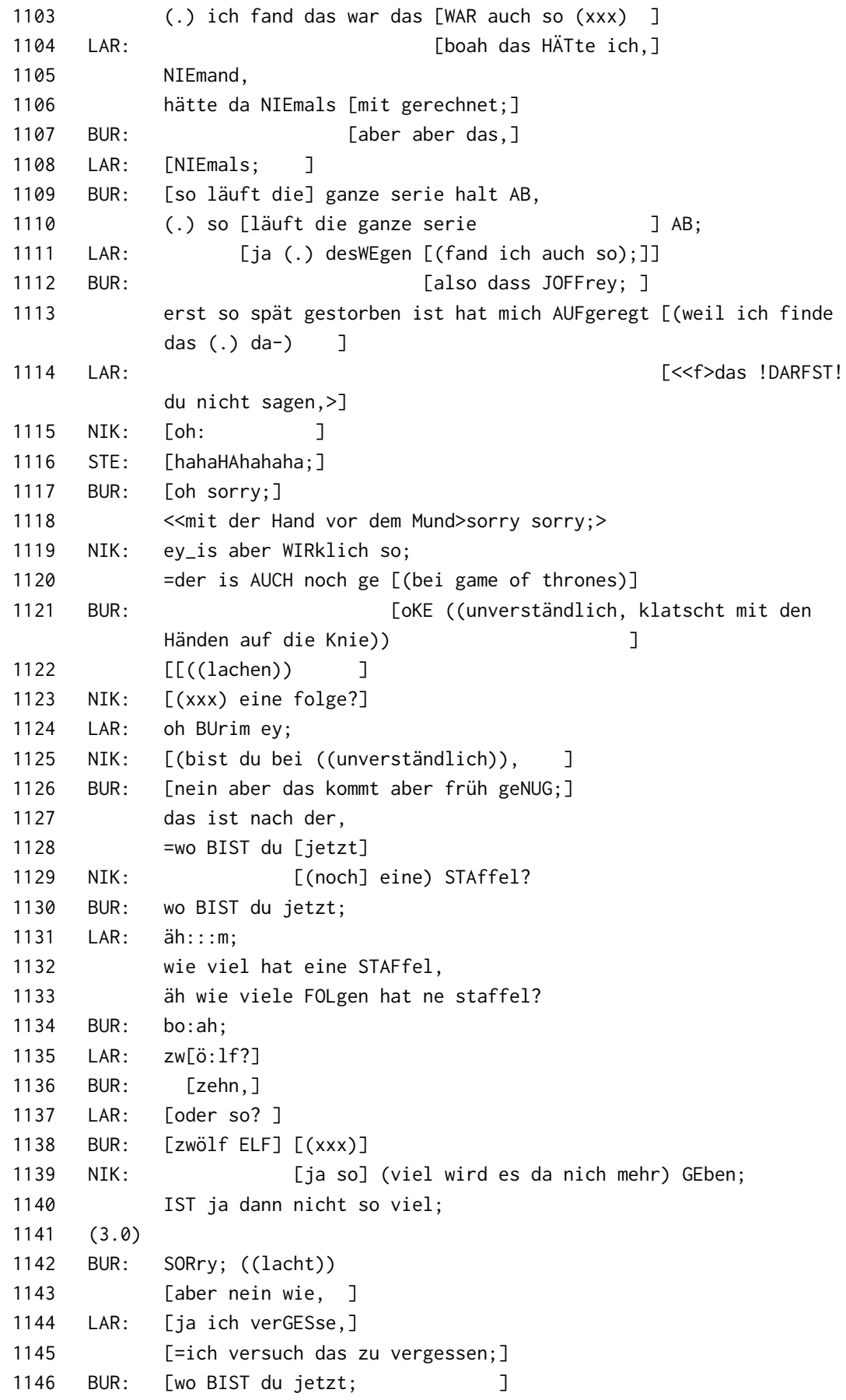




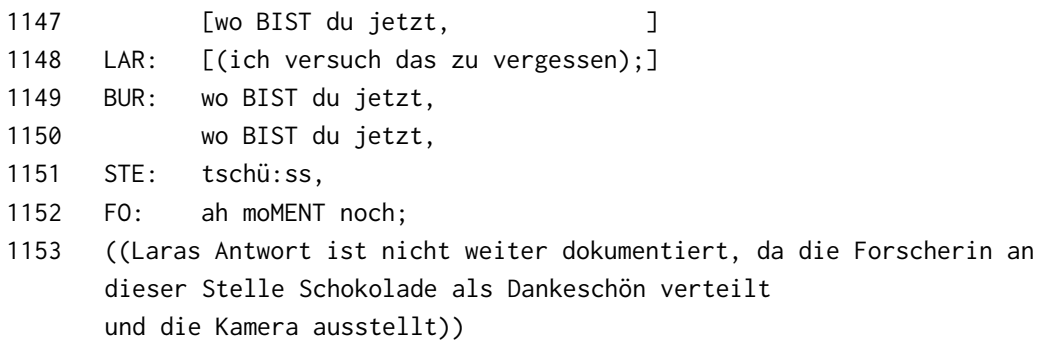

Diese Sequenz bildet insofern ebenfalls eine Ausnahme, als sie nach offizieller Beendigung der Gruppendiskussion stattfindet. Mit dem Ende der zur Verfügung stehenden Unterrichtsstunde hatte die Forscherin zuvor das Gespräch unterbrechen müssen (vgl. Abschnitt 5.1.1), die Kamera läuft jedoch noch weiter. Die Teilnehmenden werden gebeten, ihre selbst gewählten Alias-Namen für die Datenauswertung auf einem Zettel zu notieren. ${ }^{8}$ Während Judith damit beginnt, führen Lara und Burim leise ein Gespräch über GAME OF THRONES; Niko und Stephanie beobachten sie dabei. Lara fordert die Bestätigung für ihre Bewertung des ersten Staffelfinales ein, in dem Ned Stark unerwarteterweise geköpft wurde (Z. 1097-1108). Burim stimmt ihr zu und bewertet dieses Handlungselement als Teil des ästhetischen Stils der Serie (Z. 1109-1110), wodurch er sich zunächst noch mit ihr vergemeinschaftet. Dann jedoch führt er mit Joffreys Tod ein weiteres Handlungselement als Beleg für das narrative Prinzip der Serie, dass jederzeit Figuren sterben können (vgl. auch Abschnitt 9.1), an. Er rahmt seine Äußerung jedoch so, dass er nicht das Ereignis selbst relevant setzt, sondern dass ihn insbesondere der Zeitpunkt des Ereignisses innerhalb der Serie „AUFgeregt“ (Z. 1113) habe. Während er zu einer Begründung ansetzt, rekontextualisiert Lara seine Äußerung als Spoiler (Z. 1114) und es folgt eine sehr lange Entschuldigungssequenz (Z. 1117-1150).

Auffällig ist Laras sichtbare Veränderung von Mimik und Körperhaltung innerhalb von Sekunden, wie sie in den Abbildungen 8.1 bis 8.3 dargestellt wird. Während Burim noch erläutert, dass „so [...] die ganze serie halt AB[läuft],“ (Z. 1109), schaut sie ihn an (vgl. Abbildung 8.1), um vermutlich das Rederecht an einem passenden TRP zu wählen (Z. 1111). Bis zu dem Zeitpunkt, an dem Burim das Wort „gestorben“ (Z. 1113) artikuliert, bleibt ihre Mimik neutral. Direkt danach scheint sie jedoch die Bedeutung seiner Aussage erfasst zu haben und sowohl ihre Augen als auch ihr Mund weiten sich (Abbildung 8.2). Sie beugt sich schnell mit dem

8 Hierbei handelte es sich um die erste Aufnahme. Bei späteren Erhebungen wurde dazu übergegangen, den Alias-Namen in die Kamera zu sprechen; vgl. Ausführungen in Abschnitt 5.2. 
Oberkörper nach vorne und vergräbt das Gesicht in den Händen (Abbildung 8.3), während sie ihn parallel zu seiner Äußerung sehr laut artikuliert adressiert: „das !DARFST! du nicht sagen, “ (Z. 1114).

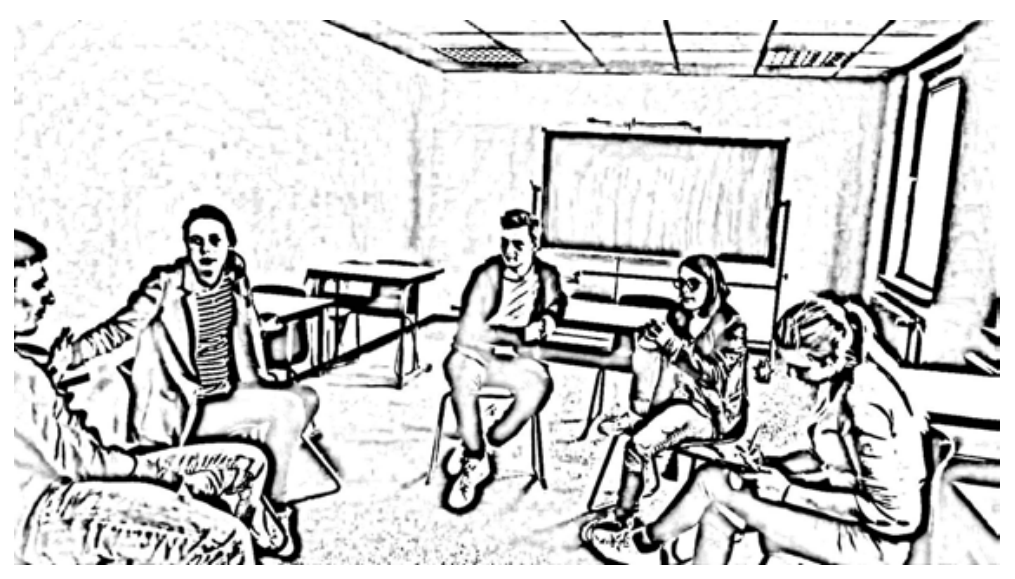

Abb. 8.1: BUR: so läuft die ganze serie halt $A B$,

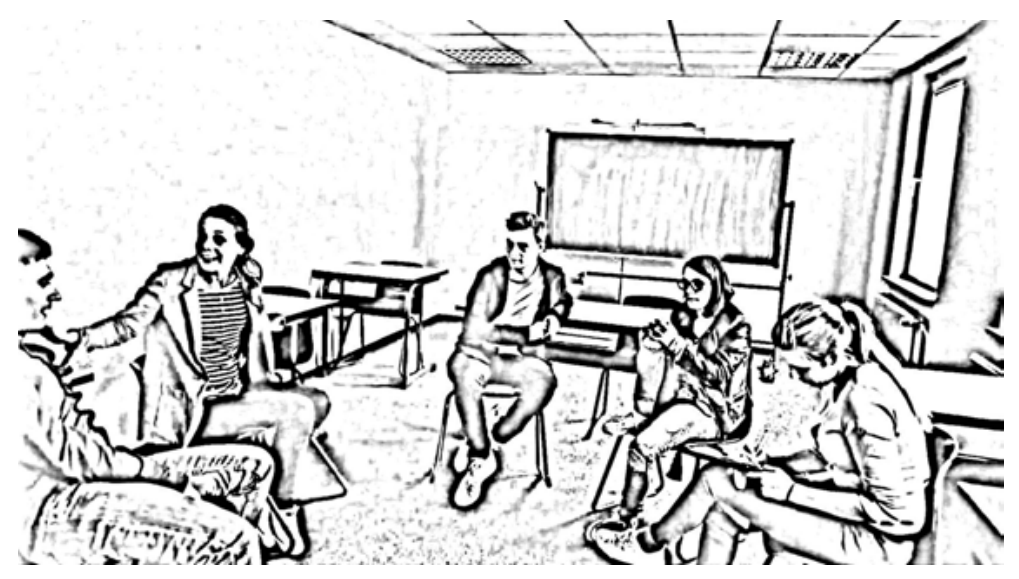

Abb. 8.2: BUR: also dass JOFFrey; erst so spät gestorben ist 


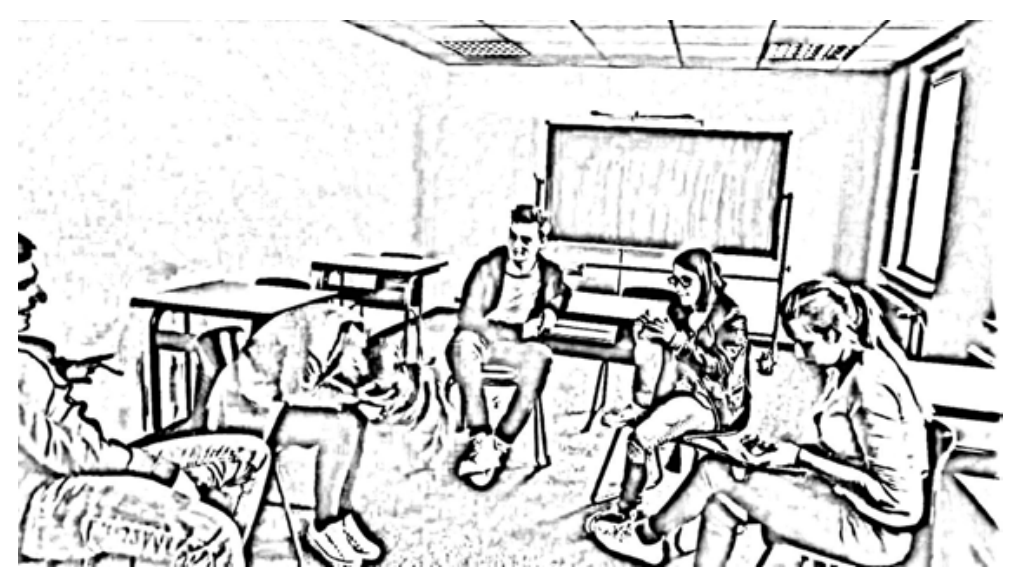

Abb. 8.3: LAR: 〈〈f $>$ das !DARFST! du nicht sagen,>

Auch wenn sie hier den Begriff nicht benutzt, wird erkennbar, dass Burim gerade - unbeabsichtigt - die dem Spoilern zugrunde liegende Handlung vollzogen hat, indem er Lara einen zu hohen epistemischen Status zugeschrieben hat und ihr aus diesem Grund $z u$ viel Wissen übermittelt hat. Während Niko und Stephanie, die die Interaktion beobachtet haben, zu lachen beginnen (Z. 1115-1116), konstruiert Burim - im Unterschied zu Ole in Beispiel 39 - keine Scherzinteraktion oder etabliert weitere Fremdpositionierungen gegenüber Lara, sondern signalisiert Einsicht in seine Normverletzung (Z. 1117-1118). So besteht die nachfolgende Aushandlungssequenz aus Reparaturen seitens Burim, um Laras tatsächlichen epistemischen Status herauszufinden (Z. 1128-1150). Da Lara jedoch keine genaue Angaben zu ihrem aktuellen Stand in Bezug auf Staffeln oder Episoden machen kann, bleibt sein Versuch, darüber zu argumentieren, dass Lara die von ihm gespoilerte Handlung zeitnah selbst sehen wird (Z. 1126-1127), unratifiziert (Z. 1149-1150). Lara bietet als alternative Lösung dagegen mehrfach an, Burims unerwünschte Wissenskommunikation schlicht „zu vergessen“ (Z. 1145, 1148).

Auch in diesem Fall wird deutlich, dass Spoilern ein Prozess ist, der interaktiv vollzogen wird. Der reine Wissenstransfer muss von der Adressatin oder dem Adressaten erst zu einer spoilernden Handlung gemacht werden. Das geschieht, indem signalisiert wird, dass das übermittelte Wissen zum jetzigen Zeitpunkt unerwünschtes Wissen darstellt. Der Unterschied zwischen absichtsvollem (Beispiel 39) und absichtslosem (Beispiel 40) Spoilern liegen in der Folgebehandlung durch die Spoilernden, die den Spoiler entweder ebenfalls als solchen anerkennen und versuchen, Schadensbegrenzung zu betreiben oder den Spoiler an sich zu relativieren und/oder mit Verweis auf die eigene epistemische Autorität und 
Medien-Wissen zu legitimieren. Der folgende Transkriptausschnitt beinhaltet einen Fall, in dem Beteiligte berichten, dass sie gespoilert wurden, woraufhin Spoiler aus einer Meta-Perspektive diskutiert werden:

\section{(41) spoiler sind eh das SCHLIMmste;}

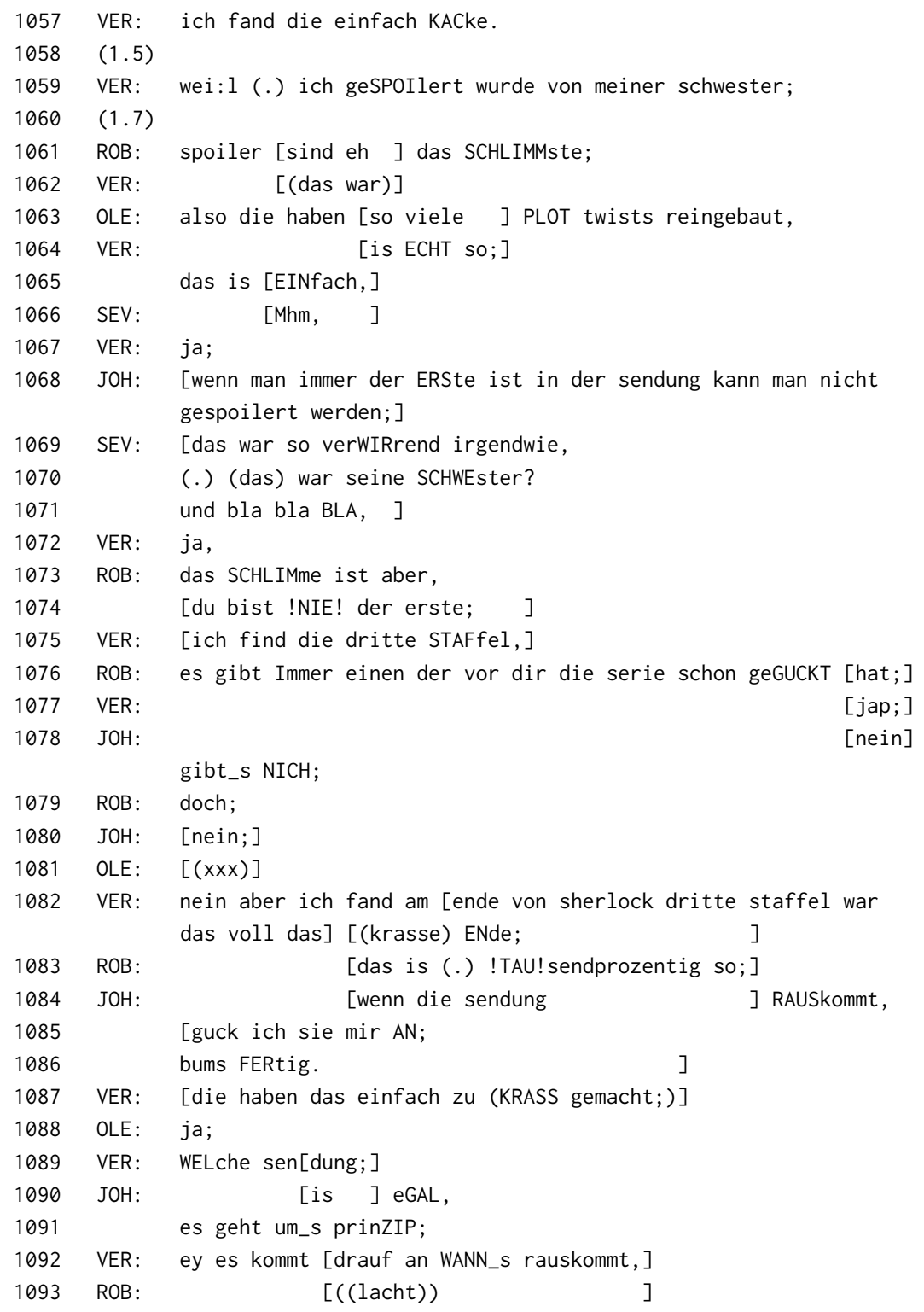




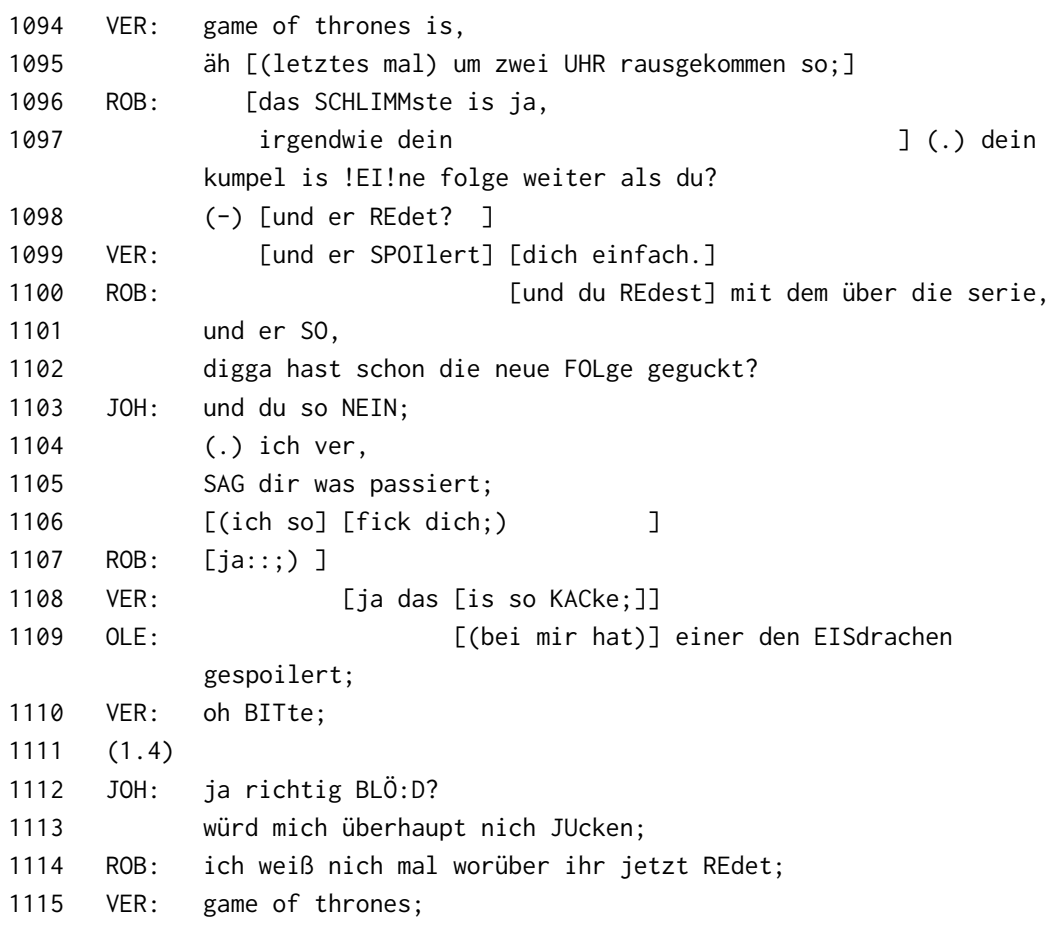

Diese Sequenz wurde bereits unter dem Aspekt, dass Verena sowohl ihre epistemische als auch evaluative Haltung herunterstuft, in Beispiel 31 analysiert. Hier steht im Folgenden im Vordergrund, dass sie als Begründung für ihre veränderte Bewertung der Serie SHERLOCK anführt, dass sie von ihrer Schwester „geSPOIlert wurde“ (Z. 1059), was zu einer Aushandlung der im Folgenden zentralen Frage führt, wie „schlimm“ Spoiler sind (Z. 1061-1113).

Auslöser ist Roberts generalisierende Aussage „spoiler sind eh das SCHLIMmste“ (Z. 1061). In dieser Hinsicht kommt es zu einem Schlagabtausch zwischen Johann und Robert (Z. 1078-1083), die sich gegenteilig zu dem Stellenwert von Spoilern positionieren. Johann widerspricht Robert mit seiner These, man könne nicht gespoilert werden, sofern „man immer der ERSte ist in der sendung “ (Z. 1068). Seine und später Verenas Versuche, Johanns Argument zu widerlegen (Z. 1076, 1083, 1094-1095, 1100-1102), schlagen jedoch fehl, da Johann weiter davon ausgeht, es sei problemlos möglich, eine Serie sofort nach deren Erscheinen zu rezipieren (Z. 1084-1086, 1112-1113). Johann plädiert als Lösung für das Spoilerproblem also für eine schnelle und kumulierte Serienrezeption (vgl. dazu Abschnitt 8.2.4.2), 
während Robert argumentiert, dass Spoilern auf einer moralischen Ebene zu bewerten ist, da damit gegen implizite Normen verstoßen wird (vgl. Beispiele 39 und 40). Bemerkenswert daran ist, dass Johann kurzfristig Vergemeinschaftung mit Robert signalisiert, als er dessen Beleg-Erzählung, die ein inszeniertes Gespräch zwischen einem Kumpel und ihm selbst umfasst, fast nahtlos Roberts Erwartungen entsprechend (Z. 1107) fortführt (Z. 1103-1106) und sogar Roberts Erzählerstimme übernimmt (Z. 1106) - nur um sich daraufhin genau davon wieder zu distanzieren (Z. 1112-1113).

Eine mögliche Interpretation dafür, dass sich die beiden voneinander distinktiv positionieren, könnte in einem unterschiedlichen Verständnis des Serien-Begriffs und Erfahrungen mit der Serienrezeption begründet sein. Johann benutzt während der Gruppendiskussion fast durchgängig den Begriff „Sendung“ sowohl für konkrete Serien als auch für einzelne Episoden (vgl. dazu auch Verenas Reparaturinitiierung in Beispiel 21, Z. 459, 461) und bezieht sich vorrangig auf Formate, die im Fernsehen ausgestrahlt werden, da er angibt, im Unterschied zu Robert kein Netflix oder ähnliche Plattformen zur Serienrezeption zu nutzen (vgl. Anhang IX: OST11, Z. 236). ${ }^{9}$ Spoiler scheinen also nicht nur interaktiv manifestiert und bestätigt werden zu müssen, sondern werden auch abhängig von den eigenen Rezeptionsgewohnheiten und -erfahrungen in unterschiedlichem Maße beurteilt.

In den Beispielen 39, 40 und 41 ist immer eine konkrete Person - sei sie der Gesprächsgruppe zugehörig (Ole und Burim), abwesend (Verenas Schwester) oder imaginiert (Roberts Kumpel) - für den Akt des Spoilerns verantwortlich. Sowohl Roberts generalisierende Formulierung „spoiler sind eh das SCHLIMmste;“ (Z. 1061) als auch Formulierungen in anderen Fällen innerhalb der Daten weisen darauf hin, dass oft auch agensloses Spoilern relevant gesetzt wird. So berichtet beispielsweise Jan davon, dass er in Bezug auf GAME of THRONEs gespoilert wurde, allerdings ohne ein auslösendes Subjekt zu nennen (vgl. Anhang VI: RHG10, Z. 728-754). Stattdessen formuliert er den Akt des Spoilerns im Passiv und bezieht sich auf sich selbst mit dem generischen „man“: „dann wird man voll krass geSPOIlert?“ (Z. 737). Spoilern wird damit zu etwas, das weder absichtsvoll noch absichtslos an einzelne Personen adressiert ist, sondern ein Nebenprodukt von online-Aktivitäten darstellt, wodurch eine größere Distanzierung möglich ist.

Insgesamt legen die Analysen der Sequenzen, in denen Spoiler in irgendeiner Art und Weise in den Gesprächen relevant gesetzt werden, folgende Erkenntnisse nahe: Spoilern ist ein interaktiv hervorgebrachtes Phänomen, wobei die Definitionshoheit dessen, was als Spoilern kategorisiert wird, bei der gespoilerten Person

9 Als die Gruppe erfährt, dass Johann keinen Netflix-Account hat, teilt Ole ihm mit, dass er Netflix zum „Überleben“ benötigt (OST11, Z. 236). 
in Abhängigkeit von deren Rezeptionsgewohnheiten und -erfahrungen liegt. Das zeigt sich an den unterschiedlichen Reaktionen von Verena und Sevcan in Beispiel 39 oder auch an der Folgebehandlung in Beispiel 23, in dem Josefine ebenfalls den Tod einer Hauptfigur preisgibt, ohne dass sich vergleichbare interaktive Konsequenzen ergeben. In Beispiel 40 war der Akt des Spoilerns mit hoher Wahrscheinlichkeit nicht von Burim intendiert, sondern wurde erst im Nachhinein durch Laras Verhalten als solcher klassifiziert. Für beide Fälle, in denen während der Gruppengespräche selbst Teilnehmerinnen gespoilert wurden, lässt sich eine Tendenz zur performativen Inszenierung des Gespoilert-werdens feststellen. Sowohl Johanns scherzhafte Beleidigung und Angebot, den Spoilernden zu „schlagen,“ (Z. 552) als auch Laras sehr körperbezogene Reaktion sowie das offensichtliche Vergnügen der anderen Beteiligten zeigen, dass die Jugendlichen den Verstoß gegen die Gruppennorm fast genüsslich zelebrieren und ihm dadurch erst Relevanz verleihen.

Das lässt sich möglicherweise darauf zurückführen, dass beim Spoilern die epistemischen Status von Interagierenden eine besondere Rolle spielen. Während in Alltags- oder institutionalisierter Kommunikation eine Präferenz für den Ausgleich von Wissensasymmetrien vorherrscht (vgl. Ausführungen in Abschnitt 4.3), wird diese Präferenzstruktur im Kontext von serienbezogenen Interaktionen umgekehrt; mehr noch, sie mündet in einem interaktiven Dilemma. Denn, wie die Analysen zu epistemischen Positionierungspraktiken in Abschnitt 7.1 und 7.2 zeigen, sind wissensausgleichende Aktivitäten und das Anzeigen von (ausreichendem) Wissen für Partizipation und damit insbesondere für Vergemeinschaftung und Distinktion einerseits essentiell notwendig. Andererseits besteht aber die Gefahr, durch zu viel Wissenspreisgabe gegen die Norm des Spoilerns zu verstoßen. Da der Wissensstand in Zeiten des optionalisierten Serienkonsums (vgl. Abschnitt 2.1.2) jedoch individuell hochgradig variiert, ist es nahezu unmöglich, die Wissensstände aller Teilnehmenden - insbesondere in heterogenen Mehrparteien-Interaktionen jederzeit adäquat bedienen zu können (wie in Abschnitt 7.1.1 analysiert). Daraus ergeben sich Konsequenzen für die Konzeption des Konzepts des common ground, die in Abschnitt 10.3 diskutiert werden.

\subsubsection{Positionieren im Spannungsfeld angemessenen Rezeptionsverhaltens}

Während sich die Analysen in Abschnitt 8.2.1 und 8.2.2 auf die Erwartungshaltung und den Anspruch der Rezipient*innen auf Serien als Medienprodukte bezogen und Abschnitt 8.2.3 die Angemessenheit der Wissensweitergabe im Kontext von Serienkommunikation beleuchtet hat, steht in diesem Abschnitt die Erwartungshaltung in Bezug auf das Rezeptionsverhalten der Interagierenden im Vordergrund. In 
allen Daten im Korpus thematisieren die Jugendlichen immer wieder die folgenden Aspekte: Die emotionale Erlebnisqualität während der Serienrezeption (Abschnitt 8.2.4.1), die Intensität (Abschnitt 8.2.4.2) und die zeitlichen Ressourcen (Abschnitt 8.2.4.3) der Serienrezeption sowie die Auswahl der Audiospur (Abschnitt 8.2.4.4).

Es kristallisiert sich heraus, dass sich die Diskussion dieser Aspekte stets unter der Frage nach der Angemessenheit bewegt, d.h. die Teilnehmenden handeln diskursiv aus, zwar emotional involviert zu sein, aber nicht $z u$ viele Emotionen zu zeigen, zwar Zeit in Serienrezeption zu investieren, aber die richtigen Zeitpunkte dafür zu nutzen usw. Anhand von jeweils drei bis vier Transkriptausschnitten wird die Bandbreite dieses Angemessenheits-Kontinuums analysiert. Angemessenheit lässt sich analytisch auf der sprachlich-interaktiven Oberfläche rekonstruieren durch die Aushandlung von Bewertungen, Rechtfertigungen, Reparaturen, dem Formulierungsaufwand für Aussagen und komplexere Positionierungssequenzen.

\subsubsection{Angemessen emotional involviert sein}

Emotionale Beteiligung an einer Serie spielt für die Rezeption eine wichtige Rolle (vgl. Abschnitt 2.1.3). Keppler verweist auf das Wechselspiel von Vereinnahmung und Distanzierung, das sich in Gesprächen über Medien erkennen lässt, wobei sie auf der Basis ihrer Analysen konstatiert, dass die ,kommunikative Verarbeitung zeigt, dass der Umgang mit Medien sehr häufig eher ein distanzierter und distanzierender ist“ (Keppler 1994: 262). Davon ausgehend wird in diesem Abschnitt analysiert, welche affektive Haltung einer Serie oder Serien im Allgemeinen entgegengebracht wird. Dafür wird das Konzept der Positionierung, wie es für narrative Interaktionsstrukturen modelliert wurde, hinzugezogen (vgl. Abschnitt 3.2.1). Denn die Positionierungsforschung zu interaktiven Erzählungen weist darauf hin, dass eine erzählende Person mit ihrer Erlebnis-Erzählung sich nicht nur in der gegenwärtigen Interaktionssituation positioniert, sondern auch sich selbst als Figur innerhalb der erzählten Geschichte (vgl. u.a. Lucius-Hoene und Deppermann 2004). Diese Möglichkeit zur Mehrfachpositionierung wird für den analytischen Zugriff auf die affektive Haltung gegenüber einer Serie folgendermaßen adaptiert: Eine Person kann in der - zeitlich zurückliegenden - Rezeptionssituation emotional involviert oder distanziert sein. In diesem Fall wird aus analytischer Sicht vom Rezeptions-Ich gesprochen, das von den Beteiligten diskursiv - häufig mittels der Ressource Rekonstruieren - hergestellt wird. Zugleich kann in der gegenwärtigen Interaktionssituation die emotionale Beteiligung des Rezeptions-Ichs emotional oder distanziert markiert kommuniziert werden. Damit soll nicht impliziert werden, dass die Jugendlichen in der Situation emotional beteiligt sind, sondern dass sie emotionale Beteiligung interaktiv mittels Ressourcen und über affektive Displays (Selting 2012, Du Bois und Kärkkäinen 2012) herstellen. Insbesondere 
wird der analytische Fokus auf die Folge-Behandlungen von Positionierungen, die (Nicht-)Emotionalität markieren, gelegt. Kennzeichnend für die Interaktionen der Jugendlichen ist ein sorgfältiges Ausbalancieren zwischen den Extremen: Sowohl $z u$ emotionales Rezipieren als auch $z u$ distanziertes Rezipieren ziehen Reparaturen, Elaborierungen, Rechtfertigungen, Argumentationen und Nachfragen nach sich.

Der Abschnitt beinhaltet vier Transkriptausschnitte, die zur Illustrierung dieses Spannungsverhältnisses analysiert werden. Beispiel 42 beinhaltet divergierende Positionierungsmöglichkeiten des emotional bzw. distanziert Rezipierens bzw. darüber Kommunizierens, daher wird es zur Einführung ausführlich analysiert. Anhand des Beispiels 43 wird gezeigt, wie eine emotionale Positionierung interaktiv abgeschwächt wird, während die Beispiele 44 und 45 den unterschiedlichen Umgang mit distanzierteren Positionierungen veranschaulichen. Davon ausgehend werden Prozesse der Vergemeinschaftung bzw. Distinktion analysiert.

(42) ich hab immer angst dass das dann WIRklich passie(h)iert;

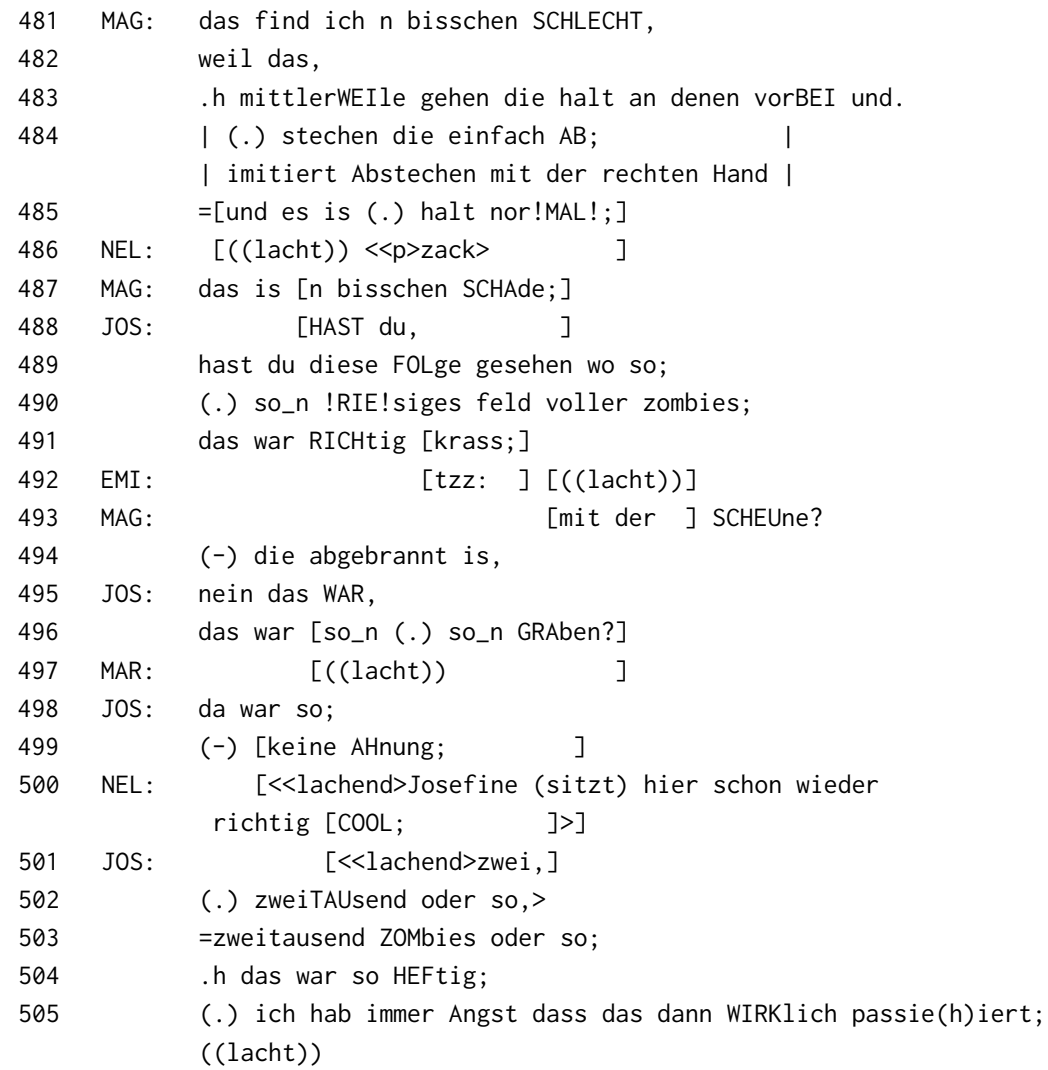


EMI: ey wenn man zu lange GUCKT, =dann fühlt man sich so krAss; $=[n e$,

MAR: $\quad[i c h]$ hab criminal MINDS geguckt, ohne WITZ,

=ich hab die sechste staffel DURCHgeguckt ich bin so behin-=

EMI: $\quad=[$ du dachtest einfach $]$ jEder mensch ist potentieller MÖRder;

MAG: [((unverständlich)) ]

EMI: ich [hab (origiNAL), ]

MAR: $\quad$ [ich hatte Übel.]

übel so_n,

[ich hatte wirklich so, ]

BIL: [das is wirklich (SCHEIße);]

MAR: [SCHEIße ich (will_s jetzt) [(unverständlich)]]

MAG: [(ich hab) (xxx) jetzt;

EMI :

wir waren im

[ich WAR im,

und (Martha) dachte unsere NACHbarn wollen uns UM[bringen; ]

LEN :

$[(($ lacht $))]$

MAR: $[<<$ lachend $>$ ey $>\quad]$ es,

EMI: [es is So krank gewesen;]

MAR: [das waren so richtig junge] HOLLänder ne und, (.) ich dachte die kommen in der NACHT so bei unsso (is) das war so richtig [(potenTIELL;)]

LEN: [oh nei:n; ]

NEL: guckt ihr lieber im [originALton,]

Die Sequenz ist eingebettet in eine Diskussion zu der Serie The WALKIng DEAD. Magnus und Josefine waren sich zuvor einig, dass die Serie mit der Zeit an Qualität verliert. Magnus begründet seine Bewertung damit, dass das ,Abstechen von Figuren' mittlerweile zur Normalität in der Serie geworden sei (Z. 481-487). Daraufhin bietet ihm Josefine eine Möglichkeit zur Vergemeinschaftung an, indem sie nach seiner Kenntnis einer spezifischen Episode fragt. Diese Episode nutzt sie wiederum als Beleg für eine emotionale Reaktion ihrerseits auf die Serie (Z. 487-505). Emilia und Martha schließen daraufhin eine gemeinschaftlich erzählte Begebenheit zur Rezeption der Serie CRIMINAL MInDs im Urlaub an (Z. 506-529). Die Praktik, derer sich Magnus, Josefine, Emilia und Martha hier vorrangig bedienen, ist die des $M a$ nagens divergenter Wissensbestände (Abschnitt 7.1.1), um die eigene epistemische Autorität und die Legitimation ihrer Bewertung zu untermauern. Der analytische Fokus liegt im Folgenden darauf, wie die affektive Haltung gegenüber THE WALKING DEAD und später CRIMINAL MINDS von den Beteiligten in unterschiedlich hohem Maße angezeigt und sukzessive aneinander angepasst wird. 
Während Magnus sich eher distanziert gegenüber emotionalisierenden Inhalten der Serie positioniert, etabliert Josefine eine genau gegenteilige Positionierung, die ihre emotionale Involviertheit während der Rezeption betont. Sprachlich wird Magnus' Positionierung deutlich an seiner starken Betonung des Wortes „normal“ (Z. 485), den Partikeln „einfach“ und ,halt“ (Z. 484-485) sowie seiner Geste, die die Beiläufigkeit des Abstechens unterstreicht (Z. 484). Josefine rekonstruiert dagegen überlappend mit ihm eine Szene, von der sie signalisiert, sie während der Rezeption als emotional empfunden zu haben. Die deiktischen Ausdrücke, die sie verwendet, verweisen zwar auf als geteilt angenommenes Wissen, das allerdings verhältnismäßig unkonkret bleibt (Z. 490-491) und auch nicht von Magnus ratifiziert wird (Z. 493-494). Ihre Äußerung ist so konstruiert, dass sie einen hohen Kontrast zu Magnus' Normalitäts-Aussage impliziert: Sie betont sehr stark das Ausmaß der Zombieanzahl (Z. 490) und markiert mit Intensifiern wie „richtig krass“ (Z. 491) oder „so HEFtig“ (Z. 504) eine affektive Reaktion, die als Gegensatz zur Magnus' Einschätzungen als ein „bisschen SCHLECHT,“(Z. 481) bzw. „bisschen SCHAde; “ (Z. 487) interpretiert werden kann. Ihre affektive Haltung gegenüber der Szene bringt sie auch mit ihrer Stimme zum Ausdruck, die lauter und ,gepresster als in anderen Sequenzen wirkt.

Beide Positionen werden von den anderen Teilnehmenden aufgegriffen und unterschiedlich bearbeitet. Auf der einen Seite stimmt Nelli in Magnus' distanzierte Positionierung ein, indem sie seine Geste imitiert, begleitet von der leisen Äußerung „zack;“ (Z. 486). ${ }^{10}$ Emilias „tzz:“ (Z. 492) oder Nellis Kommentar zu Josefines Sitzposition (Z. 500) deuten darauf hin, dass Josefines Äußerungen interaktiv als unangemessen behandelt werden. Zudem verschiebt Emilia direkt danach Josefines Schilderung ihrer Reaktion auf eine spezifische Szene hin zu einer allgemeineren Ebene, die über THE WALKING DEAD als Positionierungsobjekt hinausgeht. Sie kommuniziert zwar inhaltlich eine ähnliche Botschaft, markiert aber eine stärkere Distanz dazu: ,wenn man zu lange GUCKT,=dann fühlt man sich SO krass; =ne " (Z. 506-507). ${ }^{11}$ Auf der anderen Seite knüpft Martha eine second story zu CRIMINAL MINDS an (ab Z. 508), die sie offenbar mit Emilia zusammen im Urlaub erlebt hat. Beide rekonstruieren abwechselnd ihr Erlebnis, dass sie sich nach ihrer Rezeption der Serie vor ihren Nachbarn gefürchtet hätten. Sie gestalten die affektive Komponente der Erzählung sorgfältig aus: EMI: „du dachtest einfach jEder mensch ist potentieller MÖRder;“ (Z. 511); MAR: „ich dachte die kommen in der NACHT so bei uns-“, (Z. 527) und laden die anderen zu Zustimmung und zur Vergemeinschaftung mit ihnen ein. Ihre Erzählung wird jedoch nur minimal ratifi-

10 Nelli agiert vergleichbar auch in anderen Situationen (vgl. z.B. in Abschnitt 7.2.1)

11 Auch Emilia agiert an anderer Stelle ähnlich (vgl. z.B. in Beispiel 15). 
ziert über zustimmende Bewertungen seitens Bilel und Leni (Z. 517, 529); danach folgt ohne weitere Kommentierung die Überleitung von Nelli zu einem neuen Positionierungsobjekt (Z. 530).

Diese Aushandlungssequenz zur emotionalen Beteiligung wird vorrangig zum Aufrechterhalten von Vergnügen genutzt. So werden sowohl Magnus' Inszenierung (Z. 484) als auch Josefines von Lachpartikeln begleitete Positionierung ihres Rezeptions-Ichs "ich hab immer Angst dass das dann WIRKlich passie(h)iert,“ (Z. 505) als nicht ernst gemeint gerahmt. Vergemeinschaftung wird in dieser Sequenz über zwei Aspekte hergestellt: Zum einen zwischen der gesamten Gruppe über Magnus' These, dass die Serie mittlerweile Gewalt als so normal darstellt, dass sie Rezipient ${ }^{\star}$ innen nicht mehr stark emotionalisiert. Zum anderen zwischen Josefine, Martha und Emilia, dass im Gegenteil die Emotionalisierung oft als so hoch wahrgenommen wird, dass sie in die Alltagswelt der Jugendlichen zurückwirkt. Zugleich hat letzteres aber auch eine Distinktionsfunktion. Denn während Magnus sich emotional distanziert als jemand positioniert, der emotional distanziert rezipiert, positioniert Josefine sich emotional involviert als eine Person, die emotional involviert rezipiert. Die Folgepositionierungen weisen darauf hin, dass sie jeweils (noch) nicht dem diskursiv als angemessen behandelten Maß entsprechen. Das zeigt sich auch an anderen Sequenzen in den Daten, wie im folgenden Beispiel:

(43) ich KONnte nich hingucken;

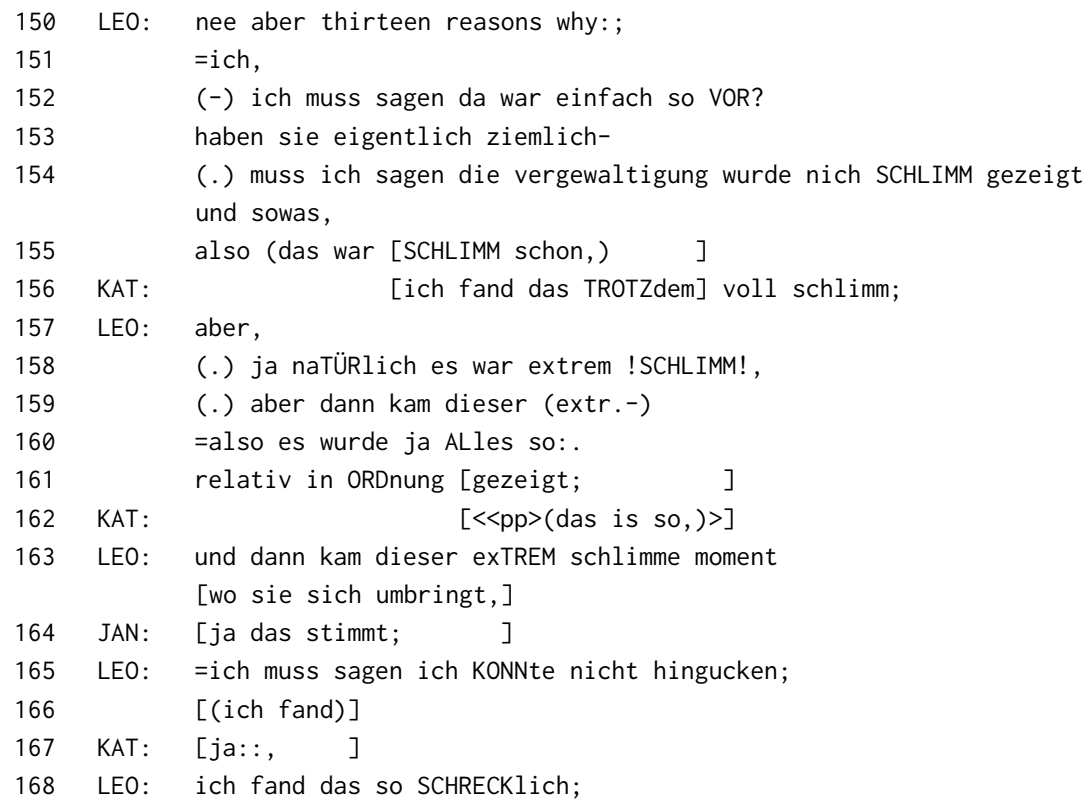




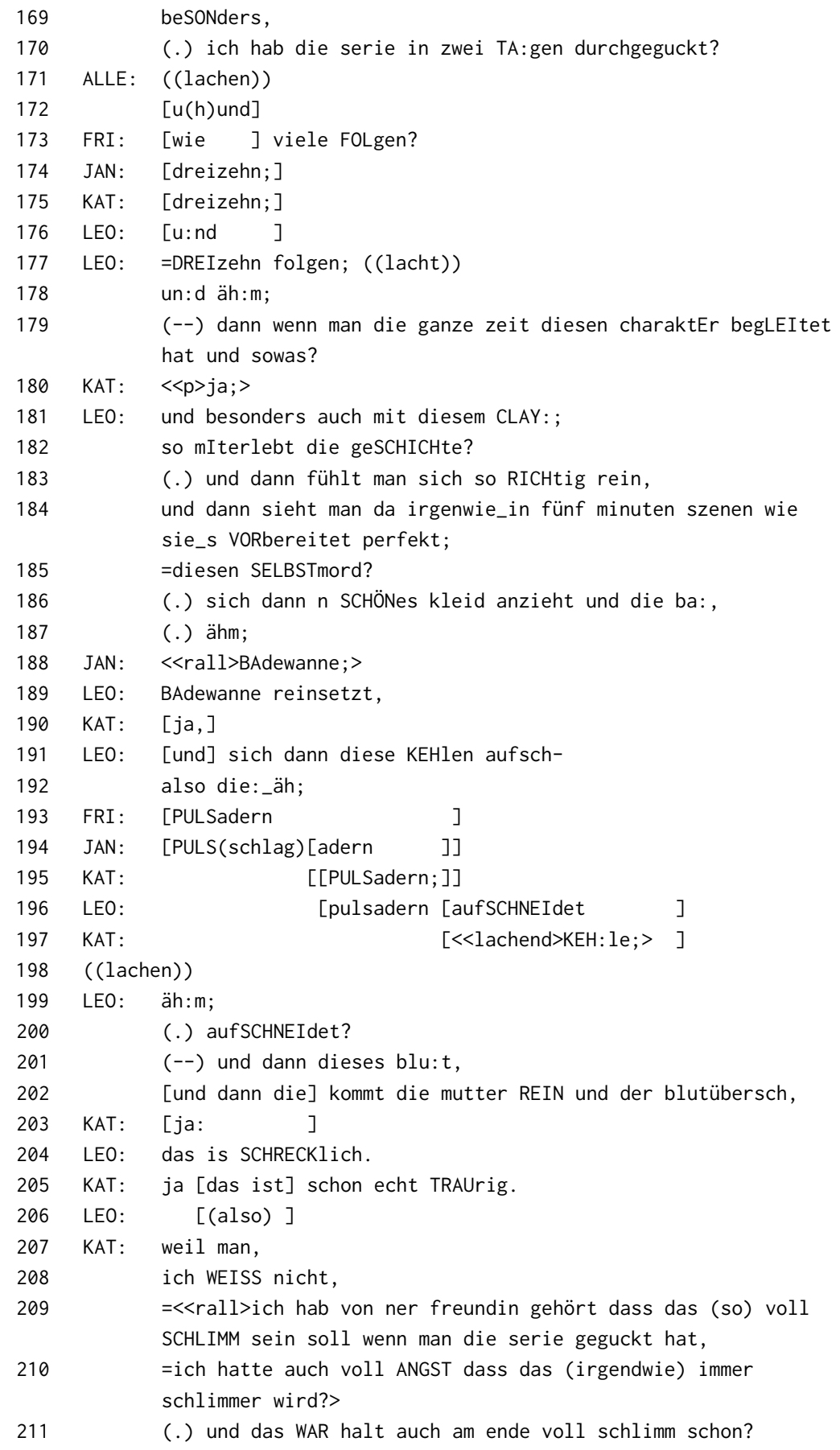


Dieser Ausschnitt schließt direkt an Beispiel 26 an und ist zeitlich vor Beispiel 36 angesiedelt. Die Gruppe diskutiert die von Katharina initiierte Frage, welche Serie sie „so richtig krass bewegt“ (Anhang VI: RHG10, Z. 058) habe, woraufhin die Serie 13 REASOnS Why diskutiert wird. Leon hebt die Szene, in der die Hauptfigur Suizid begeht, als besonders aufwühlend hervor (Z.150-168; 177-203). Im Rahmen einer Nebensequenz wird das Rezeptionstempo kommuniziert (Z. 169-176; vgl. dazu auch Analysen in Abschnitt 8.2.4.2) und abschließend bewertet Katharina die Serie (Z. 204-2012). Im Folgenden wird rekonstruiert, wie Katharina und Leon im Laufe der Sequenz gemeinsam die Frage nach dem emotionalen Erleben der Serie auf der Ebene der ästhetischen Darstellung bearbeiten und sehr unterschiedlich damit umgehen.

So positionieren beide auf der einen Seite ihr Rezeptions-Ich als von der Serie emotional berührt, wenn auch auf verschiedene Handlungselemente bezogen. Das zeigt sich an Leons Äußerung „,ich muss sagen ich KONNte nicht hingucken“(Z. 165), mit der er auf die Szene verweist, in der sich die Protagonistin das Leben nimmt. Die Vergewaltigung - ebenfalls ein potentiell emotionalisierendes Handlungselement der Serie - stuft Leon dagegen als „nich SCHLIMM gezeigt und sowas, “ (Z. 154) ein. Dieser Aussage widerspricht Katharina: „ich fand das TROTZdem voll schlimm“ (Z. 156). Auf der anderen Seite kommunizieren sie in der gegenwärtigen Gesprächssituation ihre emotionalen Positionierungen in unterschiedlicher Art und Weise. Leons Turn-Konstruktionen signalisieren ein hohes emotionales Involvement. So betont er, wie schnell er die Serie rezipiert hat (Z. 170-178), dass er sich in die Hauptfigur hineinversetzt (Z. 179-183, vgl. dazu auch die Analyse zu Beispiel 36) und rekonstruiert im szenischen Präsens sehr detailliert und mit Listen-Intonation die Suizid-Szene (Z. 184-202) sowie seine affektive Reaktion darauf (Z. 204). Katharina schwächt dieses Emotionalitäts-Display jedoch wieder ab, indem sie sich im Anschluss an seine Bewertung „SCHRECKlich.“ mit einer deutlich distanzierteren Haltung äußert: „ja das ist schon echt TRAUrig.“(Z. 205). Auch danach elaboriert sie aus einer distanzierten Perspektive unter Berufen auf die Bewertung anderer (vgl. Abschnitt 7.2.2), sie habe gehört, dass die Serie schlimm sein soll. Daran anknüpfend signalisiert sie zwar wiederum einen hohen epistemischen Status mit der Formulierung „und das WAR halt auch am ende voll schlimm schon?“, allerdings signalisiert sie damit auch eine weniger hohe emotionale Beteiligung als Leon zuvor. Danach wendet sich die Gruppe insgesamt wieder sachlicheren Themen zu (über die zu dem Zeitpunkt geplante zweite Staffel der Serie, Z. 213-224). 
Anders als in Beispiel 42 findet hier Vergemeinschaftung über das als geteilt angenommene emotionale Erleben auf die Serie als Ganzes bezogen statt. Da die Teilnehmenden ihre Emotionalität jedoch auf unterschiedliche Handlungselemente (Suizid vs. Vergewaltigung) bezogen markieren, kommt es zu einer interaktiven Herabstufung der Emotionalität und schließlich zu einem Wechsel zu als weniger emotional behandelten Positionierungsobjekten. Im Unterschied dazu zeigen die folgenden zwei Beispiele interaktive Aushandlungen, die entstehen können, wenn das eigene Rezeptionserleben - sei es emotional oder distanziert - aus Sicht der Gruppe $z u$ distanziert kommuniziert wird.

\section{(44) da hatte ich erstmal n HEULkrampf,}

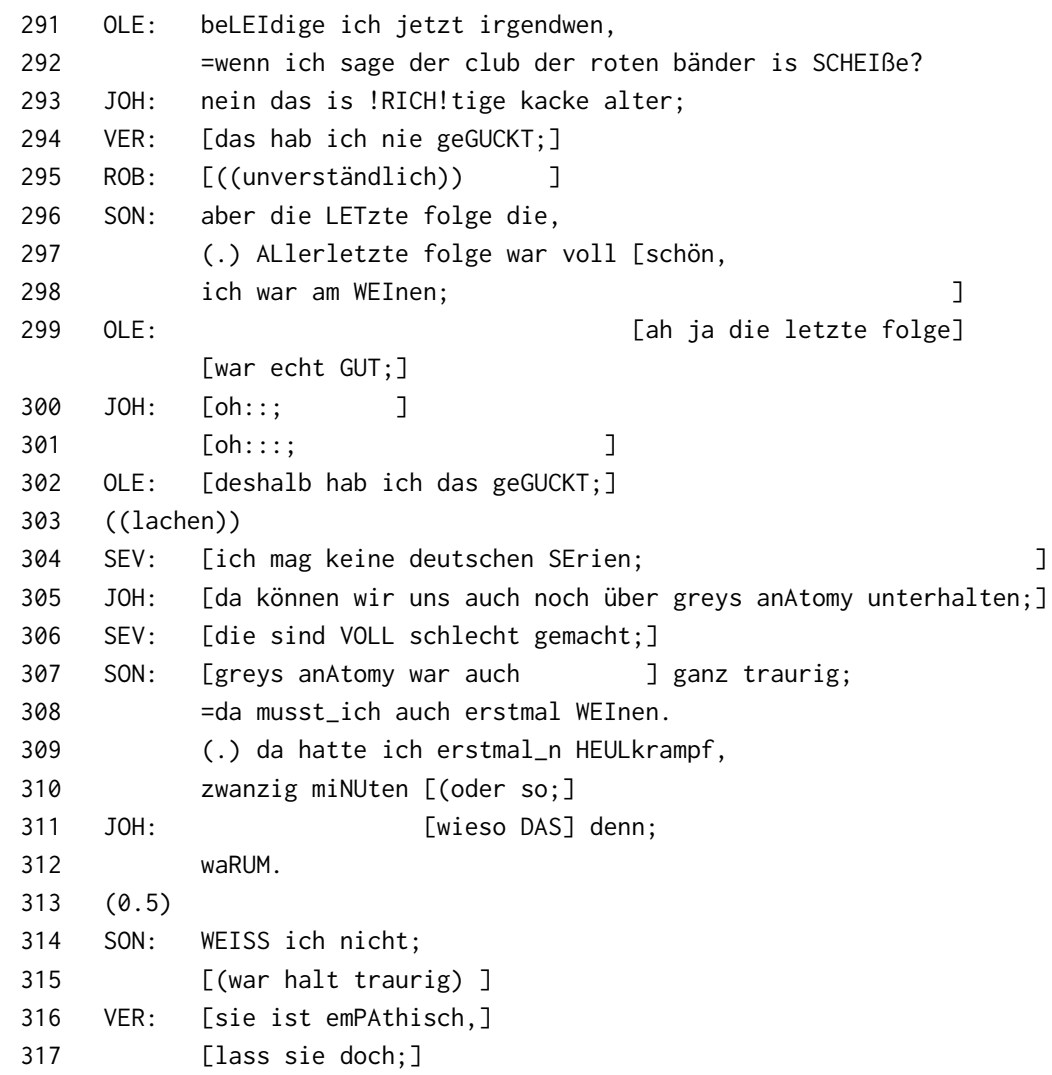


Die Gruppe bewertet die Serie CLUB DER ROTEN BÄNDER sehr unterschiedlich (Z. 291-304). Nach einer kurzen Diskussion über GREY's ANATOMY (Z. 305-310) konfrontiert Johann Sonja mit ihren emotionalen Displays bezogen auf beide Serien (Z. 311-315) und Verena interveniert (Z. 316-317). Im Folgenden wird untersucht, wie die Gruppe Affekt interaktiv behandelt. Dabei wird zunächst sequenziell Sonjas diesbezügliche Positionierung nachgezeichnet, bevor analysiert wird, wie die Gruppe darauf reagiert.

Ole positioniert sich eingangs als jemand, der die Serie CLUB DER ROTEN BÄNDER nicht mag (Z. 291-292). Als Folgepositionierung formuliert Sonja eine von Oles Bewertung abweichende positive Einschätzung der letzten Episode (Z. 296-298), der Ole auch zustimmt und damit seine Bewertung revidiert (Z. 299). Sie begründet ihre Einschätzung damit, dass die Folge „voll schön“ (Z. 297) war und sie deswegen „am WEInen;“ war (Z. 298). An dieser Stelle wird ihre emotionale Positionierung interaktiv nur von Johann aufgegriffen, der sein - vermeintliches - Mitgefühl zwei Mal ausdrückt (Z. 300-301). Nachdem er die Serie GREY's ANATOMY thematisiert (Z.305), greift Sonja ihre vorherige Äußerung wieder auf und bewertet diese Serie in Relation zu CLUB DER ROTEN BÄNDER ebenfalls als „traurig“ (Z. 307). Mit „zwanzig miNUten oder so;“ gibt Sonja einen Zeitraum für ihren „HEULkrampf“ (Z. 308-310) an. ${ }^{12}$ Damit positioniert sie sich zwar als eine Person, die während der Rezeption emotional hochgradig involviert war; im Unterschied zu Josefine in Beispiel 42 markiert sie allerdings innerhalb der aktuellen Gesprächssituation kaum emotionale Beteiligung (vergleichbar mit Katharinas Positionierung in Beispiel 43). Sie berichtet über ihre Reaktion während der Rezeptionssituation in einer sachlichen Art und Weise, wobei sie anders als andere Teilnehmende in den Daten auch keine Lachpartikeln o.ä. nutzt, um ihre Aussage zu relativieren.

Die interaktive Reaktion darauf besteht darin, dass Johann sie mehrfach nach dem Grund fragt. Die Verwendung von „denn“ und die Betonung auf dem „das“ (Z. 311), die Wiederholung der Frage (Z. 312) mit stark sinkender Intonation sowie die halbsekündige Pause im Anschluss (Z. 313) deuten darauf hin, dass es sich dabei nicht um die erwartete, d.h. präferierte Reaktion auf ihre Äußerung handelt. Sonja antwortet ausweichend: „weiß nich“ und bedient den von Johann etablierten Rechtfertigungszwang zur Elaborierung nicht. Stattdessen antwortet sie erneut sachlich-distanziert mit „war halt traurig“ (Z. 315), ohne eine weitere Begründung $\mathrm{zu}$ formulieren. Überlappend dazu findet eine Fremdpositionierung von Verena

12 Vergleichbares findet sich auch in anderen Daten des Korpus: So äußert Sina, sie habe vierzig von fünfundvierzig Minuten während VAMPIRE DIARIES geheult und positioniert sich emotional beteiligt durch die Formulierung „danach hab ich erst mal ganz lange $n$ halben emotionalen $z$ SAMmenbruch“" (Anhang VIII: RGM11, Z. 008-016). Auch diese Positionierung wird im Folgenden abgeschwächt und auf eine sachlichere Ebene verschoben. 
gegenüber Sonja statt, die sie an Johann adressiert: Sie weist Sonja die Eigenschaft „emPAthisch“ zu (Z. 316) und markiert seine Nachfrage damit im Nachhinein als unangemessen (Z. 317). Die Reparaturen in dieser Sequenz weisen darauf hin, dass es potentiell heikel sein kann, $z u$ emotional involviert $z u$ rezipieren. Weiterhin kann es interaktiv relevant werden, wenn die Positionierung zwischen dem rekonstruierten Rezeptions-Ich und der gegenwärtig interagierenden Person als nicht passend wahrgenommen bzw. behandelt wird. Das zeigt sich ebenfalls in folgendem Beispiel:

(45) mit so ner geWISsen (-) emotionalen disTANZ

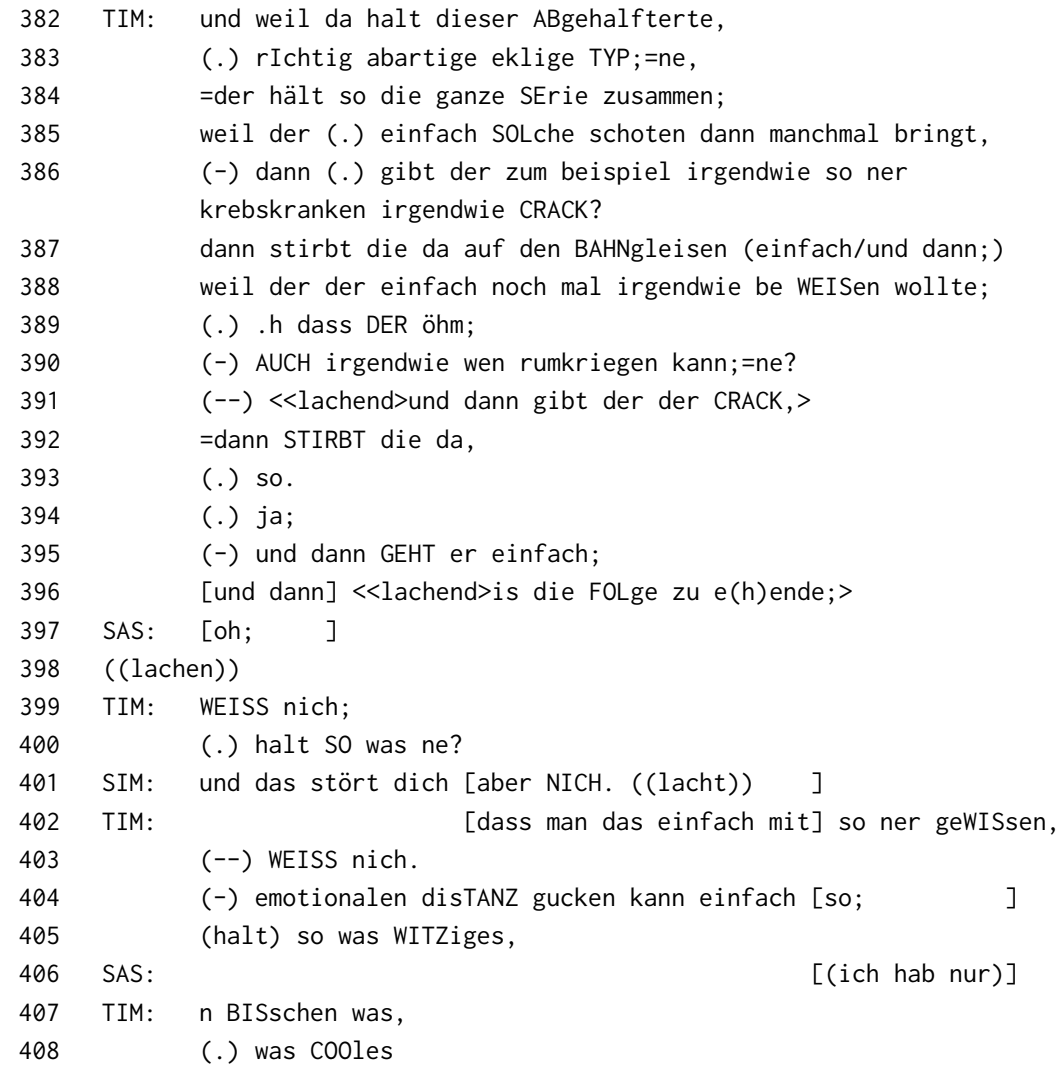


Tim beschreibt in dieser Sequenz Szenen aus der Serie ShameLESS ${ }^{13}$ (Z. 382-396), die er als lustig rahmt (Z. 391, 396). Es folgt eine Frage von Simon, die eine nicht geteilte Bewertung dieser Szene nahelegt (Z. 402). So begründet Tim anschließend im Rahmen mehrerer Äußerungen seine Präferenz für diese Art von Serientyp (Z. 397-408). Der analytische Fokus liegt im Folgenden darauf, wie Tim sich in Bezug auf Emotionalität positioniert und wie die Gruppe darauf reagiert.

Tim positioniert sich als jemand, der eher distanziert als involviert rezipiert und - ähnlich wie Magnus in Beispiel 42 - auf Vergemeinschaftung durch Vergnügen abzielt. Diese Reaktion bleibt jedoch aus und die anderen ratifizieren seine Rahmung nicht. Im Gegenteil: Simon fordert ihn heraus, indem er ihn als jemanden positioniert, den das nicht „stört“ (Z. 401). Damit impliziert er, dass Tims Schilderung der Szene durchaus eine höhere emotionale Beteiligung erforderlich machen würde. Tim bedient den Zugzwang und elaboriert seine Position, die er durch die mehrfache Verwendung von „WEISS nich.“14 abschwächt: „dass man das einfach mit so ner geWISsen, (-) WEISS nich. (-) emotionalen disTANZ gucken kann einfach so;“ (Z. 402-404). Die Formulierung „emotionale disTANZ“ beinhaltet mehrere Implikationen: Zum einen bestärkt er seine eingangs formulierte Positionierung des distanzierten Rezipienten, der sich von anderen abgrenzt, zum anderen nimmt er darauf Bezug, dass die Serie (bzw. Serien allgemein) eine emotionale Beteiligung und eine entsprechend kommunizierte Haltung dazu nahelegen. In dieser Gruppe wurde allerdings schon an anderer Stelle zu emotionales Rezipieren mit face-bedrohenden Äußerungen sanktioniert (vgl. auch Analysen in Abschnitt 9.1.1), so dass er hier anscheinend versucht, sich an die gruppenbezogene Definition von angemessenem emotionalen Involvement anzupassen. Diese Interpretation lässt sich auch durch Tims Bewertung der Serie als „so was WITziges“ und „, bisschen was cooles“ $(\mathrm{Z} .405,407)$ stützen, mit der er einen Kontrast zu der inhaltlich offenbar vorhandenen Brutalitätsdarstellung der Serie etabliert.

Insgesamt zeigt sich, dass emotionale Involviertheit ein komplexer Aspekt ist, der potentiell sowohl zur Vergemeinschaftung als auch zur Distinktion funktionalisiert werden kann. Szenen, Episoden oder generell Serien, die Gewalt, Tod und Sterben beinhalten, werden so behandelt, dass sie problemlos als emotional involviert diskutiert werden können. Diese Serien oder Szenen können auch ohne Weiteres mit einer affektiven Haltung kommuniziert werden bzw. eine solche Haltung wird zum Teil sogar erwartet (wie in Beispiel 45). Ein Display sehr hoher emotionaler Involviertheit wird jedoch ebenfalls als eher dispräferiert behandelt

13 Diese Sequenz wird auch unter dem Aspekt der epistemischen Positionierung von Tim in Beispiel 27 analysiert.

14 „weiß nich“ könnte allerdings auch idiosynkratischer Natur sein, da Tim diese Formulierung sehr häufig produziert. 
und in Folgepositionierungen sukzessive abgeschwächt (Beispiele 42 und 43, vgl. auch Anhang VIII: RGM11, Z. 018-021). Interaktiv problematisch scheint auch eine als zu groß wahrgenommene Kluft zwischen der Positionierung des RezeptionsIchs und der gegenwärtig sprechenden Person zu sein (vgl. Beispiel 44). Somit kann für diese Daten eine Präferenz für ein etwas höheres, aber nicht $z u$ hohes emotionales Involvement angenommen werden. Letzteres deckt sich mit Kepplers Befunden, dass Rezipient*innen sich zwar bis zu einem gewissen Grad von Medien vereinnahmen lassen, in den Gesprächen jedoch eine stärkere Distanz dazu etablieren. Möglicherweise ist dieses Ergebnis jedoch auch der Art der Datenerhebung und insbesondere dem Öffentlichkeitsgrad (Abschnitt 6.1.2) geschuldet, so dass in anderen Kontexten auch andere Präferenzstrukturen denkbar sind.

\subsubsection{Angemessen intensiv rezipieren}

Im Folgenden werden Sequenzen analysiert, die sich sowohl explizit auf Formen der ,(Serien-)Sucht` als auch implizit auf schnellen Serienkonsum, d.h. das so genannte Binge-Watching beziehen, das die Jugendlichen selbst überwiegend als „(durch-)suchten“ bezeichnen. ${ }^{15}$ An dieser Stelle wird zunächst noch nicht die quantitative Dimension der in Serienkonsum investierten Zeit in den Blick genommen (dieser Aspekt wird in Abschnitt 8.2.4.3 diskutiert), sondern die Intensität des Serienkonsums, also ob in Form eines ,Serienmarathons' mehrere Episoden oder Staffeln am Stück geschaut werden und den interaktiven Umgang damit. Dennoch sind beide Phänomene natürlich eng miteinander verbunden. Wie bei der Thematisierung emotionalen Involvements verhandeln die Teilnehmenden implizit immer wieder die Frage, wie viel Intensität bei der Serienrezeption angemessen ist. Exemplarisch verdeutlicht das Sophies sequenzinitiierende Frage „ähm aber WENN also wenn ihr so ne serie GUCKT, guckt ihr dann so richtig SCHNELL,=also jeden tag irgendwie so mehrere FOLgen oder, “(Anhang VI: RHG10, Z. 302-304), auf die eine „kommt drauf an“-Antwort folgt (Z. 305; vgl. für die Analyse der sich daraufhin entfaltenden Diskussion Abschnitt 7.3.3).

Begonnen wird mit der Analyse von Beispiel 46, in dem Paul sich selbst ex negativo als gerade nicht intensiver Rezipient positioniert, während Verena in Beispiel 47 sich ausdrücklich als ,Suchti` kategorisiert. Daraufhin folgt die Analyse von Beispiel 48, in dem sich zwei Teilnehmer oppositionell in Bezug auf diesen Aspekt positionieren.

15 Diese Arbeit schließt sich hier - sofern es sich nicht um Zitate der Teilnehmenden handelt - der Terminologie der kumulierten Serienrezeption nach Czichon (2019) an (vgl. für eine Begründung Abschnitt 2.1.2 und für gesellschaftliche Implikationen Abschnitt 2.1.3). 
(46) ich bin eigentlich NICH so der intensive seriengucker;

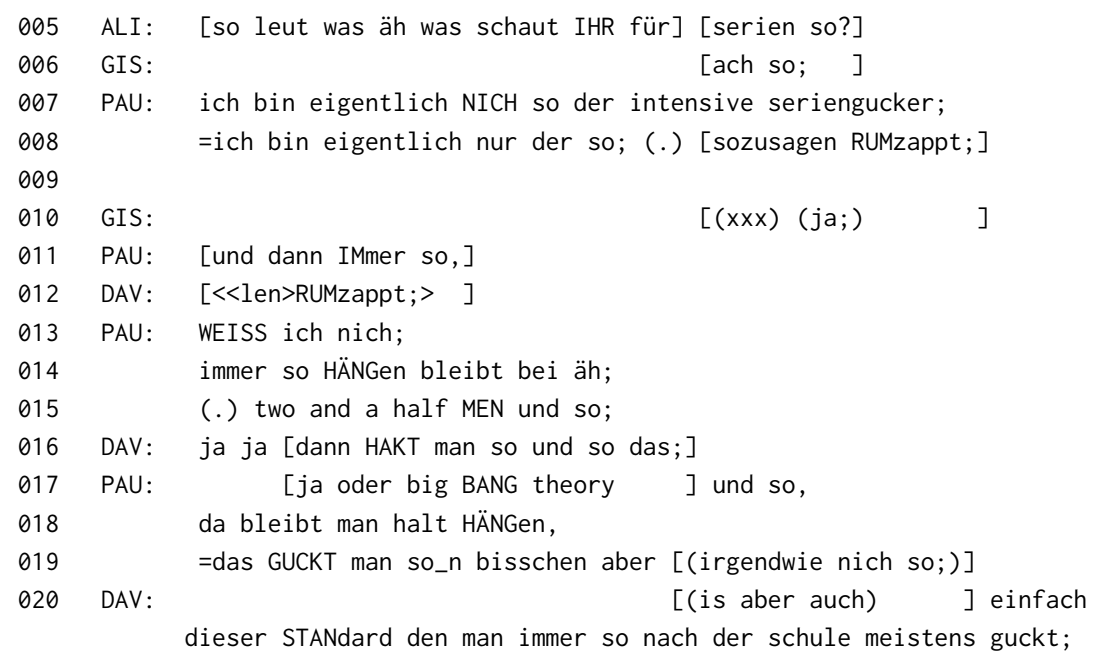

Die Sequenz ist direkt zu Beginn der Gruppendiskussion lokalisiert. Auf Alis einleitende Frage hin, welche Serien die anderen schauen (Z. 005) antwortet Paul mit der Selbstkategorisierung als ,ich bin eigentlich NICH so der intensive seriengucker; “ (Z. 006), die er im Folgenden weiter elaboriert (Z. 008-015) und für die er von den anderen Bestätigung erhält (Z. 016-020). Aus der sequenziellen Platzierung seiner Äußerung unter Berücksichtigung des weiteren Interaktionsverlaufs ließe sich die Deutung ableiten, dass seine Kategorisierung die Funktion einer Art Anleitung für die anderen Gruppenmitglieder erfüllen könnte, wie sie seine Beiträge zu der Diskussion im Hinblick auf das Ziel der Partizipation (Abschnitt 6.2.1) verstehen können: Er gibt prophylaktisch einen Disclaimer dafür an, sich nicht an jedem Thema gleichermaßen beteiligen zu können (wie es z.B. in MNG13, Z. 158-159, 418, 812 deutlich wird; vgl. jeweils Anhang V). Zugleich fordert er damit vorsorglich Rekonstruktionen von Serien ein, die er mit hoher Wahrscheinlichkeit nicht kennt und gibt den anderen damit die Chance, sich als Expertinnen zu positionieren. Tatsächlich ist diese Gruppe im gesamten Korpus diejenige, in der die Teilnehmenden die meisten Plots und Szenen einzelner Serien nacherzählen bzw. performativ inszenieren und dabei häufig mit ihren Blicken Paul adressieren.

Die Beteiligten selbst setzen Pauls Positionierung jedoch in dieser Hinsicht nicht relevant, sondern stimmen ihm zu (Z. 010), indem sie u.a. seine Aussagen reformulieren (Z. 016) und als im common ground verankert behandeln. Als typischer „nicht so intensiver Seriengucker“ kann demzufolge also eine Person 
gelten, die nur sporadisch, nicht zielgerichtet oder bewusst Serien auswählt (,immer so HÄNgen bleibt“, Z. 014), Serien dann rezipiert, wenn es zeitlich passt („nach der SCHUle meistens“, Z. 020; vgl. auch Analysen in Abschnitt 8.2.4.3) und dann Serien konsumiert, bei denen Rezeption und Präsentation zeitgleich stattfinden („RUMzappt“, Z. 008). Paul distanziert sich damit von diesem Typ intensiver Rezipient*innen und zugleich von den Gruppenmitgliedern, die sich möglicherweise damit identifizieren. Dadurch, dass die meisten anderen ihm erkennbar zustimmen, kommt es jedoch zur Vergemeinschaftung innerhalb der Teilnehmenden. Eine gegenteilige Positionierung in Form einer Selbstkategorisierung findet sich in folgendem Transkriptausschnitt:

(47) ich bin AUCH so_n suchti,

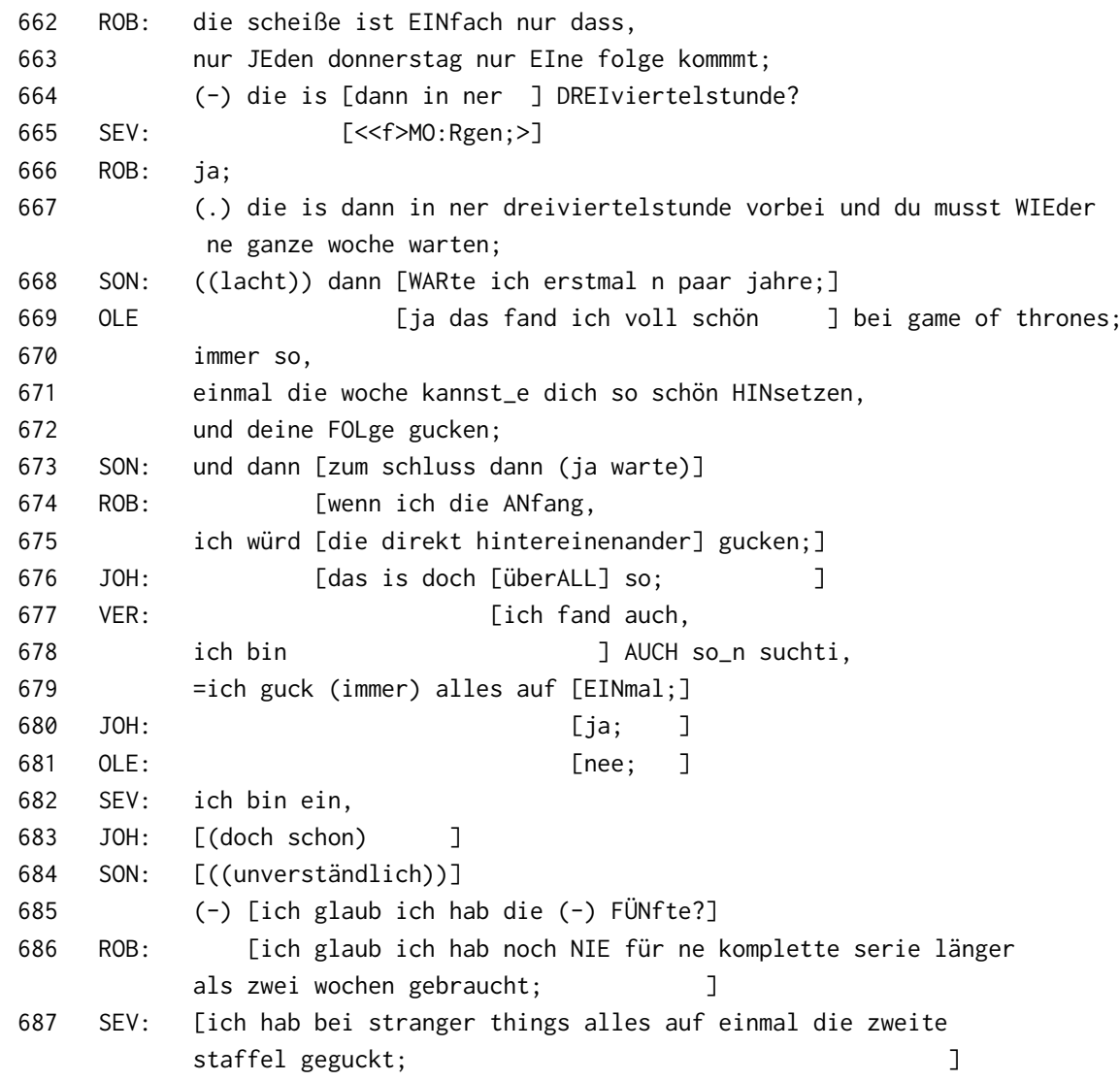


Ole bewertet die Periodizität der Ausstrahlung von GAME of Thrones (Z. 669-672) positiv, während Robert dafür plädiert, alle Folgen hintereinander zu schauen (Z. 674-675). Dann äußern sich Verena, Sevcan, Sonja und Robert zu ihrem Rezeptionstempo (Z. 677-689). Robert hatte sich zuvor bereits als jemand positioniert, der sehr lange und intensiv einzelne Serien schaut (vgl. Anhang IX: OST11, Z. 277-279) und es negativ bewertet, dass die Serie RIVERDALE nur ein Mal pro Woche ausgestrahlt wird (Z. 662-667). In diesem Zusammenhang wird Verenas Verwendung und Betonung des Konnektors „auch“ (Z. 678) bei ihrer Selbstkategorisierung als „so_n Suchti“ (Z. 678) erklärbar. Damit signalisiert sie einerseits Zustimmung gegenüber Robert, andererseits positioniert sie nicht nur sich selbst, sondern ihn zugleich implizit auch als ,Suchti` fremd. Dieser Kategorisierung widerspricht Robert nicht, sondern bekräftigt sie kurz darauf: ,ich glaub ich hab noch NIE für ne komplette serie länger als zwei wochen gebraucht; “ (Z. 686). Aufgrund der Attribute, die der Kategorie ,Suchti ' in diesem Kontext interaktiv zugeschrieben werden kumulierte und häufige Rezeption (Z. 675, 679, 686) sowie zielgerichtet konkrete Serien zur Rezeption auswählen $(Z .669,687,688)$-, kann sie als dichotom zu Pauls Kategorisierung in Beispiel 46 gelten.

Auffällig ist die Geste, die Robert produziert, als er anzeigt, dass er mehrere Folgen direkt hintereinander schaut (vgl. Abbildung 8.4). Er schnellt mit der rechten, flach ausgestreckten Hand mehrfach vor und wieder zurück, die Handfläche zeigt dabei nach unten. Diese Geste ähnelt der, die fallübergreifend Teilnehmende in ähnlichen Kontexten benutzen. So möchte Sophie von den anderen Teilnehmenden wissen, ob sie Serien ,so richtig schnell“ (Anhang VI: RHG10, Z. 303), d.h. „jeden tag irgendwie so mehrere FOLgen“ (Z. 304) gucken würden. Jan führt daraufhin die Serie GAME OF THRONES als exemplarisch für eine solche Serie an, die er schnell rezipiert hat (Z. 309-310). Diese Äußerung intoniert er passenderweise in einem höheren Sprechtempo als sonst. Es folgt eine kurze Pause, in der Friederike lacht und parallel zu Jans Äußerung lautmalerisch und gestisch sein schnelles Rezipieren imitiert (vgl. Abbildung 8.5). Auch Emilia nutzt eine ähnliche Bewegung, wenn sie das Suchtpotential von GAME OF THRONEs hervorhebt (vgl. Abbildung 8.6, im Transkript Anhang IV: MNG11, Z. 426-427). 


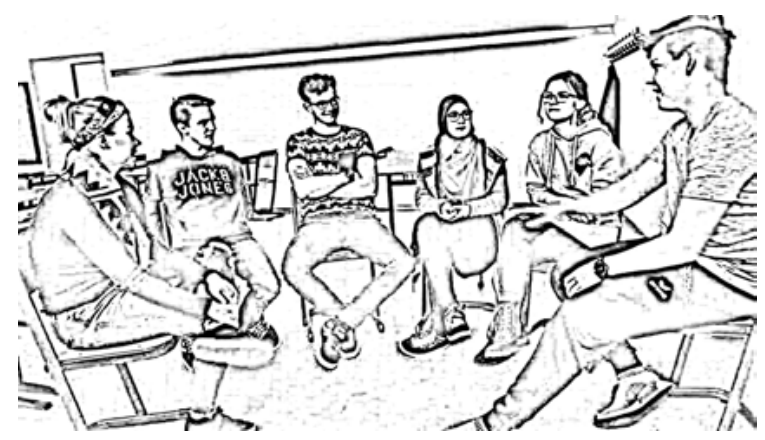

Abb. 8.4: ROB: direkt hintereinander;

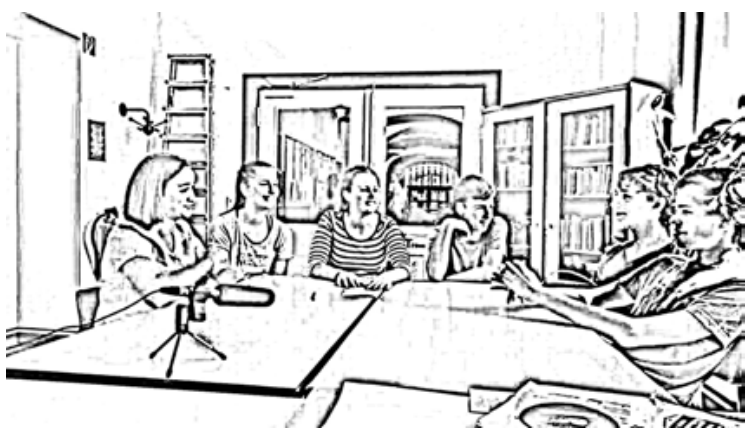

Abb. 8.5: FRI: tsch tsch tsch;

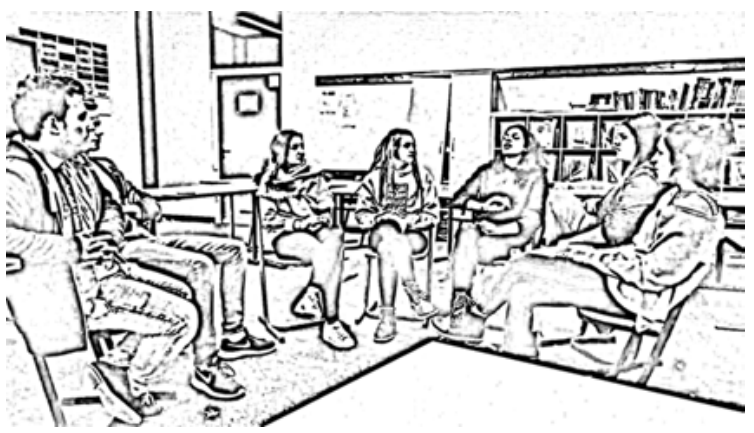

Abb. 8.6: EMI: du denkst so SCHNELL die nächste 
Diese Geste scheint zumindest in den vorliegenden Daten für intensives und suchtähnliches, überwiegend aber positiv bewertetes Rezeptionsverhalten konventionalisiert zu sein. In den analysierten Fällen wird sie zudem immer in Kontexten genutzt, in denen sich Beteiligte vergemeinschaften und darin übereinkommen, dass sie bei bestimmten Serien (i.d.R. GAME OF THRONES) gar keine andere Wahl haben, als sie kumuliert zu rezipieren. Auch im folgenden Beispiel wird implizit auf das ,Suchtpotential' von Serien verwiesen, allerdings mit der Funktion der Distanzierung statt Vergemeinschaftung:

(48) hast du nich diesen DRANG;

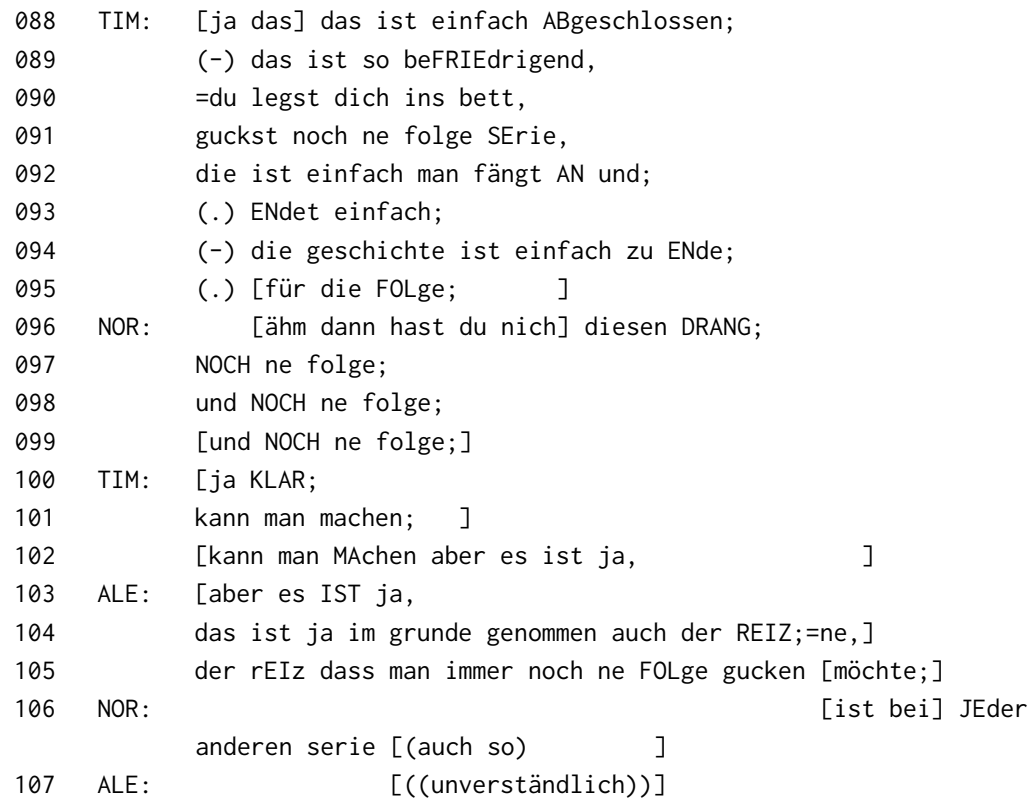

Tim positioniert sich in dieser Sequenz - vergleichbar mit Paul in Beispiel 46 als jemand, der gerade nicht suchtet, sondern stattdessen die Episodenhaftigkeit und die Beendbarkeit von Serien schätzt (Z. 088-095; vgl. dazu auch Abschnitt 8.1.3 sowie seine Positionierung zu emotional involvierenden Serien in Beispiel 45). Daraufhin wird konträr dazu das Bedürfnis nach Fortsetzung als typisch für Serien diskutiert (Z. 086-107). So verweist Norbert implizit auf den Sucht-Aspekt, indem er Tim fragt, ob er nicht das Bedürfnis hätte, „NOCH ne folge“ (Z. 096-099) zu schauen. Die Iterativität von Serien, die intensives Serienschauen überhaupt erst 
bedingt, äußert sich hier sowohl prosodisch durch die sich drei Mal wiederholende Intonationskontur der Äußerung als auch durch eine entsprechende Geste, die denen in Abbildungen 8.4, 8.5 und 8.6) ähnelt, auch wenn sie deutlich langsamer vollzogen wird. Tim signalisiert Alex, dass er diesen „DRANG“ (Z. 096) zwar als prototypisch und geteiltes Wissen behandelt (Z. 100-102), er selbst distanziert sich jedoch zugleich davon und bekräftigt später diese Aussage erneut (vgl. Anhang II: EMS53, Z. 317-318).

Auf suchtbezogene Kategorien und Positionen wird nicht immer explizit Bezug genommen, sie schwingt jedoch in vielen Kontexten implizit mit, indem die Jugendlichen auf mit ihr verbundene Attribute und letztlich die normativen Vorstellungen, die mit dem Aspekt der Sucht verbunden sind, verweisen (vgl. z.B. Anhang IV: MNG11, Z. 934-944). Serienrezeption wird damit als ambivalent charakterisiert, da ,Seriensucht' einerseits negativ konnotiert ist (vgl. Anhang VI: RHG10, Z. 916; siehe auch Ausführungen in Abschnitt 2.1.3) und damit zur Distinktion (Beispiel 46 und Beispiel 48) funktionalisiert werden kann. Andererseits birgt die geteilte Erfahrung des ,Nicht-aufhören-könnens“ (Beispiel 47) auch ein Potential zur Vergemeinschaftung. Neben zustimmenden Äußerungen bei Verweisen auf das Suchtpotential von Serien deutet darauf auch die in Ansätzen konventionalisiert scheinende Geste (Abbildungen 8.4, 8.5 und 8.6) hin (vgl. auch die Analyse der Sequenz 49).

\subsubsection{Angemessene zeitliche Ressourcen investieren}

Der in diesem Abschnitt analysierte Aspekt unterscheidet sich von Abschnitt 8.2.4.2 dadurch, dass es hier nicht (nur) darum geht, ob Serien kumulativ geschaut werden, sondern vor allem zu welchen Zeiten oder Zeitpunkten und wie viel Zeit grundsätzlich für die Rezeption aufgewendet wird. Implizit wird dabei auch der in Abschnitt 2.1.3 beschriebene Trivialitätsdiskurs (vgl. dazu auch die Analysen in Abschnitt 8.2.2) evoziert, d.h die Frage danach, wie viel Zeit in populärkulturelle Produkte investiert werden kann. Die so bezeichneten zeitlichen Ressourcen für die Serienrezeption werden von den Teilnehmenden in allen Gesprächsdaten teilweise auch mehrfach - thematisiert. Manchmal entstehen derartige Sequenzen auf explizite Fragen hin, z.B. von Leni: „ey eine FRAge so; (.) wenn ihr jetzt so: WOChenende (.) habt ne? wie viele folgen oder STAFfeln würdet ihr schaffen; (Anhang IV: MNG11, Z. 879-882), teilweise ergeben sie sich auch aus anderen Gesprächsthemen heraus. Daraus kann auf der einen Seite Vergemeinschaftung entstehen, wenn die Teilnehmenden sich Anerkennung und Zustimmung für ein hohes zeitliches Engagement aussprechen (Beispiel 49; vgl. auch Beispiel 47). Auf der anderen Seite wird häufig intensiv diskutiert, welcher Serienkonsum interaktiv als (noch) angemessen gilt, vor allem in Bezug auf die Frage, wann zeitlich 
aufwändiger Serienkonsum legitim ist (Beispiele 50 und 51), woraus wiederum Distinktionsaktivitäten resultieren.

(49) zieh ich bis sechs uhr DURCH;

NEL: das ist voll SCHLIMM wenn man dann an seinem HANdy noch is, und dann hat man gar nicht mitbekommen was da so pasSIERT; [=ne, ]

Alle: $[\mathrm{ja} ;]$

((unverständlich, ca. 5 Sek.))

EMI: (das is einfach so;)

wenn richtig SCHÖnes wetter is, du SIEHST einfach so?

(.) du siehst einfach so das schöne WEtter, [aber du bleibst im BETT, (.) weil du so denkst so, $=$ (das is)

JOS: [was wurde denn ((unverständlich)) bei netflix?]

MAR: [((unverständlich)) ]

JOS: [doch gibt es ]

BIL: [ey ich mach das NICHT so;]

(.) ich ich mach immer was ich MAChe?

(.) ne?

und dann [((unverständlich)) ]

NEL: [du machst was du MACHST?] ((lacht))

MAG: [abends wenn es richig gemüTlich is ne?]

BIL: [(aber wenn) wenn es wenn es ]

MAG: $[j a ;]$

BIL: [drei]undzwanzig UHR oder so zwölf uhr, zieh ich bis SECHS uhr durch;

EMI: was ich richtig

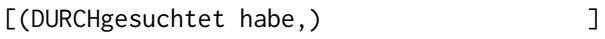

LEN: [(bevor es aber FERien ((unverständlich))]

JOS: ich FIND die briserie richtig intereSANT, aber (.) da k überkommt mich einfach die MÜdigkeit, =da bin ich !WEG; !

((unverständlich, ca. 7 Sek.))

NEL: das ist voll schlimm wenn man bei (.) serien EINschläft? und dann (.) man das einfach nicht mehr MITbekommen hat, JOS: [ja: : ; ]

NEL: [und dann] irgendwann wacht man so auf und dann ist man auf einmal bei staffel DREI; 
Eingeleitet wird die Sequenz von Nelli, die konstatiert, es sei „voll SCHLIMM“ (Z. 950), der Handlung einer Serie nicht mehr folgen zu können, weil man mit dem Handy beschäftigt ist (Z. 951), wofür sie von der Gruppe Zustimmung erhält (Z. 952). Emilia führt anschließend scherzhaft gerahmt mittels einer Inszenierung vor, welchen Effekt das Serienschauen hat, wenn draußen eigentlich schönes Wetter ist, sie aber der Serie wegen im Bett bleibt (Z. 954-960). Daraufhin produziert Bilel einen starken Kontrast („ey ich mach das NICHT so“, Z. 964), indem er erläutert, dass er Serien nur zu bestimmten Zeiten intensiv anschaut (Z. 973). Josefine bedauert es, zu den von Bilel genannten Zeiten während der Rezeption immer einschlafen zu müssen (Z. 978-981), wofür sie Zustimmung erhält (Z. 983-987). Dazu folgen keine interaktiven Reaktionen mehr, sondern die Sequenz wird durch Martha beendet, die das Thema auf das Genre der Kriminalserien lenkt (Z. 988). Angemessene zeitliche Ressourcen verhandeln die Teilnehmenden hier unter dem Gesichtspunkt, dass Serienrezeption Zeit benötigt, in der sie sich mit nichts anderem beschäftigen. Dieser Aspekt wird als problematisch bewertet und unter der Frage diskutiert, wie sie mit konkurrierenden Aktivitäten (Handynutzung, nach draußen gehen, schlafen) umgehen ${ }^{16}$ - insbesondere unter der Bedingung, dass Serien das Verlangen nach Fortsetzung auslösen (vgl. Abschnitt 8.2.4.2). Lenis Äußerung, die das Wort „FErien“ (Z. 977) beinhaltet, bleibt leider aufgrund von Überlappungen unverständlich. Aus dem Kontext könnte eventuell geschlossen werden, dass sie einwendet, nächtelanges Serienschauen sei nur in den Ferien möglich. Bilel präsentiert seine Strategie, Serienrezeption zeitlich so zu priorisieren, dass er nachts schaut, wenn keine anderen Verpflichtungen anstehen (Z. 964-973). Dafür erhält er zwar wohlwollende Zustimmung, allerdings wird sein Vorschlag auch als nicht praktikabel behandelt (Z. 975-976). Hieran zeigt sich, dass die Ressource Zeit zur Vergemeinschaftung über geteilte Erfahrungen funktionalisiert werden kann, die darin besteht, zwar den Wunsch nach Fortsetzung zu einer spannenden Serie zu haben (Z. 972-974; vgl. auch Beispiele in Abschnitt 8.2.4.2), aber - leider - über nicht ausreichend zeitliche Ressourcen dafür verfügen zu können (Z. 978-986). Insbesondere in dieser Gruppe fallen Thematisierungen des Zeitaufwands sehr kooperativ aus und dienen zum gemeinsamen Amüsieren und zur Scherzinteraktion. Es ist aber auch andersherum möglich, dass bei Dissens über die den meisten

16 Vergleichbar mit der hier diskutierten Kontrastierung ist auch Leons Unterscheidung zwischen „aktivem“ und „passivem“ Serienschauen in Beispiel 32, Abschnitt 7.3.3. 
Fällen zugrundeliegende Prämisse - wenn Freizeit zur Verfügung steht, ist es legitim, sie mit Serienkonsum zu füllen - Fremdpositionierungen entstehen:

(50) wie viel GUCKST du denn da(h)ann,

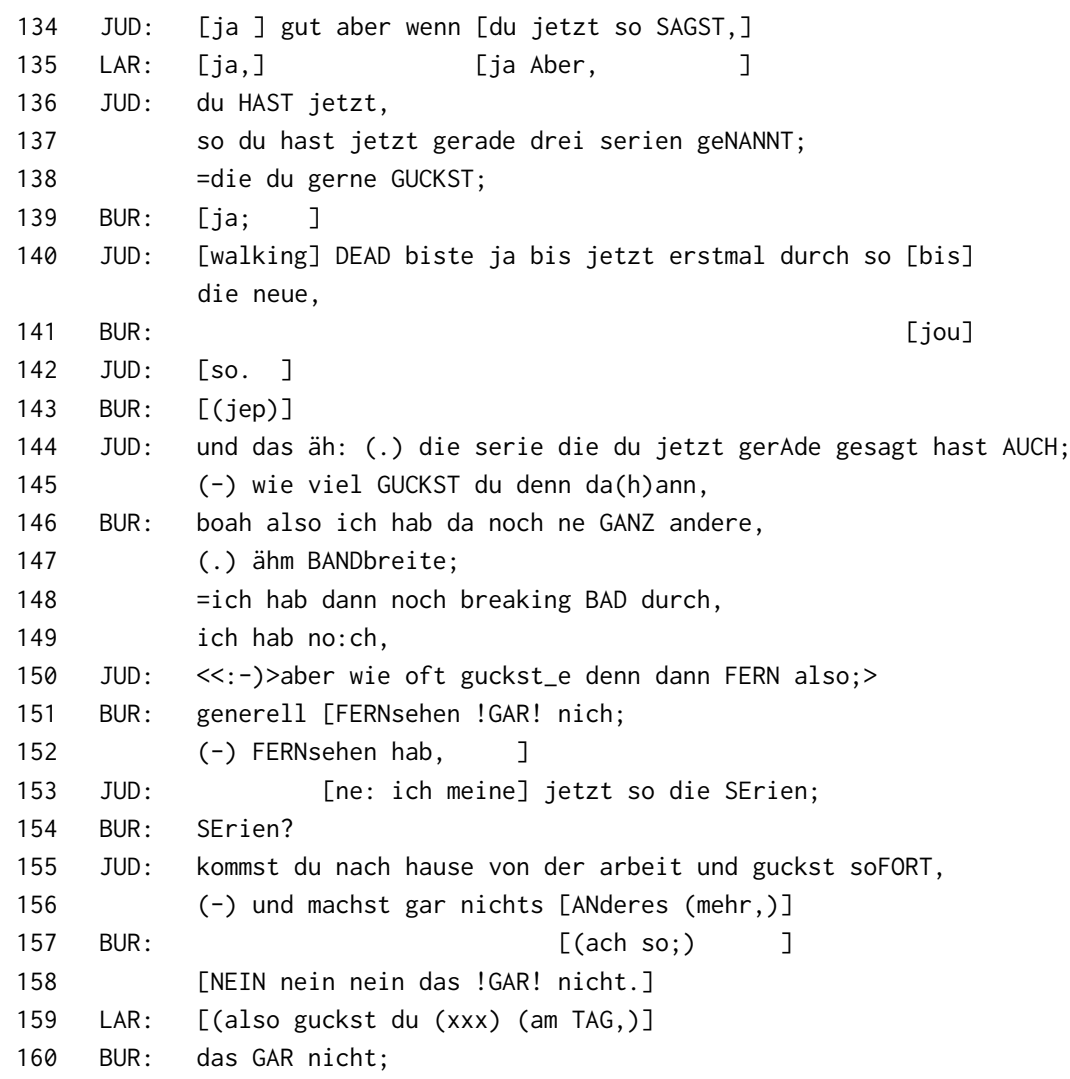

In dieser Sequenz fallen der Sucht-Aspekt, damit einhergehende moralische Implikationen und die Frage danach, wie viel Zeit für den Serienkonsum als angemessen gilt, zusammen. Der analytische Fokus liegt im Folgenden auf der diesbezüglichen Etablierung der Fremdpositionierung von Judith gegenüber Burim, die sie über eine längere Sequenz hinweg vorbereitet und die er zunächst nicht als solche behandelt bzw. auf einer anderen Ebene zurückweist. Zunächst paraphrasiert Judith die vorherigen Aussagen Burims (Z. 134-142), mit denen sie seine Serienrezeptionsgewohnheiten verständnissichernd zusammenfasst. Er bestätigt sie jeweils, 
allerdings kommt es dabei zu mehreren Reparaturen (Z. 144-158). Schließlich fragt Judith ihn, ob er „gar nichts ANderes mehr,“ (Z. 156) machen würde, was er negiert (Z. 157-160).

Judiths Gestaltung ihrer Äußerungen - ähnliche Intonationskontur, die rhythmische Strukturierung durch Mikropausen, die Lachpartikel in „dann“ (Z. 145), die Verwendung von „denn“ sowie die insgesamt mit einer „Smiling Voice“ intonierte Äußerung „aber wie oft guckst_e denn dann FERN also;“ (Z. 150) - setzen eine Antwortverpflichtung in hohem Maße konditionell relevant (vgl. auch Deppermann 2009). Insgesamt forciert sie eine Rechtfertigung von Burim zu der implizit mitschwingenden moralischen Frage: Ist es legitim, ,so viele Serien` zu schauen? Tatsächlich jedoch scheint Burim Judiths Aussage zunächst als positive Zuschreibung aufzufassen, da er sich als vielseitig interessierter Serienrezipient positioniert: „ich hab noch ne GANZ andere, (.) hm BANDbreite;“ (Z. 147), d.h. sich grundlegend als wissender Unterstützer von Serien darstellt. Zugleich grenzt er sich von ihr ab, da er Serien gucken und Fernsehen gucken als Oppositionen etabliert (Z. 151), während Judith beides offenbar synonym verwendet. Erst als durch Judiths mehrfache Reparaturen erkennbar wird, dass ihre Fremdpositionierung anders gemeint war (Z. 150, 153), weist Burim ihre Unterstellung von sich und relativiert seine Äußerung mit der Einschränkung, er würde „nur am WOCHenende“ (Z. 162) Zeit in Serien investieren. Es schließt sich eine Diskussion der ganzen Gruppe an, innerhalb derer sich Judith, Lara und Niko zum Teil mit viel Formulierungsaufwand (vgl. z.B. Anhang I: EMS51, Z. 190-201) als Rezipient`innen positionieren, die Serienkonsum stets die niedrigste Priorität einräumen (Z. 213-225, 205-209). Während Stephanie und Burim zunächst noch dagegen argumentieren (Z. 163-175, 184-187), partizipieren sie kurz darauf aber nicht mehr oder nur minimal an der Interaktion ( vgl. Abschnitt 6.2.1). So endet die Sequenz mit dem Konsens der drei hauptsächlich Interagierenden, dass sie Serien überwiegend abends anschauen, wenn sie dafür Zeit haben (Z. 226-237). In dem folgenden Beispiel wird deutlich, wie die Aushandlung des Faktors Zeit auch potentiell face-bedrohend werden kann:

(51) wie viel ZEIT habt ihr;

\begin{tabular}{|c|c|c|c|}
\hline 463 & MOR: & \multicolumn{2}{|c|}{ [wahrscheinlich ((unverständlich))] } \\
\hline 464 & SIM: & \multicolumn{2}{|c|}{$<<$ lachend $>$ [wie viel ZEIT habt ihr, $>$ ] ((lacht)) } \\
\hline 465 & ?: & {$[(($ unverständlich)) } & ] \\
\hline 466 & SAS: & [(lass sie REden;) & ] \\
\hline 67 & \multicolumn{2}{|c|}{$(($ lachen $))$} & \\
\hline 468 & ALE: & \multicolumn{2}{|l|}{ [guck ich halt ne folge; ] } \\
\hline 469 & NOR: & \multirow{2}{*}{\multicolumn{2}{|c|}{$\begin{array}{l}\text { [und du spielst in dEr zeit,] } \\
\text { HIER:=ne. }\end{array}$}} \\
\hline 470 & & & \\
\hline
\end{tabular}




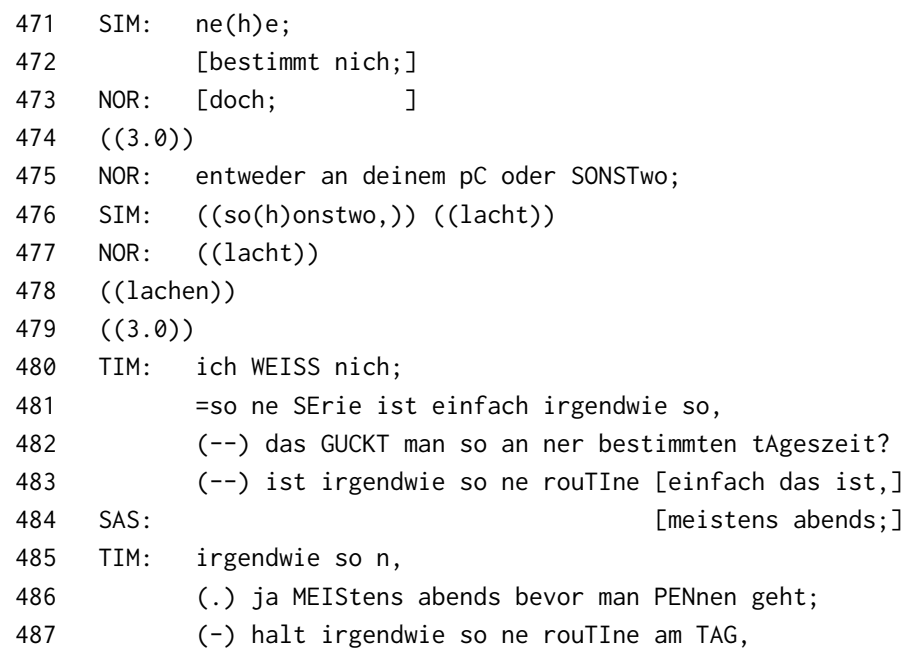

Kontextualisiert ist diese Sequenz in eine Belustigungsaktivität zwischen Norbert, Tim, Hendrik, Moritz und Alex über diverse Serien, die auf Pro Sieben ausgestrahlt werden, und deren Qualität (Anhang II: EMS53, Z. 443-463; vgl. dazu auch Abschnitt 8.2.2). Daraufhin fragt Simon lachend in die Runde, „wie viel ZEIT“ (Z. 464) die anderen hätten. Vergleichbar mit der Fremdpositionierung von Judith in Beispiel 50 behandelt Norbert nun Simons Äußerung so, als habe er die zeitlichen Prioritäten der Gruppe moralisch in Frage gestellt. Die dann seinerseits etablierte Fremdpositionierung ,und du spielst in $\mathrm{dEr}$ Zeit, HIER; =ne, an deinem $p C$ oder SONSTwo;“ (Z. 470, 475) markiert einerseits Simons Äußerung als kontextuell unangemessen - denn er hat nicht an der vorherigen Vergemeinschaftungsaktivität partizipiert, in der sich die Gruppe über einzelne Serien amüsiert - und hebt andererseits das Gespräch auf eine ironische und mit sexuellen Anspielungen versehene Ebene. Dadurch etabliert er nicht nur Distinktion, sondern kreiert zugleich eine potentiell für Simon face-bedrohende Situation. So betreiben Simon und die Gruppe zunächst face-work (Z. 476-478), bevor Tim inhaltlich Simons Äußerung aufgreift. Vergleichbar mit den Beispielen 49 und 50 wird das abendliche Serienschauen als legitim behandelt (Z. 480-488).

Insgesamt sind in den vorliegenden Daten solche face-bedrohenden Aktivitäten selten; die Teilnehmenden legen stattdessen überwiegend Wert auf Kooperativität, Partizipation und Vergemeinschaftung (vgl. Abschnitt 6.1.2). Auch in anderen Sequenzen der Daten werden Viel- und Intensiv-Rezipient*innen ohne Zwischensequenzen oder Reparaturen positiv ratifiziert (vgl. u.a. Beispiele 49 oder 
47). Dennoch zeigt sich, dass Zeit auf einem Kontinuum der Angemessenheit der Serienrezeption verortet wird und damit auch zu Distinktionszwecken funktionalisiert werden kann, indem es moralisch aufgeladen wird. (Beispiel 50 und 51). Teilweise wenden die Jugendlichen viel Formulierungsaufwand für Rechtfertigungen von zeitintensivem Serienkonsum auf, wie beispielsweise Sophie, die angibt, mit ihrer Schwester zusammen Serien zu schauen, auch wenn sie eigentlich noch viel zu tun hätte (vgl. Anhang VI: RHG10, Z. 363-367). Als angemessen wird offenbar ein hoher zeitlicher Aufwand für Serienkonsum vor allem abends oder nachts akzeptiert ${ }^{17}$ sowie dann, wenn die Jugendlichen Freizeit in Form von Schulferien zur Verfügung haben: „das kannst_e echt sechs wochen lang DURCH machen;“(vgl. Anhang II: EMS53, Z. 663; vgl. auch Lenis Äußerung in Beispiel 49, Z. 977) oder JAN: "wenn man gerade nix besseres zu TUN hat dann eigentlich schon;" (Anhang VI: RHG10, Z 327) und FRI: „so (.) kurz vor den SOMmerferien,=wo eigentlich nichts mehr pasSIERT da; da HAT man eben nichts mehr zu tun;“ (RHG10, Z. 342-345). Viel Zeit in Serienrezeption zu investieren scheint also dann legitim zu sein, wenn alltägliche Pflichten wie Arbeit oder Schule aufgrund von ungewöhnlichen Umständen (Krankheit, Ferien) nicht vernachlässigt werden - denn das wäre Leon zufolge „natürlich nich GUT“ (RHG10, Z. 353-372). Letztlich sind sich die Jugendlichen meistens darin einig, dass Serien nicht der „HAUPTbestandteil“ ihres Lebens (RHG10, Z. 373; vgl. auch Anhang I: EMS51, Z. 213-225) sind.

\subsubsection{Angemessene Wahl der Audiospur}

In Zeiten des optionalisierten Serienkonsums und einer transnationalen Serienkultur ist es jederzeit möglich, Serien in der Sprache ihres Produktionsorts anzuschauen bzw. Untertitel bei Bedarf ein- oder auszublenden (vgl. Abschnitt 2.1.2). Diesen Aspekt thematisieren die Jugendlichen, indem sie einander fragen, ob sie Serien (lieber) auf Deutsch oder auf Englisch schauen. Die folgenden drei Beispiele veranschaulichen, dass damit nicht immer ein reiner Erfahrungsaustausch verbunden sein muss, sondern dass die Wahl der Sprache häufig in argumentative Sequenzen eingebettet ist, die sich auf die technischen Möglichkeiten des Umschaltens (Beispiel 52), Varietäten des Englischen (Beispiel 53) und die erforderlichen Sprachkompetenzen (Beispiel 54) beziehen.

17 Allerdings kann auch das als unangemessen behandelt werden, denn als Jan erläutert: „guck ich schon mal so irgendwie vier folgen am STÜCK; =irgendwie NACHTS; “(Anhang VI: RHG10, Z. 317318) schaut Leon ihn daraufhin ,entsetzt‘ an. 
(52) EINmal, ENGlisch bitte;

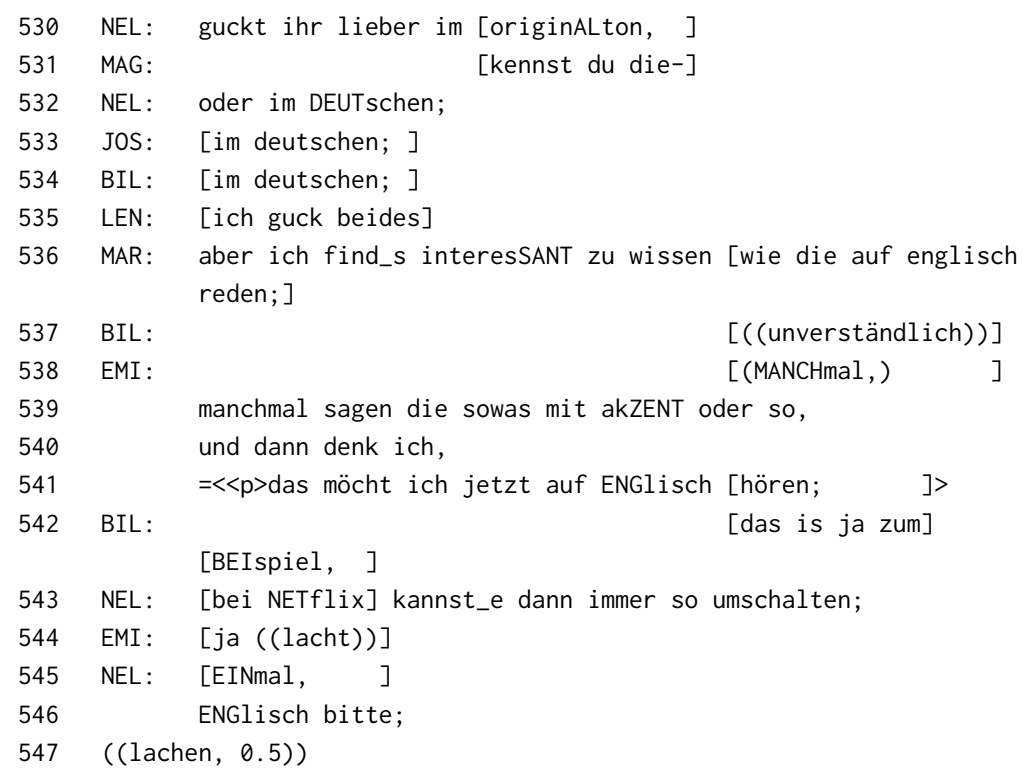

Nelli initiiert die Sequenz, indem sie die anderen fragt, ob sie lieber im „originAlton, oder im DEUTschen; “ (Z. 530) Serien anschauen. Die meisten Gruppenmitglieder antworten nahezu unisono, dass sie Deutsch präferieren (Z. 532-535) und beginnen dann zu elaborieren, wann sie auf Englisch umschalten (Z. 536-547). So findet Martha es „interesSANT zu wissen wie die auf englisch reden;“ (Z. 536). Das Kriterium der Verständlichkeit wird hier anders als in den Beispielen 53 und 54 nicht angeführt, stattdessen scheint es sich eher um eine punktuell zu stillende Neugier auf die Originalfassung zu handeln. Emilia und Martha elaborieren diesen Aspekt interaktiv weiter und bewerten es positiv, dass sich bei Streaming-Plattformen wie Netflix unkompliziert der Ton umstellen lässt. Schließlich inszeniert Nelli per Redewiedergabe, wie sie Netflix auffordert, die Sprache auf Englisch zu verändern (Z. 543-546). Das gemeinsame Lachen signalisiert, dass hier Konsens herrscht und sich die Beteiligten über ihre geteilte Einschätzung der präferierten Sprache vergleichbar mit Beispiel 53 vergemeinschaften.

(53) normAlerweise guckst du auf DEUTSCH?=oder.

$\begin{array}{ccc}782 & \text { SOP: } & \text { aber sonst }[\text { guckst du auf ] DEUTSCH? } \\ 783 \text { OLI: } & {[(\text { aber ich weiß, })]}\end{array}$




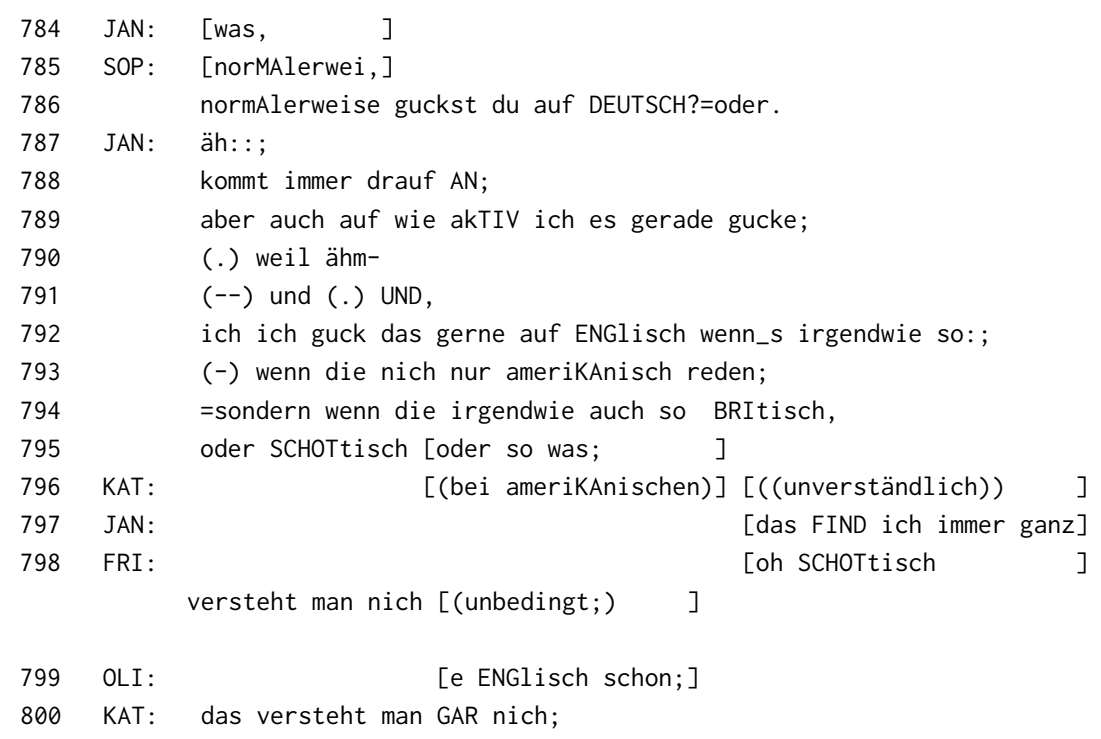

Die Gruppe hatte bereits einige Minuten zuvor die Frage nach der bevorzugten Sprache gestellt, dann jedoch interaktiv den Fokus auf Qualität von Soaps verschoben (vgl. Analysen in Abschnitt 7.3.3, 8.1.3 und in 8.2.2). An dieser Stelle adressiert nun Sophie Jan - nach dessen Ausführungen, dass er GAME of THRONEs am liebsten auf Englisch schaut (vgl. auch Abschnitt 9.1) - mit der Frage, ob er Serien denn ansonsten üblicherweise auf Deutsch schauen würde (Z. 782-786). Jan bezieht sich implizit in seiner Antwort auf Leons Kontrastierung zwischen aktivem und passivem Rezipieren (Z. 787-791; vgl. dazu auch Beispiel 32). Als weiteres Kriterium zur Auswahl der Sprache führt er dann die sprachlichen Varietäten der Schauspieler^innen an (Amerikanisch, Britisch, Schottisch) (Z. 792-795), woraufhin sich eine kurze Aushandlungssequenz bezüglich der Verständlichkeit einzelner Sprachen anschließt. ${ }^{18}$ Schließlich vergemeinschaftet sich die Gruppe über die Verständigung der geteilten Wahrnehmung und Bewertung der Varietäten. Jan, Katharina und Friederike positionieren sich zudem als $K^{+}$, indem sie signalisieren, über serienexternes Wissen zu verfügen (vgl. Abschnitt 7.1.2). Die Verständlichkeit fremdsprachiger Serien wird auch im folgenden Beispiel diskursiv bearbeitet.

18 Obgleich eine Analyse dieser Äußerungen aus sprachideologischer Perspektive (vgl. dazu in Ansätzen die Ausführungen in Abschnitt 3.2.4.3) sicherlich aufschlussreich wäre, würde sie an dieser Stelle leider zu weit führen. 
(54) ja aber wir sind doch keine MUTtersprachler;

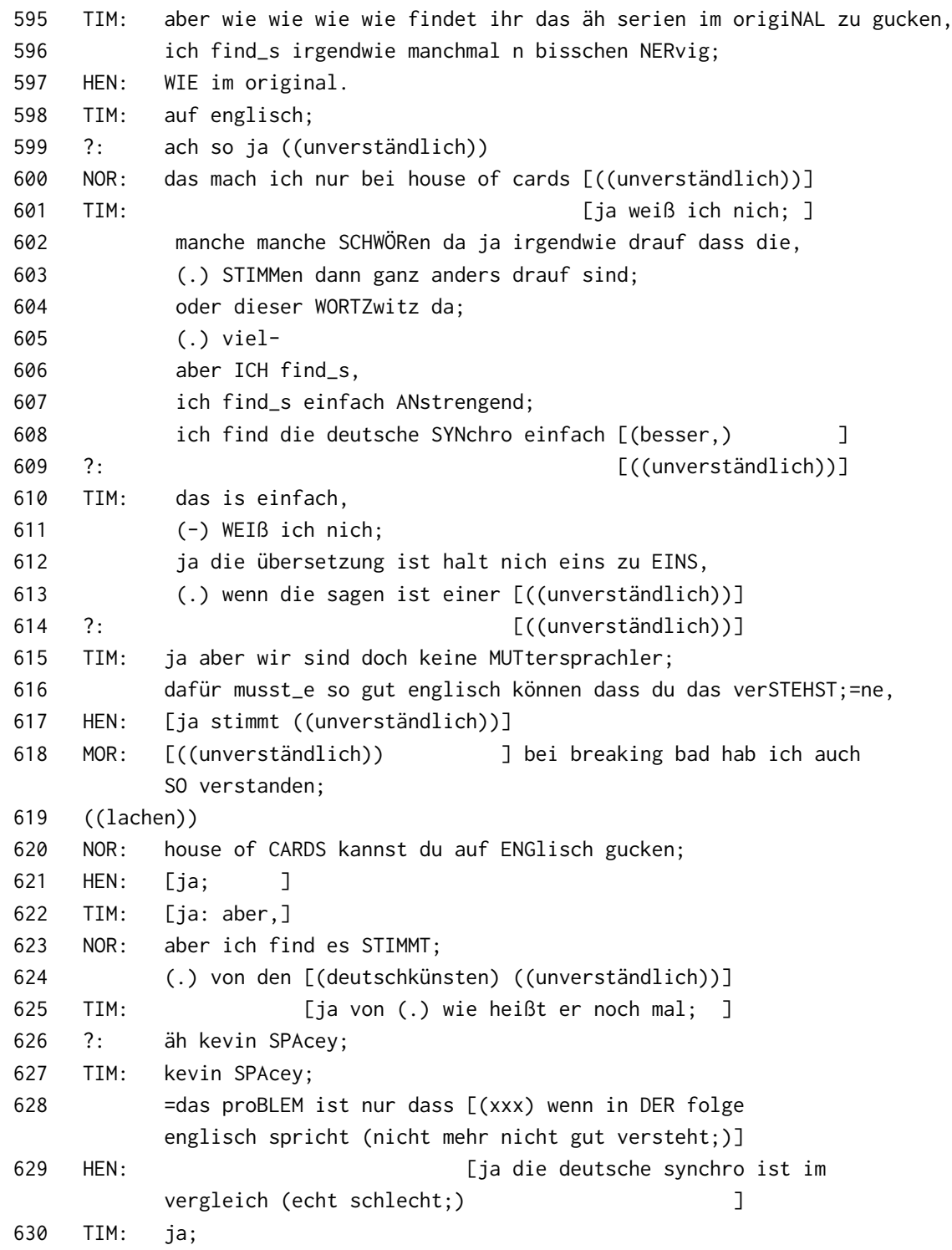

EMS53, 10:56-12:01

Tim erfragt die Sprachwahl der anderen Gruppenmitglieder (Z. 595-598) und erläutert seine eigenen Präferenzen (Z. 596-616), woraufhin Serien diskutiert werden, 
die in englischer Sprache rezipiert werden können (Z. 617-630). Anders als Nelli in Beispiel 52 macht Tim nicht nur ein Positionierungsangebot mit seiner Frage nach der rezipierten Sprache (Z. 595), sondern positioniert sich selbst direkt im Anschluss explizit kritisch dazu (Z. 596). Er distanziert sich von Personen, die „da ja irgendwie drauf [SCHWÖren] “ (Z. 602). Damit verwendet er die Praktik des Berufens auf die Bewertungen anderer (Abschnitt 7.2.2) und zitiert Unterstützer*innen, die Serien im Original anschauen, mit deren Argumenten, die die Andersartigkeit der Stimmen und den Wortwitz betreffen. Demgegenüber positioniert er sich kontrastiv mit der Begründung, dass er es „einfach ANstrengend“ (Z. 607) und die „deutsche SYNchro einfach besser“ (Z. 608) fände. Die Verwendung von „einfach“ deutet an, dass er für seine Bewertung keine Begründungs- oder Elaborierungsnotwendigkeit sieht, was die anderen Teilnehmenden allerdings nicht ratifizieren. Zwar sind die Beiträge leider weder akustisch verständlich noch einem konkreten Sprecher zuzuordnen (Z. 609, 614), dennoch geht aus dem Kontext hervor, dass offenbar jemand Tim widerspricht, sodass er doch weitere Erklärungen für seine Präferenz angibt. In diesem Zuge erläutert er, dass es für ein adäquates Verständnis einer Serie im Original notwendig sei, die Sprache auf nativem Niveau zu beherrschen (Z. 610-616). Auch wenn ihm manche Teilnehmer zustimmen (Z. 617), führen sowohl Moritz mit BREAKING BAD (Z. 618) als auch Norbert mit HousE of CARDs (Z. 620) Serien an, die sie selbst auf Englisch verstanden haben, und widerlegen so seine Behauptung. Potentiell geht damit auch eine face-Bedrohung gegen Tim einher, da sie zugleich implizit seine Englischkenntnisse kritisieren. Dennoch einigt sich die Gruppe im Folgenden auf die Bewertung der Qualität der Synchronisation von Kevin Spacey, der Frank Underwood spielt (Z. 623-630).

Während in den Beispielen 53 und 52 die Vergemeinschaftung über die Bewertung der Sprachwahl stattfindet, nutzt Tim diese Frage zur Distinktion von einer nicht anwesenden Gruppe, um sich in Relation dazu zu positionieren. Ausschlaggebendes Kriterium ist vor allem die (inhaltliche) Verständlichkeit, wofür sicherlich auch das Alter der Teilnehmenden eine Rolle spielt (die Schüler aus der Gruppe EMS53 sind älter als die der Gruppen MNG11 und RHG10). Mit der Diskussion von Spracheinstellungen (im doppelten Wortsinn!) ergibt sich eine Ambivalenz, der jedoch aufgrund der Datengrundlage nur in begrenztem Maße empirisch nachgegangen werden kann: Es ist den Jugendlichen offenbar bewusst, dass es bestimmte Wertungen gibt, die mit englischsprachiger Rezeption einhergehen, z.B. Wortwitz, der besser übertragen wird, Stimmen, die authentischer klingen (Beispiel 54 und 52) usw. Dennoch signalisieren sie eine Präferenz für die Rezeption auf Deutsch, weil sie Englisch zuschreiben, viel Konzentration und gute rezeptive Sprachkenntnisse zu erfordern. 


\subsubsection{Zusammenfassung: Normative Vorstellungen}

In den in diesem Kapitel analysierten Gesprächsdaten wird Distinktion über nicht geteilte oder in Frage gestellte Bewertungen und/oder Erfahrungen hergestellt, was sich auf der interaktiven Oberfläche in erhöhtem Formulierungsaufwand, Rechtfertigungen und Disclaimer $n$ manifestiert. Vergemeinschaftung etablieren die Interagierenden dagegen über die wechselseitige Vergewisserung und Bestätigung als geteilt angenommenen Rezeptionsverhaltens und -wahrnehmens. Normative Vorstellungen werden dabei auf den drei Ebenen der Serie, der Gruppe und des Individuums diskursiv bearbeitet. Auf der Ebene der (Rezeptions-)erwartungen an Serien vergemeinschaften sich die Teilnehmenden beispielsweise über die geteilte Erwartung, dass das fiktive Weltkonzept in sich stimmig sein sollte (Abschnitt 8.2.1). Distinktion findet dann statt, wenn zwar der gleiche Maßstab angelegt wird, aber Serien unterschiedlich dementsprechend bewertet werden. Dieser Unterschied kann in argumentativen Sequenzen aufgelöst werden, wenn die Teilnehmenden Begründungen für die Nicht-Nachvollziehbarkeit angeben. Außerdem zeigen die Beteiligten, dass Serientypen unterschiedliche Rezeptionsmodi nahelegen (Abschnitt 8.2.2). Sie kategorisieren Serien und Serientypen diskursiv bzw. stellen als geteilt angenommenes Wissen und Bewertungsmaßstäbe zur Disposition. Darüber können komplexe Positionierungssequenzen entstehen. Auf der einen Seite kann Vergemeinschaftung über einen als geteilt behandelten Geschmack hergestellt werden und es können auch Vergemeinschaftungsangebote an diejenigen adressiert werden, denen der ,bessere‘ Geschmack zugeschrieben wird. Auf der anderen Seite bieten sich dabei auch vielfältige Distinktionsmöglichkeiten. Hier zeigt sich die Gratwanderung zwischen Individualität und Gemeinschaft: Das Wechseln zwischen doing togetherness und doing being extraordinary muss sorgsam an die kontextuellen Anforderungen angepasst und abgestimmt werden.

Weiterhin werden normative Vorstellungen auf der Ebene der Gruppe sichtbar. So ist die implizit oder explizit vereinbarte Gruppennorm, während der Diskussionen einander nicht zu spoilern, im common ground verankert. Wenn diese Norm verletzt wird, findet keine Vergemeinschaftung statt, sondern überwiegend Distinktionsaktivitäten und es werden Reparaturen erforderlich. Andersherum muss ein Spoiler interaktiv auch erst als solcher produziert und ratifiziert werden. Die Analysen zeigen ebenfalls, dass wechselseitig bestätigtes Spoilern performativ in Szene gesetzt werden kann (Abschnitt 8.2.3).

Schließlich werden normative Vorstellungen auf der Ebene des individuellen Rezeptionsverhaltens bearbeitet. Die vier von den Teilnehmenden unter der Frage nach der Angemessenheit ihres Rezeptionsverhaltens diskursiv bearbeiteten Aspekte lassen sich als emotionale Erlebnisqualität (Abschnitt 8.2.4.1), Intensität (Abschnitt 8.2.4.2) und zeitlicher Aufwand (Abschnitt 8.2.4.3) sowie Auswahl der 
Audiospur (Abschnitt 8.2.4.4) rekonstruieren. Es erscheint akzeptabel - und durchaus erwünscht -, auf emotionalisierende Inhalte entsprechend zu reagieren, aber nicht $z u$ emotional. Es erscheint akzeptabel, viel Zeit in Serienrezeption zu investieren und Serien kumuliert anzuschauen, aber nicht $z u$ viel Zeit dafür aufzuwenden bzw. abzuwägen, ob nicht andere Dinge für die zur Verfügung stehende Zeit priorisiert werden sollten. Es erscheint akzeptabel, Serien in ihrer Synchronfassung zu konsumieren, allerdings wird es teilweise präferiert behandelt, sie auf Englisch anzuschauen. Über das tatsächliche Rezeptionsverhalten der Schüler`innen kann aus der Analyse heraus keine Aussage getroffen werden, da die Teilnehmenden retrospektiv bzw. iterativ ihre Gewohnheiten und Präferenzen schildern und sie miteinander abgleichen. Dabei werden ihre Bemühungen deutlich, die Balance zu halten und ein diskursiv als angemessen behandeltes Rezeptionsverhalten zu kommunizieren. Ausschlaggebend dafür für als angemessen behandelte Aspekte sind zum einen der jeweils hergestellte Kontext und zum anderen die erste Positionierung, an der sich die anderen Beteiligten ausrichten.

\subsection{Bündeln prototypischer und normativer Vorstellungen von Serialität und Serienrezeption: „das ist aber ja bei JEder serie so" als argumentative Ressource zum Distinktionsmanagement}

In Abschnitt 8.1.1 wurde herausgearbeitet, dass die Teilnehmenden gelegentlich die Grenzen des Gesprächsgegenstands ausloten: Welches Produkt ist (noch) ein Film, welches (schon) eine Serie? Anhand der darauf folgenden Abschnitte 8.1.2 bis 8.1.5 konnte gezeigt werden, dass sie sich an prototypischen Vorstellungen serielle Erzählungen und Produktionen betreffend orientieren, während Aspekte der Serienrezeption ebenfalls typischen, aber insbesondere normativen Vorstellungen unterliegen (Abschnitt 8.2). Sowohl prototypische als auch normative Vorstellungen verdichten sich in fast allen Gesprächen des Korpus in Varianten der formelhaften Wendung „das ist (doch/aber/ja) bei jeder Serie so“ (vgl. z.B. Beispiel 48, Z. 106 oder Beispiel 38, Z. 941). Gesprächsorganisatorisch verschieben Teilnehmende damit das Positionierungsobjekt meistens von einer konkreten Serie auf eine abstraktere Ebene (vgl. Abschnitt 6.5.1). Zudem kommen einer so formulierten Äußerung zwei Funktionen für die Interaktion zu: Zum einen kann über das Anzeigen von Wissen darüber, was typischerweise Serien und Serienrezeption kennzeichnet, ein hoher epistemischer Status kommuniziert und so epistemische Autorität beansprucht werden. Zum anderen kann dieses Wissen wiederum als argumentative Ressource zum Distinktionsmanagement 
funktionalisiert werden. Beides wird anhand des folgenden Fallbeispiels - das repräsentativ für die Kollektion steht - analysiert:

(55) ja stirbt da nich jede zweite folge irgend eine figur,

651 ALI: jeder ZWEIte guckt the walking dead;

652 IGD: nein ich [guck das nich; ]

653 GIS: [nein ich guck das] AUCH nich;

654 DAV: (ey ich [AUCH nich;)]

655 ALI: [das is ] HAMmer,

656 das is HAMmer die serie;

657 GIS: zu brutal;

658 IGD: true detective

659 ALI: [das DING is, ]

660 GIS: [du GUCKST das?]

661 ALI: die die figuren in der serie in dieser serie die sind richtig krass;

662 PAU: [nei(h)in; ]

663 IGD: [prison break;]

664 ALI: RICHtig krass [(sind die) ]

665 TUF: [prison break] guck ich AUCH;

666 DAV: ja stirbt da nich jede zweite folge irgend eine figur,

667 ALI: ja [((unverständlich)) ]

668 PAU: [ja die einzige diskusSION immer,]

669 WER is gestorben;

670 wer is gestorben,

671 wer is gestorben;

672 DAV: ja ja desWEgen;

673 (-) SAG mir nich wer geSTORben ist;

674 ALI: aber das sind DIE,

675 die von anfang an DA sind;

676 (.) je LÄNger die serie andauert,

677 desto $\mathrm{d} d \mathrm{~d}$ [mehr, ]

678 DAV: [das is] aber ja bei JEder serie so;

679 [damit kannst du, ]

680 ALI: [nein das is nich bei jeder serie so]

681 DAV: [doch; ]

682 GIS: [ALI ALI guckst du anime,]

683 ALI: was

684 GIS: guckst du Anime;

685 ALI: nein anime guck ich nich;

MNG13, 12:09-12:35

Ali elaboriert seine positive Bewertung der Serie THE WALKING DEAD (Z. 651-661), die die anderen Gruppenmitglieder vor allem im Hinblick auf sterbende Figuren 
abweichend bewerten (Z. 662-673). Es schließt sich eine Diskussion an, inwiefern sich das Kommunikationsverhalten von Rezipient*innen bei verschiedenen Serien unterscheidet (Z. 674-681), bevor die Sequenz durch Etablieren eines neuen Positionierungsobjekts von Gisem beendet wird (Z. 682-684).

Ali nutzt die hohe Anzahl der Zuschauer*innen von THE WaLKING DeAD zusätzlich als Begründung für seine eigene Präferenz der Serie (Z. 651-665). Mit der generalisierenden Formulierung ,jeder ZWEIte guckt the walking dead;“ (Z. 651) bereitet er die folgenden Generalisierungen vor. Er erhält wenig Zustimmung für seine Äußerung (Z. 652-654), stattdessen versucht Tufan mit PRISON BREAK erfolglos, ein neues Positionierungsobjekt zu etablieren (Z. 663, 665; Abschnitt 7.2.3). Schließlich greift David Alis generalisierende Formulierung ,jede(r) zweite " auf und fordert die Ratifizierung partiellen Wissens ein (Z. 666, Abschnitt 7.2.1). Paul stimmt ihm zu, indem er iterativ agenslose Diskussionen über die Serie karikiert (Z. 669-671), wofür er Affirmation von David erhält (Z. 672-673). Beide belustigen sich über die Serie und signalisieren damit zugleich, sie nicht zu mögen; sie positionieren sich also oppositionell zu Ali als Kritiker. Der wiederum festigt seine evaluative Positionierung und beansprucht Expertise, indem er dafür plädiert, die Mortalitätsrate der Figuren differenzierter zu betrachten (Z. 661, 674-677). An dieser Stelle unterbricht ihn David mit der Äußerung „das is aber ja bei JEder serie so;“ (Z. 678), dessen generalisierendem Anspruch Ali widerspricht (Z. 680). Davids Reaktion (Z. 681) wird hier nicht weiter ausgeführt, da Gisem Ali mit der Frage adressiert, ob er Anime-Serien (Z. 684) schauen würde. Prototypische und normative Vorstellungen fallen in Davids Äußerung folgendermaßen gebündelt zusammen: Prototypische Vorstellungen beziehen sich auf die Prämisse, dass Serienfiguren üblicherweise „krass“ - also z.B. erwartungsnonkonform zu sterben - von Produktionsseite aus konzipiert werden. Zugleich signalisiert er implizit normative Vorstellungen dahingehend, dass Rezipient`innen Serienfiguren üblicherweise deswegen auch als „krass“ wahrnehmen bzw. diesen Aspekt so kommunizieren.

Zum einen beansprucht David als unwissender Kritiker der Serie (Z. 654) mit dieser Formulierung epistemische Autorität, indem er sie mit hoher epistemischer Gewissheit als typische Serie klassifiziert und diesem Wissen auch eine hohe Glaubwürdigkeit zuweist, da er es als geteilt behandelt (,ja“, Z. 678). Mit dieser Formulierung besteht also die Möglichkeit, den eigenen epistemischen Status hochzustufen. Zum anderen betreibt David darüber auch Distinktionsmanagement: Ali hatte zuvor die Figuren in THE WALKING DEAD als herausragend und besonders markiert (Z. 647-677). Indem er die Serie als besonders positioniert, positioniert er zugleich sich selbst auch als ,individueller Serienrezipient'. Wenn David jetzt also der Serie den Status des Besonderen abspricht - u.a. indem er das Positionierungsobjekt von konkret zu abstrakt verschiebt -, fremdpositioniert er ebenfalls Ali und torpediert 
gewissermaßen dessen Distinktionsbemühen als doing being extraordinary . Im gleichen Zuge grenzt er sich durch nicht mit Ali geteilte Bewertungen von ihm ab.

Diese Struktur kann auch in anderen Sequenzen der Kollektion beobachtet werden. Wenn jemand einen seriellen Aspekt wie etwa Figurentypen, ${ }^{19}$ Figurenkonzeption ${ }^{20}$ oder ein Rezeptionsverhalten, wie z.B. den Wunsch nach Fortsetzung ${ }^{21}$ oder auch, dass es immer eine gewisse Anzahl an Fans einer Serie gibt, ${ }^{22}$ als einzigartig modelliert, kann diese widersprechende Formulierung - insbesondere unter Verwendung epistemischer Gewissheit markierender Partikeln wie „doch“ oder ,ja“ - dazu verwendet werden, diese Singularität in Frage zu stellen. So kann dieses Ergebnis jedenfalls vor dem Hintergrund der meisten Studien zum Generalisieren interpretiert werden, die sich überwiegend auf Personenkategorien in der Redewiedergabe beziehen. Beispielsweise zeigt König (2013: 209), dass mit dem Generalisieren „die wiedergegebene Rede nicht als ein singuläres, sondern als ein wiederkehrendes und somit, generelles“ Redeverhalten der genannten Person oder einer Personenkategorie kontextualisiert" wird. Auch die Modellierung von Spitzmüllers stance-Dreieck basiert darauf, dass sich etwas über das stance object erfahren lässt, indem Personentypen in generalisierender Weise stilisiert werden (vgl. Abschnitt 3.2.4.3).

\subsection{Zusammenfassung: Positionieren mit globaler Reichweite: Vergemeinschaftung und Distinktion entlang medien- und rezeptionsbezogener Aspekte}

In Abschnitt 8.1 wurden medienproduktbezogenen Elemente beschrieben, die von den Teilnehmenden in (fast) allen Gruppen unter Bezugnahme auf prototypische Vorstellungen relevant gesetzt wurden. Dazu gehört beispielsweise, Serialität als Formprinzip zu modellieren und Serienästhetik über ihre Abgrenzung zur Werkästhetik zu definieren (Abschnitt 8.1.1). Diskussionen um Seriengenres und -typen (Abschnitt 8.1.2), Varianten des seriellen Erzählens (Abschnitt 8.1.3) und Funktionen von Serienfiguren (Abschnitt 8.1.4) werden genauso als relevant behandelt wie der Umstand, dass Serien gestaltete Medienprodukte sind (Abschnitt 8.1.5). In Abschnitt 8.2 wurden diejenigen Elemente beschrieben, die von den Teilnehmenden als rezeptionsbezogen relevant gesetzt und unter Fragen der normativen

19 EMS51, Z. 858-941, vgl. Beispiel 38.

20 EMS53, Z. 288-291, vgl. Analysen in Abschnitt 9.1.1

21 EMS53, Z.103-107, vgl. Beispiel 48.

22 OST, Z. 1003-1007, vgl. Analysen in Abschnitt 9.1.2. 
Angemessenheit diskutiert werden. Normative Vorstellungen können auf den Ebenen der (Rezeptions-)Erwartungen an serielle Formate (Abschnitt 8.2.1 und 8.2.2), der Erwartungen an angemessenes Verhalten der Gruppenmitglieder (Abschnitt 8.2.3) sowie der Erwartungen an angemessenes individuelles Rezeptionsverhalten (Abschnitt 8.2.4) bearbeitet werden. Besonders deutlich treten prototypische und normative Orientierungen in generalisierenden Formulierungen (Abschnitt 8.3) zutage, über die sowohl Expertise beansprucht als auch Distinktionsmanagement betrieben werden kann.

Insgesamt wird deutlich, dass alle rekonstruierten Aspekte des Positionierungsobjekts (Abschnitt 6.5.1) sowohl zur Vergemeinschaftung als auch zur Distinktion funktionalisiert werden können, allerdings in unterschiedlichem Maße. So werden beispielsweise Kategorisierungen von Serien in - mit Wertungen versehenen (Abschnitt 8.2.2) - Genres (Abschnitt 8.1.2), die Thematisierung von Figuren (Abschnitt 8.1.4) - und ihrer plausiblen Konzeption (Abschnitt 8.2.1) - sowie das Absprechen des Anspruchs auf Einzigartigkeit singulärer Serien (Abschnitt 8.3) eher zur Distinktion genutzt. In medienproduktbezogenen Interaktionen wird Distinktion insbesondere dann relevant, wenn entweder ein im common ground befindliches Element abweichend bewertet wird oder die eigenen Präferenzen als vom Typischen abweichend kommuniziert werden (Abschnitt 8.1.4). Über geteilte Erfahrungen (Abschnitt 8.1.3) und Bewertungen (Abschnitt 8.1.5) kann dagegen eher Vergemeinschaftung hergestellt werden. In rezeptionsbezogenen Interaktionen findet die Aushandlung von Vergemeinschaftung und Distinktion nuancierter statt. Je nach sequenziellem Kontext werden die Elemente für zustimmende oder abgrenzende Positionierungen genutzt (vgl. z.B. Abschnitt 8.2.3 oder die Aspekte in Abschnitt 8.2.4). Wesentlich für die diskursive Bearbeitung von Gemeinschaft und Distinktion erscheint es, dass Äußerungen den jeweiligen kontextuellen Anforderungen entsprechend platziert werden. Oft bilden sich auch Subgruppen, so dass durchaus komplexe Positionierungen zur Vergemeinschaftung und Distinktion gemanagt werden, wie beispielsweise die Analysen in Abschnitt 8.2.2 zeigen. Solche komplexen Konstellationen interaktiver Vergemeinschaftung und Distinktion lassen sich mit Hilfe des im Rahmen dieser Studie erarbeiteten Analysemodells systematisch untersuchen (vgl. Kapitel 9). 